\title{
How powerful are Real Business Cycle models for explaining fluctuations in Spain and the UK?
}

Erik Andres Escayola

Tutor: Vahagn Jerbashian

Department of Economics

Bachelor's degree in Economics, February 2017

Bachelor Thesis

Facultat d'Economia i Empresa 

To my family and Dana for their unconditional help and support. 



\section{ABSTRACT}

This thesis aims to assess the predictions of standard neoclassical Real Business Cycle models for Spain and the United Kingdom by comparing statistical moments that describe real business cycles and the empirical moments. For this, I present the neoclassical theory of business cycles and its modelling methodology. I continue showing how I derive the model used. Then, I undertake modifications of the model in order to relax some of the stringent neoclassical assumptions for the purpose of checking if these extensions help the model better fit the data for these countries. Out of the most appropriate extensions, I put together a final model so to compare the standard version with an extended version of the Neoclassical model. Moreover, I explain how to translate the theoretical mechanisms described into an empirical exercise for Spain and the UK. I later discuss the results I obtain and its intuition behind. Finally, I evaluate the results in order to conclude which model extension is most appropriate for the countries analysed.

Key-words: Business cycles, European economies, Neoclassical theory, Real Business Cycle model, Exogenous shock, Calibration and Dynamic stochastic general equilibrium.

Esta tesis tiene como objetivo evaluar el modelo neoclásico de los ciclos económicos reales para los países de España y Reino Unido mediante la comparación de momentos estadísticos que describen las fluctuaciones económicas reales y los respectivos momentos empíricos. Para ello, presento la teoría neoclásica de los ciclos económicos y su metodología para modelar la economía. Continúo mostrando cómo derivo el modelo en cuestión. Además, llevo a cabo modificaciones del modelo para así atenuar las estrictas suposiciones neoclásicas y de esta manera mejorar la adhesión estadística del modelo a los datos de ambos países. Basándome en las extensiones que han obtenido mejor resultado, confecciono un nuevo modelo con el fin de comparar una versión estándar con una extendida del modelo neoclásico. Procedo a explicar cómo traduzco los mecanismos teóricos descritos anteriormente a un ejercicio empírico para España y el Reino Unido. Después presento e interpreto los resultados obtenidos así como su intuición económica. Finalmente, evalúo dichos resultados para determinar qué extensión del modelo es la más apropiada para los países analizados.

Palabras clave: Ciclos económicos, Economías europeas, Teoría neoclásica, Modelo de los ciclos económicos reales, Shock exógeno, Calibración y Equilibrio general dinámico estocástico. 



\section{TABLE OF CONTENTS}

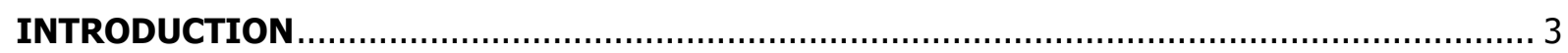

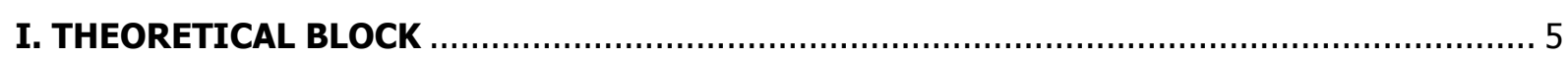

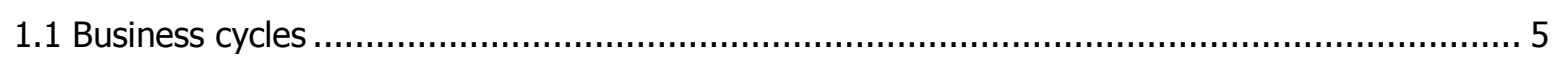

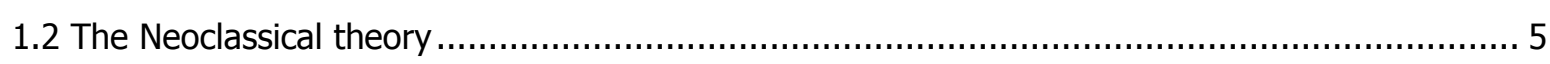

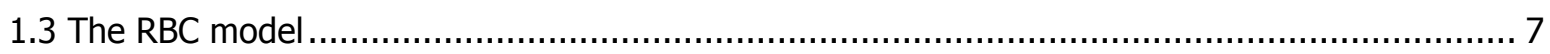

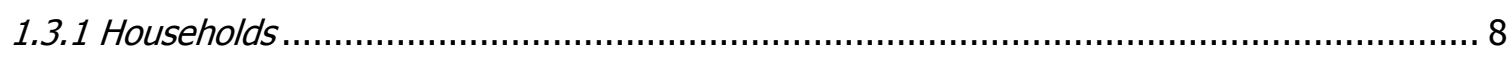

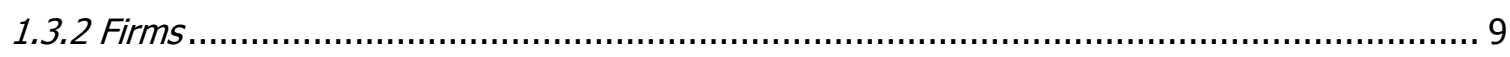

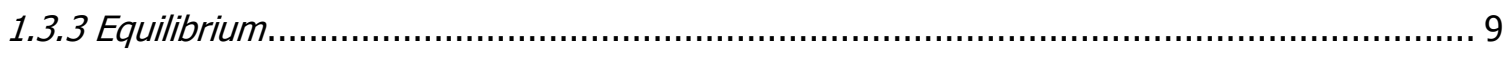

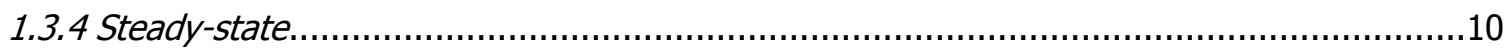

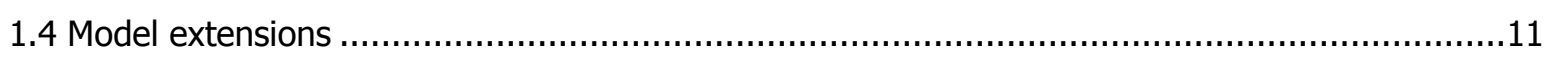

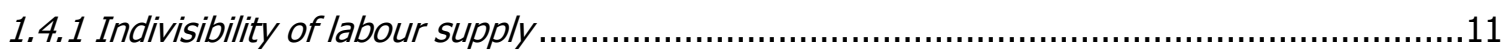

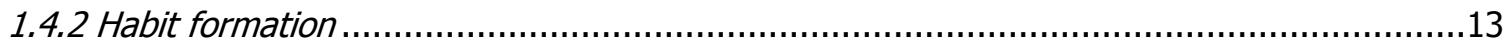

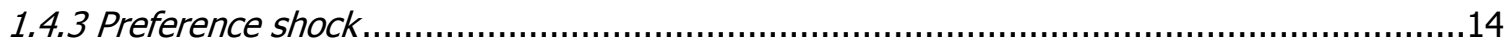

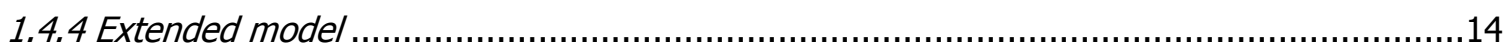

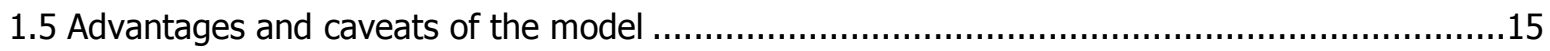

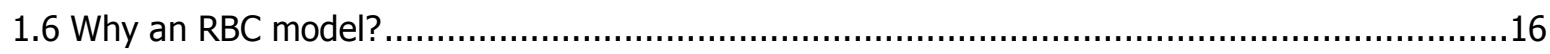

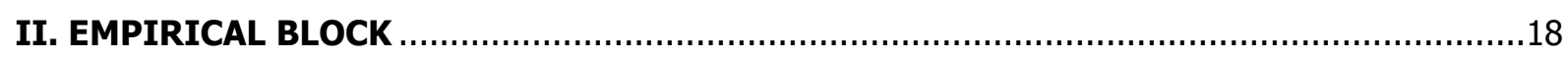

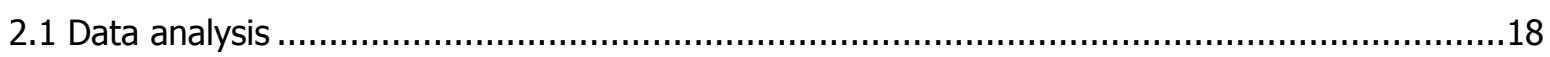

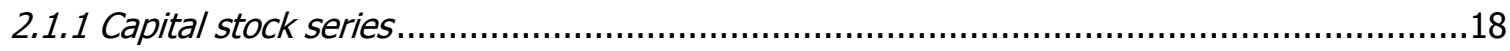

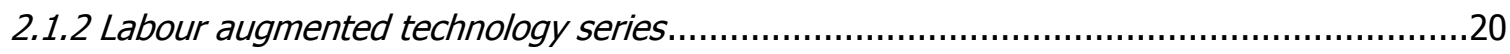

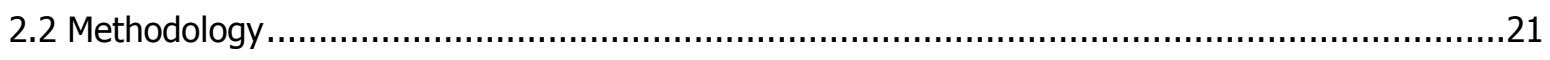

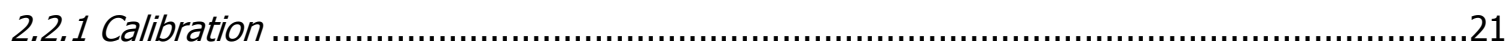

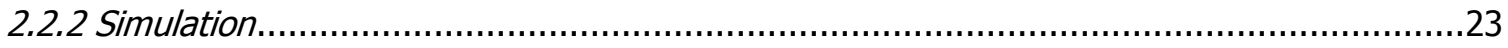

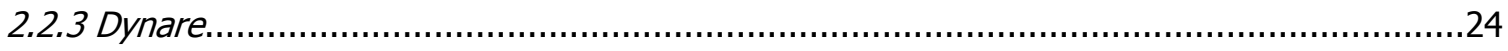

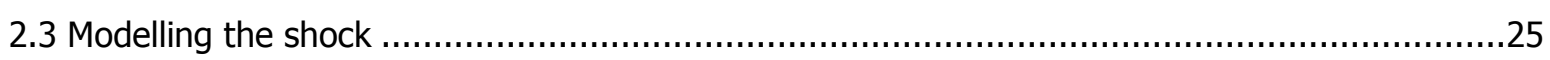

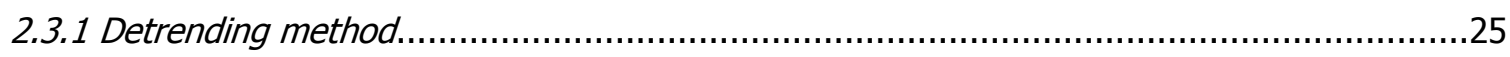

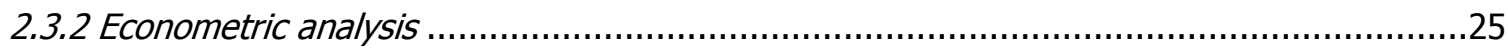

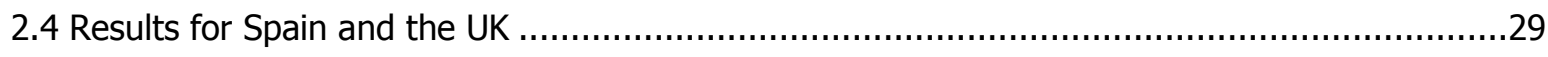

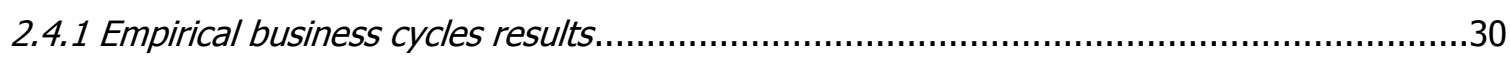

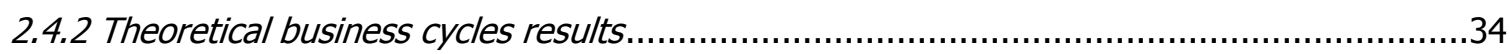

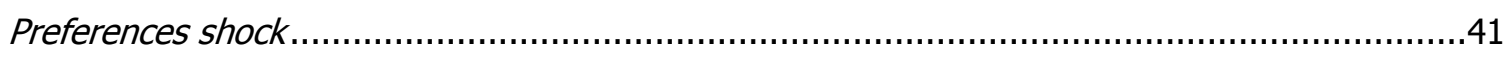

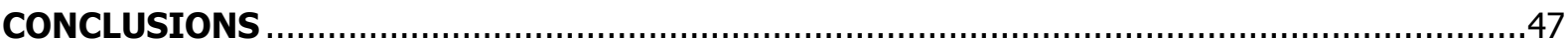

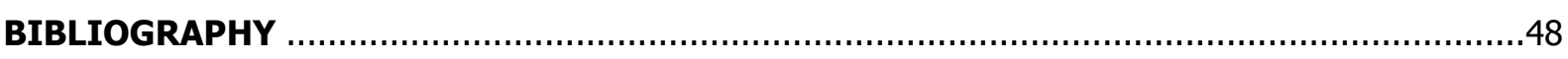

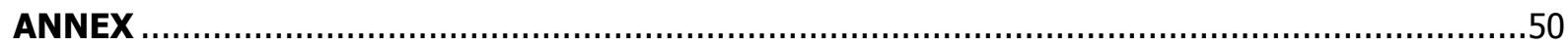




\section{INTRODUCTION}

Business cycles are the essence of short-run macroeconomics. It is unavoidable that national economies follow certain patterns. A period of expansion, or above-average growth, continues until it reaches a peak; then a period of contraction, or below-average growth, follows until it reaches a low point. The downturn is then followed by another swing, then a recession and so on. This repeating cycle, the business cycle, is the basis for analysing economic indicators and patterns. In today's world, we constantly get information about fluctuating economic indicators in the media and from the government. This information on real business cycles allows households, businesses, central banks and governments to know the course of an economy. In other words, real business cycles are the most transparent and loyal reflection of the health of an economy, hence they are like the radiography of a country's economic situation for a particular period of time. Many of these economic agents rely on the information that the business cycles analyses provide and accordingly form their expectations of future business cycle characteristics.

The aim of the present essay is to contrast the hypothesis of whether the baseline model for business cycles is able to capture real business cycles for Spain and the UK and whether including more realistic features improves the performance of the standard model. However, I base my analysis on the findings of US business cycle features replicated in Kydland's and Prescott's model and assess whether they are applicable to other economic systems, focusing on the model's performance, not on the historical issues underlying the period analysed. In a parallel way, my objective is to compare Spain and the UK by analysing the results obtained from each model version. Hence, being able to conclude for which country the Real Business Cycle model and its extensions replicates in the best way the observed business cycles.

The countries analysed are in the European Union. Yet, their economic systems follow different patterns in terms of infrastructures and economic activity. Without delving too much into the particularities of both countries, I can firmly assert that the UK is less structurally rigid than Spain. With its great financial hub in London, the UK is specialised in providing high-quality financial services as well as industrial products. Spain in turn, depends heavily on low-value services as for instance seasonal tourism, construction or energy sectors. Remarkably, Spain is far more pro-European and close to the European institutions in comparison to the UK that could be defined as more distant to the European model. Additionally, Spain is usually thought to be a country with many policy distortions and the UK is thought to have much fewer distortions. Moreover, this latter is closer to the economic model of the USA analysed in Kydland's and Prescott's paper from 1982. Thus, a priori one would expect that the Neoclassical model does a better job for the UK and this is what I'm about to test in this thesis.

I make use of a modified version of the well-known Real Business Cycle (RBC) model, first introduced by Kydland and Prescott. Accordingly, I calibrate and simulate the model using data for Spain and the UK. Finally, I evaluate and interpret the results.

As a result, the structure of this thesis is as follows: First, I start with a Theoretical block where the Business Cycles theory is introduced and the RBC model is presented. I continue showing a range of model extensions that improve the model performance in terms of capturing the empirical secondorder moments for the countries considered. I finish this block by explaining the model's pros and cons and my motivation behind using this type of models. Then, I proceed to describe how the model 
is applied to the analysis of Spain and the UK in the Empirical block. For this, I shortly discuss the data set used, I explain the methodology undertaken for the empirical analysis of the model and assess the technique implemented for modelling the technology shock. Moreover, I show and discuss the empirical moments for Spain and the UK in order to analyse the characteristics of their real business cycles. Furthermore, I present the theoretical moments from the model simulations for each country. Respectively, I discuss the results obtained by comparing the theoretical moments from the benchmark (and model extensions) to the empirical moments. Most importantly, I make a comparison between Spain and the UK. Lastly, based on my final conclusions I determine which economic system is most suitable for the RBC model. 


\section{THEORETICAL BLOCK}

\subsection{Business cycles}

The term business cycles is used to coin fluctuations in aggregate output and other economic variables in short-term. In an economy, short-term is usually associated with a period of several months or years. Fluctuations can be both upward and downward. Given production inputs (i.e. capital, labour and technology), a certain level of output is achieved given a production function. The level of output that prevails in the long-run depicts the output trend. Business cycles represent the short-run fluctuations around this trend. The periods when output is above its trend are called an economic boom, and the periods when it is below the trend are called a recession. A relatively longlasting recession is named depression.

Regarding the generation of a business cycle it is best understood through the following scheme:

$$
\text { IMPULSE } \longrightarrow \text { PROPAGATION } \longrightarrow \text { BUSINESS CYCLE }
$$

Economists agree on these three components describing the generating process of business cycles. However, the Frisch-Slutsky paradigm emphasises that there is great controversy on agreeing upon the identification of this process. For example, there are apparent differences between Neoclassical economists and New-Keynesians in terms of the identification of the impulse and propagation mechanisms of business cycles. The Neoclassical economists have focused on the stochastic properties of the Neoclassical growth workhorse model, leaving out any type of nominal rigidities, imperfect information, money or Phillips curve. This modelling approach was named Real Business Cycles and its contributors are known as "fresh water". On the other side, the New-Keynesians also labelled "salt water" movement took the fundaments and methodology of the Neoclassical economists but added imperfections along several dimensions: nominal rigidities, efficiency wages, credit constraint etc.

This mixture of research groups co-existing during the same time period didn't remain without frictions (i.e. see a debate between Prescott and Summers in Manuelli 1986). Nevertheless, at the end, the new tools developed by the Neoclassics dominated whereas New-Keynesians managed to bring imperfections back into business cycle models.

\subsection{The Neoclassical theory}

The Neoclassical benchmark model for business cycles maintains a series of assumptions. The economy is closed, so national income is absorbed entirely by domestic demand. Within this model, the economic system is characterised by a set of identical representative agents that display rational behaviour in terms of taking optimal decisions at every point in time and forming expectations. The households consume and supply labour such that given real wages and the real interest rate they maximise lifetime utility that depends on subjective time preferences. Growth is depicted as in the Neoclassical growth model (say Solow model) but with Ramsey's extension of endogenising savings of 1928. So, savings are determined by optimising consumers which in turn directly affect the level of investments. Capital accumulates through investments. Firms, in turn, form the demand for labour 
and capital and produce the final output, which is a homogeneous good. They are ordinary profit maximisers and take as given technology and factor prices. These micro foundations make this model immune to the Lucas critique (1976) since agents don't make systematic errors. There is perfect competition in the goods and labour markets, and markets always clear. What is more, it is assumed that prices are fully flexible and there is complete monetary neutrality. This latter concept means there is no role for monetary policies or money, at all. Lastly, technological shocks are the sole cause of business cycles in the model, however, they have a discerned effect on the short and long-run. These shocks create fluctuations, and the propagation mechanism in the model augments the business cycle. In the long-run where the steady-state rests, the exogenous shock disappears restoring in this way the trend level of each of the model variables.

Technological perturbations considered in this model are of considerable relevance due to the fact that in today's technology-dependent world, fluctuations in this factor determines our capacity to transform production inputs into outputs. Moreover, these technological changes make output and employment fluctuate, too. When technology for production improves, the economy produces more and real wages increase. As a consequence of the intertemporal substitution of households regarding labour supply, the improvement of technology also has a positive impact on employment and hence on output. The technology shock is assumed to be long lasting so that they die out slowly. Also, they are assumed to follow an autoregressive process of order 1 . This means that the current value of technology depends on its own lag weighted by a parameter and a stationary random variable. This latter variable is assumed to be white noise ${ }^{1}$.

$$
z_{t}=\rho z_{t-1}+\varepsilon_{t}, \quad \text { assuming } \varepsilon_{t} \sim \text { White noise. }
$$

The defenders of the Real Business Cycle model tend to state that recessions are periods of "technological regress". According to their models, production and employment decrease during recessions because the existent production technology deteriorates, making production and incentives for working decrease. Detractors of the RBC model doubt about technology experiencing great perturbations. They more frequently suppose that technological progress is gradual. Thus, critics sustain that especially technological regress is improbable: technological knowledge accumulation can decrease but it is difficult to imagine that it regresses. Nonetheless, supporters of the RBC theory respond by adopting a wide understanding of technological perturbations. They claim that there are many events that even though they are not literally technological they affect the economy as much as if they would be technological fluctuations. For instance, bad weather, the adoption of a strict environmental law or the increase of fuel prices worldwide have similar consequences as technological changes: all of them reduce our capacity to transform capital and labour into goods and services.

Therefore, despite technological progress is considered as a rather unsatisfying source of business cycles, it is also backed up by many economists to be a convenient stand-in. In particular, for the sake of explaining fluctuations of labour supply and shifts in labour demand it is a valid assumption to rely just on this type of shocks. Actually, the key market for understanding the process generating business cycles is the labour market. Accordingly, I consider a positive technology shock and analyse the consequences in the labour market in order to understand the underlying dynamics of the model:

\footnotetext{
${ }^{1}$ The term white noise means that a random variable has an independent and identical probability distribution. This entails having the properties of zero mean, finite variance and serial uncorrelation.
} 
Figure 1: Positive technology shock on the labour market

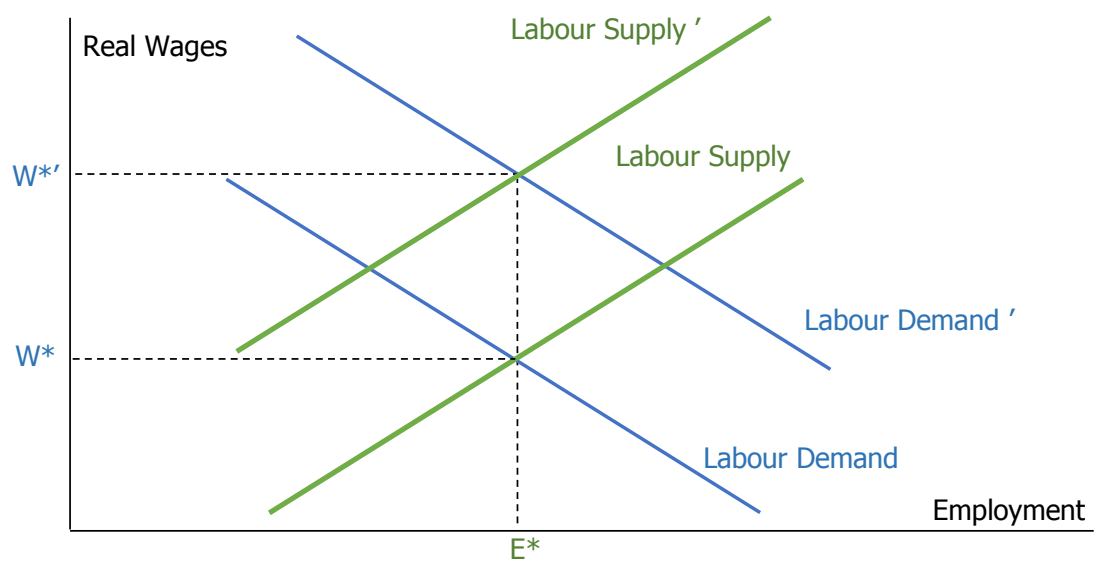

A positive technological shock makes the elastic downward sloping labour demand function shift upwards. This makes wages increase at a first stage. Due to the household's optimal response, the increase in wages has two opposing effects on labour supply. On the one hand, higher wages imply higher returns to each hour of work such that households are willing to supply more labour. On the other hand, they also increase income making households less likely to work and hence leading to a decrease in labour supply. Nevertheless, in the usual calibrations of the model, labour supply increases with wages since labour supply is procyclical in the data, indicating that the first effect dominates over the second. Accordingly, the labour supply curve shifts upwards. Moreover, the increase in labour supply leads to a further increase in the labour demand which in turn makes wages even higher. This process repeats itself in the labour market until the long-run equilibrium is restored. As a result, this is capturing the idea of the model's propagation mechanism.

\subsection{The RBC model}

The model I use follows a modified version of the RBC model which is introduced by Jesús FernándezVillaverde (2016) in his graduate macroeconomics course. All the variables of the model are in real and in per capita terms ${ }^{2}$. The structure of the economy is determined by the following variables:

Table 1: Theoretical definitions of the model

\begin{tabular}{cl}
\hline Variable & \multicolumn{1}{c}{ Meaning } \\
\hline$y_{t}$ & Output per capita \\
$c_{t}$ & Consumption per capita \\
$i_{t}$ & Investment per capita \\
$l_{t}$ & Hours worked per worker \\
$k_{t}$ & Capital stock per capita \\
$w_{t}$ & Real wage per hour \\
$r_{t}$ & Real interest rate \\
$z_{t}$ & Technology \\
\hline
\end{tabular}

\footnotetext{
${ }^{2}$ Per capita is understood as each variable being divided by the population aged $16+$.
} 


\subsubsection{Households}

Households' tradeoff is in terms of consumption and saving decisions and the time they devote to work and leisure. Accordingly, households maximise their utility over lifetime subject to a constraint that income is equal to expenditure. The economy is closed and savings are equal to investments. Capital accumulates following the standard law of motion. As a result, households demand goods and supply labour and capital in the economy.

Thus, the optimisation problem is:

$$
\begin{gathered}
\max _{c_{t}, l_{t}, k_{t+1}} U_{t}=E_{t}\left[\sum_{t=0}^{\infty} \beta^{t}\left(\ln c_{t}+\psi \ln \left(1-l_{t}\right)\right)\right] \\
\text { s.t. } \\
w_{t} l_{t}+r_{t} k_{t}+(1-\delta) k_{t}-c_{t}-k_{t+1}=0, \\
\text { where } k_{0}>0 \text { is given. }
\end{gathered}
$$

The solution to this problem is given by the following first-order conditions:

$$
\begin{gathered}
F O C: \\
\frac{1}{c_{t}}=\lambda_{t}, \\
\frac{\psi}{1-l_{t}}=\lambda_{t} w_{t}, \\
\lambda_{t}=\beta E_{t}\left[\lambda_{t+1}\left[r_{t+1}+(1-\delta)\right]\right],
\end{gathered}
$$

the Budget constraint, and a transversality condition:

$$
\begin{gathered}
k_{t+1}=w_{t} l_{t}+r_{t} k_{t}+(1-\delta) k_{t}-c_{t}, \\
\text { TVC }: \lim _{t \rightarrow \infty} \beta^{t} \lambda_{t} k_{t+1}=0 .
\end{gathered}
$$

I rearrange the first-order conditions and the Budget constraint in order to get the following characteristic equations:

$$
\text { Euler equation: } \frac{1}{c_{t}}=\beta E_{t}\left[\frac{1}{c_{t+1}}\left[r_{t+1}+(1-\delta)\right]\right] \text {. }
$$

This equation has a special name and is called Euler equation. It determines the household's intertemporal choice (how much to consume and save). In equilibrium, the disutility from one unit less of consumption today equals the expected discounted value of consuming $r_{t+1}+(1-\delta)$ units more tomorrow.

$$
\text { Labour supply: } \psi \frac{c_{t}}{1-l_{t}}=w_{t} \text {. }
$$

This equation determines the household's intratemporal choice (how much to consume and work). In equilibrium, the utility of one unit more of leisure should be equal to the utility from consuming the correspondent compensation (real wage). 
Law of motion of capital accumulation: $k_{t+1}=w_{t} l_{t}+r_{t} k_{t}+(1-\delta) k_{t}-c_{t}$.

This equation depicts the standard law of motion of capital. It determines how capital stock accumulates over time given its past value of capital stock devaluated by the depreciation rate and the contemporaneous level of investment.

\subsubsection{Firms}

Firms decide upon production given factors of production and their prices. The inputs are labour and capital. They select the amounts of factor inputs to maximise profits. Firms have a labour augmenting technology.

Their optimisation problem is:

$$
\max _{k_{t}, l_{t}} \Pi_{t}=k_{t}^{\alpha}\left(e^{z_{t}} l_{t}\right)^{1-\alpha}-w_{t} l_{t}-r_{t} k_{t}
$$

I solve this problem by determining the following first-order conditions:

$$
\begin{gathered}
\text { FOC: } \\
\alpha k_{t}^{\alpha-1}\left(e^{z_{t}} l_{t}\right)^{1-\alpha}=r_{t}, \\
(1-\alpha) k_{t}^{\alpha}\left(e^{z_{t}} l_{t}\right)^{1-\alpha} l_{t}^{-1}=w_{t} .
\end{gathered}
$$

I rearrange these equations to get the expressions of factor compensations:

$$
\text { Marginal product of labour and capital: } w_{t}=(1-\alpha) \frac{y_{t}}{l_{t}} \text { and } r_{t}=\alpha \frac{y_{t}}{k_{t}} \text {. }
$$

The marginal products indicate that the price of a factor input is equal to the increase in output for an additional unit of that factor in particular.

\subsubsection{Equilibrium}

After having revealed all the equations integrated into this general equilibrium framework, I need to make markets clear by setting demand equal to supply. The result is captured by the following Dynamic Equilibrium Conditions:

$$
\begin{gathered}
\frac{1}{c_{t}}=\beta E_{t}\left[\frac{1}{c_{t+1}}\left[\alpha k_{t+1}^{\alpha-1}\left(e^{z_{t+1}} l_{t+1}\right)^{1-\alpha}+(1-\delta)\right]\right] \\
\psi \frac{c_{t}}{1-l_{t}}=(1-\alpha) k_{t}^{\alpha}\left(e^{z_{t}} l_{t}\right)^{1-\alpha} l_{t}^{-1} \\
c_{t}+k_{t+1}=k_{t}^{\alpha}\left(e^{z_{t}} l_{t}\right)^{1-\alpha}+(1-\delta) k_{t} \\
z_{t}=\rho z_{t-1}+\varepsilon_{t} .
\end{gathered}
$$

To understand how the mechanics of the model work with these equations, I analyse how a positive technology shock would affect the general equilibrium resulting in business cycles. Consider 
technology shocks as being for example changes in labour market regulations, changes in the patenting system and changes in environmental regulations or supply side energy shocks.

At time $t$ households having $k_{t}$ units of capital, observe a positive shock on the stochastic disturbance $\varepsilon_{t}$. This affects directly the level of technology in the economy. Accordingly, output increases due to the structure of the production function. This is backed up by the optimal decisions of firms that with higher technology want to supply more goods, so they demand more labour and capital. Then, households optimise their intertemporal decisions on consumption and hours worked. Given firms demand more labour making wages increase, labour supply increases accordingly for the reasons explained above. The same happens to the other factor of production. Given demand for capital increases, its rental price increases, too, making households prefer saving rather than consuming because they earn greater interest rate. Given savings must equal investments, this latter also increases. Thus, in line with the law of motion of capital, more capital stock is supplied in the next period $k_{t+1}$. This means that at $t+1$ the story repeats given more factor inputs will be demanded and so on. The long lasting persistence in the technological process is crucial for embodying the business cycle. The key assumption of $\rho$ being high implies that technology creates long lasting fluctuations in the economy through the mechanism just described. This happens until the economy returns to the long-run steady-state equilibrium.

\subsubsection{Steady-state}

Along with the neoclassical theory, I assume that there is no uncertainty in the long-run and that the economy is in the steady-state. Therefore, the steady-state is characterised by the following equations:

$$
\begin{gathered}
\frac{1}{\beta}=\left[\alpha \frac{k^{\alpha} l^{1-\alpha}}{k}+(1-\delta)\right], \\
l=1-\psi c \frac{1}{1-\alpha} \frac{l}{k^{\alpha} l^{1-\alpha}} \\
c=k^{\alpha} l^{1-\alpha}-\delta k .
\end{gathered}
$$

The solution ${ }^{3}$ to this system of equations delivers the following results:

$$
\begin{gathered}
l^{s s}=\frac{(1-\alpha)\left(\frac{1}{\beta}-(1-\delta)\right)}{\psi\left(\frac{1}{\beta}-(1-\delta)-\alpha \delta\right)+(1-\alpha)\left(\frac{1}{\beta}-(1-\delta)\right)}, \\
k^{s s}=\left(\frac{\alpha}{\frac{1}{\beta}-(1-\delta)}\right)^{\frac{1}{1-\alpha}} l^{s s},
\end{gathered}
$$

\footnotetext{
${ }^{3}$ For an alternative way to solve the model refer to annex A.1.
} 


$$
\begin{aligned}
& y^{s s}=k^{s s^{\alpha}} l^{s s^{1-\alpha}}, \\
& c^{s s}=y^{s s}-i^{s s} .
\end{aligned}
$$

\subsection{Model extensions}

In this part, I try out a variety of model extensions commonly known in the RBC literature by relaxing some assumptions imposed in the benchmark RBC model. The aim is to endow the standard model with more realistic features that should improve the fit of the model along with several dimensions. Lastly, based on the results obtained for each extension, I construct an extended version of the RBC model that includes those extensions that matched best the empirical moments.

The first set of model extensions is focused on changing some functional specifications of the characteristic equations. It follows new sources of shocks to the model and finally imperfect competition is added to the model. I offer some of these additional model extensions in the annex B. I want to underline that this variety of model extensions follow Eric Sims (2016) notes.

\subsubsection{Indivisibility of labour supply}

A common critique of the standard RBC model is that it captures hours worked at odds with reality: fluctuations in labour emerge from the intensive margin (i.e. average hours worked) as opposed to the extensive margin (the binary choice between working or not). Usually, people have a fixed number of hours of work per day, therefore fluctuations in hours worked are mainly caused by changes in the participation rate of the labour market. Actually, families face two decisions: (1) work or not and (2) conditional on working, how much to work. This entails difficulties to model this aspect given it introduces discontinuity into households' decisions.

Following Hansen (1985) and Rogerson (1988) the conventional technical fix is reflected in the household's utility function:

$$
\ln c_{t}+\psi \frac{\left(1-l_{t}\right)^{1-\xi}-1}{1-\xi}
$$

This functional specification is a mixture between the standard case and the extension on controlling the Frisch elasticity exposed in the annex A.1. This is like this because I'm modelling utility via leisure (standard case) but I'm getting rid of the natural logarithm in the second term of the function (as in the extension on Frisch elasticity).

The labour supply analogue of equation (2) is:

$$
\psi\left(1-l_{t}\right)^{-\xi}=\frac{1}{c_{t}} w_{t}
$$

Log-linearizing about the steady-state, I get:

$$
\xi \gamma \tilde{l}_{t}=-\tilde{c}_{t}+\widetilde{w}_{t}, \quad \text { with } \gamma=\frac{l^{*}}{1-l^{*}} .
$$


Where a variable $\tilde{x}$ is defined as $\tilde{x}=\frac{\left(x_{t}-x^{*}\right)}{x^{*}}$, being $x^{*}$ the steady-state value of that variable.

Proceeding as shown in the extension of annex A.1, the Frisch labour supply elasticity here is $\frac{1}{\xi_{\gamma}}=$ $\frac{1-l^{*}}{\xi l^{*}} \Leftrightarrow \frac{d \tilde{l}_{t}}{d \widetilde{w}_{t}} \mid \tilde{\lambda}_{t}=\frac{1}{\xi \gamma}$. Playing with the value of $\xi$ allows me to control the Frisch elasticity and have it not simply dependent on $l^{*}$ as it was in the log case (hence, as in the functional specification of annex A.1 I also can control for the Frisch elasticity here).

Consider the following economic scenario with indivisible labour. Households either work or they don't. If they do, they work $\bar{l}$ hours, with $\bar{l} \in(0,1)$. Each period, there is a chance of working $\tau_{t}$ with $\tau_{t} \in(0,1)$. This probability is indexed by $t$ because it is a choice variable: essentially the households can choose its probability of working, but not how much they work if they do. There is a lottery such that households may work at a rate of $\tau_{t}$. Moreover, there is perfect insurance in the sense of households getting paid whether they work or not. For this reason, in expectation households will work $l_{t}=\tau_{t} \bar{l}$ and they will have identical consumption. This latter statement is true because of the implicit assumption of perfect insurance combined with separability across consumption and leisure. Consequently, the household's utility function becomes:

$$
\ln c_{t}+\tau_{t} \psi \frac{(1-\bar{l})^{1-\xi}-1}{1-\xi}+\left(1-\tau_{t}\right) \psi \frac{(1)^{1-\xi}-1}{1-\xi} .
$$

Given $\tau_{t}$ is linear in the preferences I can take common factor and substitute the relation from above $\tau_{t}=\frac{l_{t}}{\bar{l}}$ in order to the following expression:

$$
\ln c_{t}+\frac{l_{t}}{\bar{l}} \psi\left(\frac{(1-\vec{l})^{1-\xi}-1}{1-\xi}-\frac{(1)^{1-\xi}-1}{1-\xi}\right)+\psi \frac{(1)^{1-\xi}-1}{1-\xi} .
$$

As long as $\xi>0$, then $\frac{(1)^{1-\xi}-1}{1-\xi}>\frac{(1-\bar{l})^{1-\xi}-1}{1-\xi}$. Hence, I re-write this as:

$$
\ln c_{t}-\frac{l_{t}}{\bar{l}} \psi\left(\frac{(1)^{1-\xi}-1}{1-\xi}-\frac{(1-\bar{l})^{1-\xi}-1}{1-\xi}\right)+\psi \frac{(1)^{1-\xi}-1}{1-\xi} .
$$

For the sake of simplicity I define the following constants:

$$
A=\frac{\psi}{\bar{l}}\left(\frac{(1)^{1-\xi}-1}{1-\xi}-\frac{(1-\vec{l})^{1-\xi}-1}{1-\xi}\right) \text { and } B=\psi \frac{(1)^{1-\xi}-1}{1-\xi} .
$$

Actually, I can drop $B$ from the analysis given adding a constant to the utility function won't change the household's optimal choices.

This implies that the final utility function is given by:

$$
\ln c_{t}-A l_{t} \text {. }
$$

This means that the utility becomes linear in labour under the above-described scenario. This holds for any value of $\xi$. Indeed, it is as if $\xi=0$, so labour supply is infinitely elastic. Even when $\xi$ approaches 1 , the labour supply still is elastic. This fact is helpful because one can generate more hours' volatility with higher Frisch elasticity and is not subject to the criticism that the labour supply elasticity is inconsistent with micro evidence. Additionally, these preferences are isomorphic to $\ln c_{t}-$ $\psi \frac{l_{t}^{1+\chi}}{1+\chi}$ when the parameter is $\chi=0$ (perfect labour supply elasticity) from the extension in annex A.1. 
In terms of the equilibrium conditions of this model, the only difference from the benchmark model is that the characteristic dynamic equilibrium equation for labour supply changes to:

$$
A c_{t}=(1-\alpha) k_{t}^{\alpha}\left(e^{z_{t}} l_{t}\right)^{1-\alpha} l_{t}^{-1} .
$$

When I pin down the new steady-state the only equation that changes is (4), which becomes now:

$$
l^{s s}=\frac{\frac{(1-\alpha)}{A}\left(\frac{k}{l}\right)^{\alpha}}{\left(\frac{k}{l}\right)^{\alpha}-\delta\left(\frac{k}{l}\right)}, \quad \text { with } \frac{k}{l}=\left(\frac{\alpha}{\frac{1}{\beta}-(1-\delta)}\right)^{\frac{1}{1-\alpha}} \text {. }
$$

\subsubsection{Habit formation}

In the basic specification of the RBC model, I've assumed two kinds of separability in preferences: intratemporal separability between leisure and consumption and intertemporal separability of leisure and consumption. I focus on this latter assumption and relax it, for instance by considering the case of non-separability across time. This usually goes by the name "habit formation", implying that people get utility not from the level of consumption, but from the level of consumption relative to its past value. The idea is that individuals get accustomed to a particular level of consumption (i.e. a habit) and utility becomes relative to that. Also, habit formation can help resolve the "excess smoothness" puzzle in the Permanent Income Hypothesis (PIH) because, the bigger is habit formation, and the smaller consumption will jump in response to news about permanent income.

I consider intratemporal separability in order for the utility from consumption to be logarithmic as in the standard case. Accordingly, the within period utility function is given by:

$$
\ln \left(c_{t}-\phi c_{t-1}\right)+\psi \ln \left(1-l_{t}\right) .
$$

Where $\phi$ is the habit persistence parameter. If $\phi=0 I^{\prime} \mathrm{m}$ in the standard case, and when $\phi \rightarrow 1$ agents get utility not from the level of consumption, but from the change in consumption. To reduce complexity in the computation I restrict $\phi<1$ since if it is exactly 1 then the marginal utility in the steady-state would be $\infty$.

I proceed to pin down the characteristic equations with this new functional specification. The only equations that change are (1) and (2), so their analogues become:

$$
\begin{gathered}
\lambda_{t}=\beta E_{t}\left[\lambda_{t+1}\left(\alpha k_{t+1}^{\alpha-1}\left(e^{z_{t+1}} l_{t+1}\right)^{1-\alpha}+(1-\delta)\right)\right], \\
\psi \psi \frac{1}{1-l_{t}} \frac{1}{\lambda_{t}}=(1-\alpha) k_{t}^{\alpha}\left(e^{z_{t}} l_{t}\right)^{1-\alpha} l_{t}^{-1}, \\
\text { with } \lambda_{t}=\frac{1}{c_{t}-\phi c_{t-1}}-\beta \phi E_{t}\left[\frac{1}{c_{t+1}-\phi c_{t}}\right] .
\end{gathered}
$$

I solve this model by not substituting out for the lagrangian multiplier but treat it as another endogenous variable $\lambda_{t}$. Accordingly, the only equation that varies in the steady-state is equation (4):

$$
l^{s s}=\frac{\left(\frac{1-\beta \phi}{(1-\phi)}\right)\left(\frac{1-\alpha}{\psi}\right)\left(\frac{k}{l}\right)^{\alpha}}{\left(\frac{\psi(1-\phi)+(1-\alpha)(1-\beta \phi)}{\psi(1-\phi)}\right)\left(\frac{k}{l}\right)^{\alpha}-\delta\left(\frac{k}{l}\right)}, \quad \text { with } \frac{k}{l}=\left(\frac{\alpha}{\frac{1}{\beta}-(1-\delta)}\right)^{\frac{1}{1-\alpha}} .
$$




\subsubsection{Preference shock}

The standard model analysed so far rests on the technology shock, but it is fruitful to include other sources of shocks. Here I evaluate preference shocks, those ones that directly affect agents' utility from consumption and leisure. I'll write down the basic model with two such shocks: an intertemporal preference shock that governs how households value current utility relative to future utility, and an intratemporal preference shock capturing how households value utility from leisure.

Introducing these shocks delivers the following utility function:

$$
\theta_{t}\left(\ln c_{t}+\vartheta_{t} \psi \ln \left(1-l_{t}\right)\right)
$$

I assume that $\theta_{t}$ and $\vartheta_{t}$ follow an $\operatorname{AR}(1)$ in the log (so that at the steady-state their levels are one).

$$
\ln \theta_{t}=\rho_{\theta} \ln \theta_{t-1}+\varepsilon_{\theta, t} \text { and } \ln \vartheta_{t}=\rho_{\vartheta} \ln \vartheta_{t-1}+\varepsilon_{\vartheta, t} \text {, assuming } \varepsilon_{\theta, t} \text { and } \varepsilon_{\vartheta, t} \sim \text { White noise. }
$$

The variable $\theta_{t}$ governs the intertemporal preference shock: it doesn't impact the value of utility from consumption versus utility from leisure, but rather how someone values utility today in comparison to tomorrow. The variable $\vartheta_{t}$ is the intratemporal preference shock: it affects how you value utility from consumption relative to disutility from labour (or utility from leisure).

The new characteristic equations are identified by the Euler equation and labour supply depicted as:

$$
\begin{gathered}
\frac{1}{c_{t}}=\beta E_{t}\left[\frac{\theta_{t+1}}{\theta_{t}} \frac{1}{c_{t+1}}\left[\alpha k_{t+1}^{\alpha-1}\left(e^{z_{t+1}} l_{t+1}\right)^{1-\alpha}+(1-\delta)\right]\right], \\
\vartheta_{t} \psi \frac{c_{t}}{1-l_{t}}=(1-\alpha) k_{t}^{\alpha}\left(e^{z_{t}} l_{t}\right)^{1-\alpha} l_{t}^{-1} .
\end{gathered}
$$

Three things attract my attention: First, $\theta_{t}$ doesn't show up in the labour supply condition: higher $\theta_{t}$ increases the marginal utility of both consumption and the marginal disutility of labour, but these cancel out. Second, an increase in $\theta_{t}$ is isomorphic to a temporary reduction in $\beta$ implying greater impatience of individuals. Third, $\vartheta_{t}$ shows up in the labour supply condition in a way analogueous to a distortionary tax rate on labour income: if I divide both sides by $\vartheta_{t}$ I see that an increase in $\vartheta_{t}$ is functionally equivalent to an increase in taxes on the MPL.

In terms of the steady-state equations, they don't vary in comparison to the benchmark case due to the fact that in equilibrium there are no shocks. Hence, as explained above I set the variables depicting the intratemporal and intertemporal processes equal to one and the standard set of steadystate equations prevails (i.e equations $(4),(5),(6)$ and (7)).

\subsubsection{Extended model}

Based on the results I obtain from analysing these model extensions separately, I end up putting together a model that includes all these extensions. In this way, I'll be contrasting the standard version of the RBC model with an improved version of it and I'll be corroborating whether combining the extensions delivers the same or better results.

Accordingly, the new utility function looks like this:

$$
\theta_{t}\left(\ln \left(c_{t}-\phi c_{t-1}\right)-\vartheta_{t} A l_{t}\right)
$$


Consequently, I modify the characteristic equations (1) and (2) which now become:

$$
\begin{gathered}
\lambda_{t}=\beta E_{t}\left[\frac{\theta_{t+1}}{\theta_{t}} \lambda_{t+1}\left(\alpha k_{t+1}^{\alpha-1}\left(e^{z_{t+1}} l_{t+1}\right)^{1-\alpha}+(1-\delta)\right)\right], \\
\vartheta_{t} A \frac{1}{\lambda_{t}}=(1-\alpha) k_{t}^{\alpha}\left(e^{z_{t}} l_{t}\right)^{1-\alpha} l_{t}^{-1}, \\
\text { with } \lambda_{t}=\frac{1}{c_{t}-\phi c_{t-1}}-\beta \phi E_{t}\left[\frac{1}{c_{t+1}-\phi c_{t}}\right]
\end{gathered}
$$

Finally, the new expression for labour in the steady-state is:

$$
l^{s s}=\frac{\frac{1-\beta \phi}{(1-\phi)} \frac{(1-\alpha)}{A}\left(\frac{k}{l}\right)^{\alpha}}{\left(\frac{k}{l}\right)^{\alpha}-\delta\left(\frac{k}{l}\right)}, \quad \text { with } \frac{k}{l}=\left(\frac{\alpha}{\frac{1}{\beta}-(1-\delta)}\right)^{\frac{1}{1-\alpha}} \text {. }
$$

\subsection{Advantages and caveats of the model}

Here, I present the main pros and cons that exist in the literature about the RBC model. However, these aspects are regarding general issues of the model, the specific assessment for Spain and the UK is introduced in the empirical block.

It is widely accepted that the RBC model is a good way of understanding business cycles for the US in the post-war period since it matches data moments very well. Kydland and Prescott find that the RBC model matches volatility of output, consumption, investment, labour productivity and TFP in a decent way. Furthermore, the model matches persistence of the endogenous variables. Lastly, it does a good job of capturing the contemporaneous correlation to output and the direction of such cyclicality. At a theoretical ground, the RBC model for business cycles is well micro-founded is an example of successful deductive analysis. This latter concept refers to the fact that the model is first constructed based on economic theory and thereafter it is tested out on data. Finally, its simplicity and lack of nominal rigidities emphasise the uniqueness of the model given it has shown to be very powerful even with classical laissez-faire assumptions.

Nonetheless, as in every drastic change in economic movements, this innovative model has been subject to severe criticism. In particular, in line with the results of the 1982 paper, the RBC model shows deficiencies on generating enough volatility of hours worked. It is also the case for the real interest rate. The correlation of the variables with output is far too inflated. Lastly, wages and real interest rate are far too procyclical compared to the data as well as the persistence level of the variables is exaggeratedly too big. Furthermore, the model is usually criticised because the Solow residual is used for capturing technology embodied as total factor productivity. This is an inaccurate proxy of technology given it is a "residual" of the production function and hence, it is representing all that what the model is unable to explain. Accordingly, it may violate the exogeneity assumption of the benchmark model in case the Solow residual is related to the endogenous variables. Another common critique is that firms expect temporary recessions rather than long lasting ones, and therefore they prefer to underutilise labour instead of dismissing labour force because of the recession and then rehiring the employees once the economic tumult is over. This logic implemented by firms is known as "labour hoarding". Moreover, the high persistence of shocks is not theoretically supported due to the negative consequences that imply non-stationary processes. At an even deeper level, economists have 
criticised RBC models because they don't seem particularly realistic. To generate fluctuations that resemble actual data, one needs large, high-frequency variation in technology. No other shock (i.e. investment, preferences, government spending etc.) is considered within the confines of the model, the main driving force behind the data cannot be other than technology shock.

To see this I consider the labour supply characteristic equation including the competitive level of real wages:

$$
\psi \frac{1}{1-l_{t}}=\frac{1}{c_{t}}(1-\alpha) k_{t}^{\alpha}\left(e^{z_{t}} l_{t}\right)^{1-\alpha} l_{t}^{-1} .
$$

I log-linearise the expression around the steady-state and get:

$$
\tilde{l}_{t}=\left(\frac{1}{\gamma+\alpha}\right)\left(-\tilde{c}_{t}+\alpha \tilde{k}_{t}+(1-\alpha) \tilde{z}_{t}\right), \quad \text { with } \gamma=\left(\frac{l^{*}}{1-l^{*}}\right) .
$$

Where a variable $\tilde{x}$ is defined as discussed above. If neither capital nor technology move, then it must be the case that hours worked and consumption move in opposite directions. Since shocks to capital don't seem plausible, shocks to technology need to be considered. These shocks must be the main driving force behind the data, otherwise consumption and hours will not be correlated strongly enough.

Even tough the above explanation justifies the inclusion of technology shocks, critics claim that assuming business cycles that result from the exogenous technological process (or regress) is unappealing (Summers, 1986). To generate recessions, one needs $z_{t}$ to decline. There is no evidence of such technology regress nor is it an economic issue that is discussed often in the news. Th, critics are uncomfortable with the fact that this model is (1) driven by technology shocks and that (2) these shocks must be large and sometimes negative. Therefore, much of the business cycle research since the 1980' has been involved in modifying the basic model to other shocks to matter (investment, preference shocks or monetary policy). Also, they tried to find ways to generate better and more realistic mechanisms for the model such that smaller shocks produce relatively large business cycles (indivisible labour, habit formation).

All in all, the RBC model has a fairly weak amplification mechanism and even weaker propagation mechanism. Amplification refers to a model's ability to have output react by substantially more than an exogenous shock (i.e. small shock creates large fluctuations). The only amplification mechanism considered is labour supply. Propagation refers to a model's ability to make shock have persistent effects. The only propagation mechanism in the model is capital accumulation. Further, it doesn't provide any endogenous persistence in output other than the assumed in technology. For this reason, I've considered to include the exposed range of model extensions in order to re-tool the benchmark model with new shocks and mechanisms that improve its performance.

\subsection{Why an RBC model?}

The improvements in technology and facilities made computing power boom leading to the possibility of solving and estimating RBC models. For instance, in this thesis, a popular software is implemented which allows me to solve and estimate systems of non-linear difference equations arising from the 
RBC model. Resulting from this, I've decided to use an RBC model for its great advantages over other methods (VAR approach) and for the arguments I'm about to expose now.

Nevertheless, it is convenient to start with recognising that many economists also disapprove some aspects of RBC models and the mathematisation of economics in general. Olivier Blanchard summarises this class of critiques quite well in terms of excessive methodology convergence in a comment of his 2008 working paper:

A macroeconomic article today often follows strict, haiku-like rules: It starts from a general equilibrium structure, in which individuals maximize the expected present value of utility, firms maximize their value, and markets clear. Then, it introduces a twist, be it an imperfection or the closing of a particular set of markets, and works out the general equilibrium implications. It then performs a numerical simulation, based on calibration, showing that the model performs well. It ends with a welfare assessment. [...] Introduction of an additional ingredient in a benchmark model already loaded with questionable assumptions. And little or no independent validation for the added ingredient.

In the past, RBC models have been repeatedly criticised for not performing a reliable quantitative data analysis as it does the Vector Autoregression (VAR) approach. In this sense, RBC models were thought to perform well on a theoretical level but they were considered to be too flexible in the calibration of the parameters.

In more recent times, RBC models have gained a much broader popularity because of the work by Smets and Wouters (2003), where they showed that a modified version of a New-Keynesian model developed by Christiano, Eichenbaum, and Evans (2005) is able to track down and forecast Euro area time series as well as (or better than) VAR estimations. Many econometricians, for instance, Fernández-Villaverde and Rubio-Ramírez (2004) or Fernández-Villaverde (2009), have been able to formalise certain aspects of the calibration in a probabilistic fashion. In particular, the most recent studies apply Bayesian techniques to estimate parameters in RBC models, just like traditionally in the VAR modelling. Currently, RBC models are effectively a model version of structural VARs with additional equation restrictions (i.e. see the relation between DSGE and VAR in Giacomini 2013). Contrary, the VAR approach applied to business cycle analysis is considered to be a reduced form VAR, hence capturing less well global features. In particular, RBC models have two desired properties in front of the standard VAR approach. First, the economic shocks that drive the dynamics of the model are assumed to be independent, which implies no correlation between the error terms as the desired property. For example, when considering a technology shock and a preference shock together (as I'll be analysing empirically later on in this thesis) there is no relation between shocks such that they are statistically independent. Secondly, variables can have a contemporaneous impact on other variables. This is particularly desirable when considering low-frequency data as in my case. For instance, tax rate changes in labour (which in turn can have the same effects as a markup shock considered in annex B) would not affect agents the day the decision is announced, but one could find an effect on this for quarterly data. This speaks clearly in favour of RBC models because this type of modelling is in line with economic theory (micro founded relations are the basis of parameter calibration) as well as it fits with the empirical evidence. What is more, this methodology allows for policymakers to assess whether policies are Pareto optimal or not, endowing abstract modelling techniques with practical economic applications. The combination of economic theory with potential computational methods makes an economic analysis from RBC models valuable. Finally, this kind of models are considered to be a powerful communicative tool for showing how the economy works as a whole without lacking on tractability. 


\section{EMPIRICAL BLOCK}

\subsection{Data analysis}

The aim of this section is to reveal the underlying data series behind the variables of the model. The yearly time range considered is 1985 until 2013. This data set has been taken from the Penn World Table (PWT) 9.0. The only variable that belongs to another source is real interest rate, which has been taken from the World Bank data.

In this thesis, the countries chosen for testing out the performance of the RBC model are Spain and the United Kingdom. Due to the neoclassical essence of the model and following the data treatment suggested by Eric Sims (2016), the series taken for analysis satisfy certain requirements. In particular, all series are in US dollars at 2011 constant prices. Moreover, all series are in per capita terms, except real interest rate and technology. Finally, for the sake of having standardised units of measurement and because of the filtering technique used, all series are in natural logs, except real interest rate and technology.

As a result, and following the same scheme as above, the data indicators for each variable are:

Table 2: Empirical definitions of the model

\begin{tabular}{cl}
\hline Variable & \multicolumn{1}{c}{ Data measure in \$US } \\
\hline$y_{t}$ & Real GDP per capita at 2011 constant prices \\
$c_{t}$ & Real consumption per capita at 2011 constant prices \\
$i_{t}$ & Real investment per capita at 2011 constant prices \\
$l_{t}$ & Average annual hours worked by person engaged \\
$k_{t}$ & Capital stock per capita constructed through PIM \\
$w_{t}$ & Average hourly wages at 2011 constant prices \\
$r_{t}$ & Real interest rate \\
$z_{t}$ & Technology constructed as the Solow residual \\
\hline
\end{tabular}

Before I continue explaining the methodology implemented using this data in order to get the statistical moments for the countries considered, I explain the procedure carried out for constructing the series of capital stock and technology.

\subsubsection{Capital stock series}

For constructing capital stock data I use the Perpetual Inventory Method (PIM) as in Berlemann and Wesselhöft (2014). Assuming geometric depreciation at a constant rate $\delta$ allows me to pin down the law of motion of capital specified in the model by using this method:

$$
k_{t+1}=i_{t}+(1-\delta) k_{t} .
$$

Accordingly, even though I can construct future values of capital stock following this accumulation process, I still need to determine the initial value of capital $k_{0}$. For this, I implement the estimation procedure introduced by Harberger (1978) known as the steady-state approach. This is the most adequate way for estimation because it employs the neoclassical growth theory and it relies on the 
assumption that the economy is at its steady-state. Consequently, along the balanced growth path, output grows at the same rate as capital stock, implying:

$$
g_{y}=g_{k} \Leftrightarrow k_{t}=i_{t}+(1-\delta) k_{t-1} \Leftrightarrow \frac{k_{t}-k_{t-1}}{k_{t-1}}=\frac{i_{t}}{k_{t-1}}-\delta .
$$

Hence:

$$
g_{y}=\frac{i_{t}}{k_{t-1}}-\delta
$$

I rearrange to get the expression equivalent to the initial value of capital stock:

$$
k_{t-1}=\frac{i_{t}}{g_{y}+\delta}
$$

Therefore, if in fact, the economy is at its steady-state, information on the current time period of investments, the growth rate on output and the depreciation rate are sufficient to calculate the capital stock of the preceding period. Still, a remarkable drawback is to rely just on a single year for computing the initial value of capital. Even this shouldn't be a problem in the case of the economy being de facto in the steady-state equilibrium; it is rather more probable to encounter some noise in the data, hence leading to a biased estimation of the initial capital stock value. Aware of this, Harberger suggests taking 3-year averages of the variables that determine the capital stock at time zero in order to have a more stable estimate. Applying this logic, for pinning down the value of $k_{0}$ I compute three year averages for investment, output growth and depreciation rate.

After constructing the series for Spain and the UK I've contrasted the results obtained with the data available in PWT 9.0 in order to check whether I'm getting coherent estimators. For Spain, I get that the PIM replicates pretty well capital stock series. When plotting this variable against time for both sources I observe an almost identical pattern of capital accumulation. The only difference is in terms of the initial value of capital stock, thus $k_{1985}$. Given the difference is not too big, Harberger's approach seems to be valid for Spain: $k_{1985}^{\text {SS approach }}=2,539,115$ Million\$US compared to $k_{1985}^{P W T}=$ 2,904,722 Million 2011 US\$.

Figure 2: Capital stock series comparison between PIM and PWT 9.0 for Spain

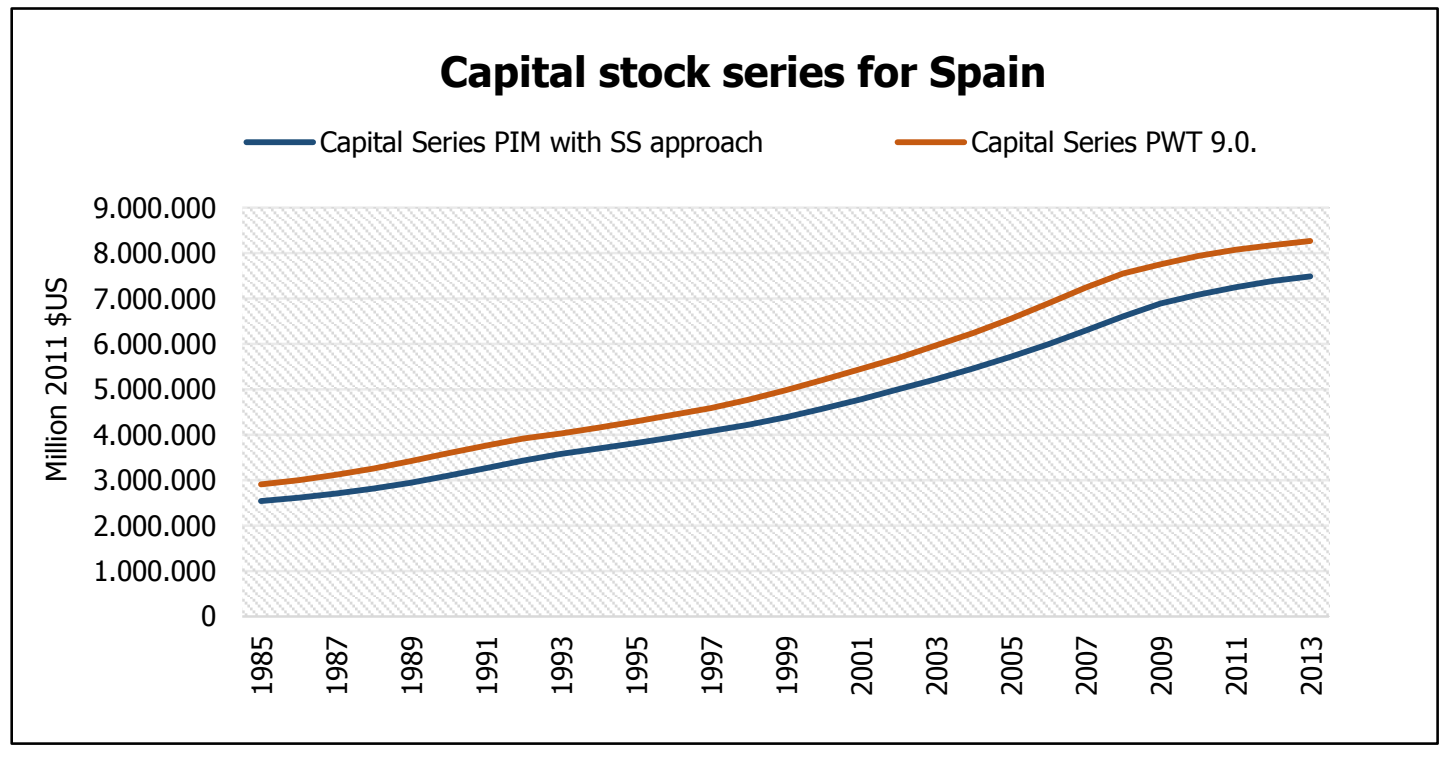


For the UK I observe that the tendency in the capital accumulation is practically the same between PIM and PWT data. However, when it comes to the initial value of capital I conclude that Harberger's approach underestimates the initial capital stock: $k_{1985}^{\text {SS approach }}=2,801,534$ Million 2011\$US compared to $k_{1985}^{P W T}=5,898,776$ Million 2011\$US. Accordingly, for the case of the UK, I've taken the data from PWT for the initial value of 1985.

Figure 3: Capital stock series comparison between PIM and PWT 9.0 for the UK

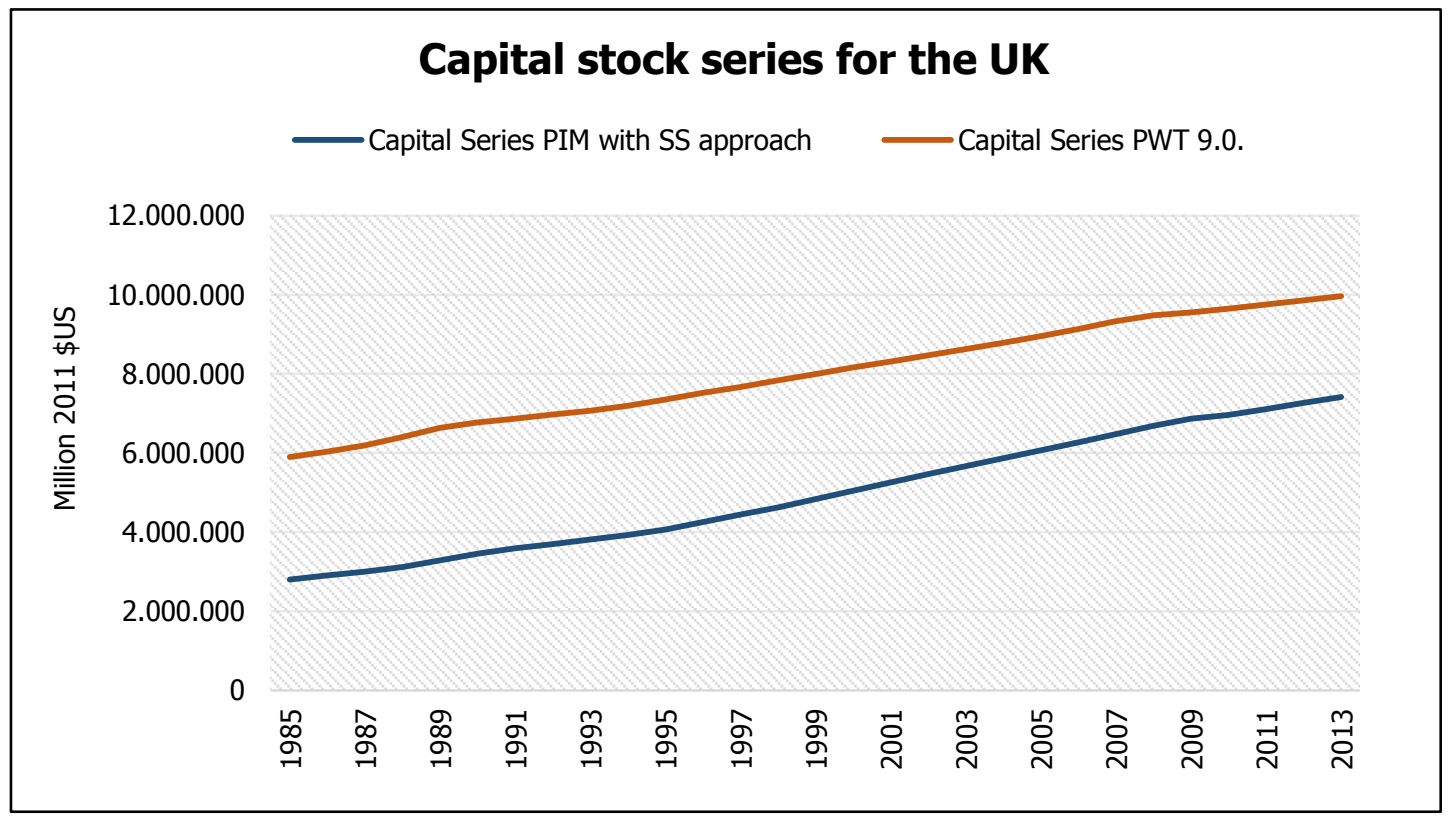

As a result, this suggests that the PIM procedure captures effectively the way capital accumulates in the data. In fact, the steady-state approach of Haberger works better for Spain than for the UK. Consequently, given I've considered as to be more appropriate to measure the variables in the same way across countries, I've taken the first observation of capital stock directly from PWT for both countries, despite the fact that Haberger's approach suits for Spain.

\subsubsection{Labour augmented technology series}

The other variable that needs further attention is technology. The popular methodology to construct series of the main driver of business cycles is by taking the Solow residual as the measure of technology. In this context, it is called "residual" because it is the part of the neoclassical growth that isn't explained by capital accumulation nor increased labour. Thus, it is capturing those aspects that the production function is unable to explain. However, sticking to Eric Sims I implement this method by isolating technology from the production function:

$$
z_{t}=\frac{1}{1-\alpha} \ln y_{t}-\frac{\alpha}{1-\alpha} \ln k_{t}-\ln l_{t} .
$$


As already explained above, I've introduced the technology along with labour and in an exponential way. This means that in this model I'm not directly representing Total Factor Productivity (TFP) as in the most literature of RBC models but I'm capturing labour augmented technology. Contrary to capital series, these series are constructed by just plugging data for each variable.

As a last insight, for the construction of capital series and labour augmented technology it is necessary to have assigned values for certain parameters (i.e. $\delta$ and $\alpha$ ). Hence, it is necessary to first determine the values of these parameters in the way explained in the calibration section before being able to construct the series.

\subsection{Methodology}

The influential paper of Finn Kydland and Edward Prescott of 1982 "Time to Build and Aggregate Fluctuations" is considered to be the cornerstone of modern business cycles research. Kydland and Prescott revolutionised the field introducing features that made it possible to study business cycles through dynamic general equilibrium models: the unification of short-run fluctuation models with growth theories by assuring consistency in terms of empirical characteristics of long-run growth. The RBC model is a simple extension of the Neoclassical growth model. It extends this model adding to it elastic labour supply and uncertainty in the form of technological shocks. This is a key feature in order to capture the dynamism of business cycles.

As in Prescott's words (2006): "Macroeconomics involves people making decisions based on what they think will happen, and what will happen depends on what decisions they make. [...] dynamism is at the core of modern macroeconomics".

In order to capture the important contributions of these prominent economists, I'm presenting the necessary tools for applying the theoretical dynamic features of the RBC model on real economies. This is made through simulations of the calibrated RBC model that capture the underlying business cycles from macroeconomic variables. The resulting empirical analysis from the statistical moments aims at describing the economy of a country in the short-run.

\subsubsection{Calibration}

The methodology for articulating these dynamic models has been a pioneering strategy known as calibration introduced first in the context of macroeconomics by Kydland and Prescott. A model within this framework is described through parameters that characterise preferences, technology and information. The procedure is to use microeconomic evidence to provide estimates for the underlying parameters. Using these measures, the model is then calibrated and can be used to provide statistical characteristics about the key variables in the model and how they co-vary, which are compared with macroeconomic data from the economy.

Contrary to the formal estimation of the parameters through econometric techniques (i.e. Bayesian or Maximum Likelihood estimation), the calibration approach is based on choosing parameter values such that the steady-state of the model matches long-run features of the data. Consequently, the identification procedure of the parameter values relies heavily on steady-state relations between variables of the model. I follow Eric Sims (2016) for pinning down particular values of the parameters 
and what is more, I present the numbers he is getting for the US so to have them as a reference. For assigning values to each parameter the following formulas are used and fitted with its corresponding data:

$$
\text { Capital elasticity to output: } \alpha=1-\frac{w l}{y} \approx 0.33 \text {. }
$$

This parameter captures the share of capital devoted to producing output.

$$
\text { Time preference discount factor: } \beta=\frac{1}{1+r} \approx 0.98 \text {. }
$$

This determines how inpatient households are regarding the utility from consumption and leisure they can gain today in comparison to the utility they could get from the future.

$$
\text { Capital depreciation: } \delta=\frac{\frac{i}{y}\left(\frac{1}{\beta}-1\right)}{\alpha-\frac{i}{y}} \approx 0.05 \text {. }
$$

This measure depicts the rate at which capital stock deteriorates along with time.

$$
\text { Capital to labour ratio: } \frac{k}{l}=\left(\frac{\alpha}{\frac{1}{\beta}-(1-\delta)}\right)^{\frac{1}{1-\alpha}} \approx 10 \text {. }
$$

This fraction relates the two input factors of the economy and it is crucial for pinning down the solution of the RBC model.

$$
\text { Leisure to labour ratio: } \frac{(1-l)}{l} \approx 2 \text {. }
$$

This ratio relates the time an individual destines to leisure compared to the time she dedicates to work. In particular, leisure is depicted as the number of hours in a natural year (360 days) minus the hours worked per year. Alternatively, this ratio can be computed by considering $l$ as the fraction of working time relative to time endowment.

$$
\text { Leisure preference: } \psi=\frac{\frac{(1-l)}{l}(1-\alpha)\left(\frac{k}{l}\right)^{\alpha}}{\left(\frac{k}{l}\right)^{\alpha}-\delta \frac{k}{l}} \approx 1.75 .
$$

This constant is capturing the household's willingness to replace work with leisure.

$$
\text { First order autocorrelation coefficient of technology: } \rho \approx 0.95 \text {. }
$$

This parameter tells me the degree of persistence in technology within two following periods.

$$
\text { Standard deviation of stochastic shock: } \sigma \approx 0.01 \text {. }
$$

This reveals how volatile the stochastic disturbance term is. In other words, it is the degree at which a random shock impacts the model economy.

I now specify the different calibrations of the new resulting parameters from the model extensions:

$$
\text { Leisure preference under indivisible labour: } A=\frac{(1-\alpha)\left(\frac{k}{l}\right)^{\alpha}}{l\left(\left(\frac{k}{l}\right)^{\alpha}-\delta\left(\frac{k}{l}\right)\right)} \text {. }
$$


Under the labour indivisibility scenario, it is not necessary to calibrate anything that goes into $A$ as for instance $\xi$. It is enough with calibrating the value of $A$, per se. I pin down this parameter in a similar way as I do it for leisure preference in the benchmark model.

Habit formation persistence: $\phi$.

For the sake of calibrating $\phi$ I run an autoregressive process of first order on the cyclical component of consumption in the form of: $c_{t}=\phi c_{t-1}+\eta_{c, t}$, assuming $\eta_{c, t} \sim$ White noise.

First order autocorrelation coefficients of preference shocks: $\rho_{\theta}$ and $\rho_{\vartheta}$.

Standard deviations of preference shocks: $\sigma_{\theta}$ and $\sigma_{\vartheta}$.

As it was the case of the technology shock, these parameters characterise the persistence and the volatility of the preference shock. Following Eric Sims I'm not parameterizing these in a formal way because for comparison purposes it is valid to consider the following values for these parameters: $\rho_{\theta}=\rho_{\vartheta}=0.9$ and $\sigma_{\theta}=\sigma_{\vartheta}=0.1$.

\subsubsection{Simulation}

Since the microeconomic foundations are well specified, this new understanding of macroeconomic modelling is suitable for conducting welfare analysis which in turn leads to a range of new opportunities for assessing economic policy, in Robert Lucas words (1980):

One of the functions of theoretical economics is to provide fully articulated, artificial economic systems that can serve as laboratories in which policies that would be prohibited expensive to experiment with in actual economies can be tested out at much lower cost. [...] Our task as I see it [...] is to write a FORTRAN program that will accept specific economic policy rules as "input" and will generate as "output" statistics describing the operating characteristics of time series we care about, which are predicted to result from these policies.

Hence, the RBC model is a clear manifest of the described theoretical tools needed for assessing economic policies. This is the case given the RBC model is able to generate artificial simulations in order to compare theoretical statistics from the model with actual statistics from data. In particular, the RBC model is a complex Dynamic Stochastic General Equilibrium (DSGE) model that has to be solved by numerical methods. In these models, it is also very hard to derive analytical comparative statics for understanding the qualitative predictions of the models. Numerical comparative statics are used instead. These latter ones are also useful for evaluation of quantitative predictions. In particular, researchers evaluate the response of the model variables over time to exogenous shocks known as Impulse Response Functions (IRF) and compare them to the patterns in real world data.

In line with Kydland and Prescott, the comparison is in terms of:

- the direction and the shape of the response of model variables;

- the magnitude of response in terms of means and standard deviations; and

- the signs and the magnitudes of correlations between model variables.

Intuitively, the direction of the IRF reflects whether the shock to the model has a negative or a positive impact on the endogenous variables. This is identified by the initial jump of the IRF for any specific variable. The shape of the IRF however, describes the process beginning from the initial 
impact of the shock up to the convergence towards the steady-state equilibrium (in the case of a stable system). Thus, the shape depends on statistical moments that capture the volatility, the cyclicality and the persistence of the model variables. In particular, the standard deviation is the statistical analogue of the variance (more precisely the square root of the variance). Also known as standard error, it describes the degree of volatility of a particular variable. Another interesting statistic is the standard deviation of the relevant variables relative to the standard deviation of output. Moreover, the next statistic captures the contemporaneous correlations between variables and output, also referred as cyclicality. This coefficient measures the degree of relation between two variables. This is the reason why it is called "co"-relation. More precisely, it corresponds to contemporaneous correlation because it is for the observations from the same period of time. Lastly, there is the first order autocorrelation measuring the persistence of a variable. This coefficient shows how much the observations of a variable are linearly interrelated. In other words, it shows how good is the current value of a variable for predicting its future value. Importantly, the optimal scenario is having this coefficient less than one in order to have a stationary process. This means the series is reverting to its mean after the shock. If the $1^{\text {st }}$ order autocorrelation is close (or equal) to 1 then an exogenous shock will stay in the process for a long time (forever). Also, this may imply having a unit root which can cause measurement errors and other inconsistencies in the model. Lastly, having the coefficient $>1$ entails an explosive system in terms of series not returning to the long-run equilibrium but shocks having permanent effects and getting larger over time.

Yet, for being able to extract all this information from the series, first I need to describe what determines the business cycle. The basic idea underlying the measurement of business cycles is that time series can be decomposed into a trend component and a cyclical component. Even though macroeconomic time series display trend growth, it is not immediately obvious what the cyclical properties of the data are. To make a comparison of the model dynamics with the cyclical properties of the empirical data, I need a procedure, a detrending method, to extract the cyclical component of the actual time series. The detrending method I use is the Hodrick-Prescott filter (HP). The origin of this filtering technique goes back to 1980 where Bob Hodrick and Edward Prescott ${ }^{4}$ constructed a functional specification for the filter that had a parameter as trend smoother. The value of it was selected such that the statistics mimicked the smooth curve. The advantage of such development was that the parameter selection for the filter for a specific type of data frequency had no degrees of freedom, making studies comparable. Today, the HP-filter is one of the most popular methods to extract cyclical components. For my case, I use a value of 100 for the HP-filter parameter given my yearly data set. Once I've identified the cyclical component, it is possible to characterise the business cycle. I'd like to be able to obtain some regularities in the data, i.e. some stylised facts that will help me understand the business cycle. In order to get these amounts of information on the fluctuations of the cyclical component of the main economic variables for Spain and the UK, I compute second-order statistical moments as shown above.

\subsubsection{Dynare}

In this thesis, I use Dynare and Matlab to simulate the RBC model for Spain and the UK. In order to generate artificial fluctuations in the RBC model, it is necessary to simulate an exogenous shock on technology that in this case is of the size of a squared standard deviation. The next step to be able to get theoretical moments from the benchmark model is to write down the model on a Dynare script.

\footnotetext{
${ }^{4}$ At that time it was a North-western University working paper. It was not until 1997 when it was published in an economic journal.
} 
The model declaration is done along different blocks that serve as instructions for Dynare. This software will be reading out each block and accordingly it will be calling Matlab routines.

What is more, for the steady-state equations, a separate Matlab function has been created that is attached to the model script. In this way, Dynare can refer directly to the specific set of steady-state equations of the Matlab function for the purpose of solving the model in much less time, hence computing the statistical results quicker. When running the calibrated model for a country in Dynare, IRF and theoretical statistical moments are generated that are then compared to the data. The intuition behind the computational process is to assume that the economy is at its steady-state in the initial period. Then, it is impacted by a random exogenous shock that is temporary. The corresponding model variables react to this shock reflected in the IRF and generating statistical properties. Whilst the shock is dying out the model variables return to its steady-state values. This process is also reflected by the IRF. Accordingly, the theoretical statistical moments are the ones that I take for the analysis since they capture the behaviour of business cycles for the model variables. For an example of such Dynare and Matlab scripts refer to annex A.2.

\subsection{Modelling the shock}

I'm including this topic to my analysis because it determines the calibration of the parameters that characterise the impulse of shocks in the benchmark model. As stated in the theoretical part I'm aiming to get high persistence in the technological process as previously shown in the reference values for rho and sigma. For this, I implement Eric Sims' way of modelling technology and calibrating the resulting parameters, adapting his procedure to my functional specifications. Additionally, I test and evaluate the validity of this modelling procedure through econometric analysis for the country of Spain and the UK.

\subsubsection{Detrending method}

For the sake of getting the desired values for the parameters derived from the autoregressive process of technology, this latter variable is filtered in a particular way, unlike the other variables of the model. For isolating the cyclical component of technology Eric Sims runs a regression on the Solow residual against a constant and a time trend. Thus, detrending the measure of technology is done by running the following regression:

$$
\hat{z}_{t}=\omega_{0}+\omega_{1} t_{t}+u_{t} .
$$

The following step is to take the fitted values of the residual which in turn is considered to be the cyclical component of technology and estimate the AR(1) process:

$$
\hat{u}_{t}=\rho \hat{u}_{t-1}+e_{t}, \quad \text { assuming } e_{t} \sim \text { White Noise. }
$$

From this regression, I get the parameter value of $\hat{\rho}$. I obtain the value of $\hat{\sigma}$ when saving the residual and displaying its descriptive statistics.

\subsubsection{Econometric analysis}


I use the econometric software Gretl to implement the methodology of Eric Sims step by step and I also analyse whether this procedure is appropriate for Spain and the UK. In particular, I check that the filtering technique of running a regression against an intercept and a linear time trend is as effective as implementing the HP-filter. Moreover, I want to know whether I get the expected values for the parameters or not and finally, I analyse the consistency of such results by testing for stationarity through a variety of formal tests. In this way, I can determine the validity of this procedure. Due to the fact that performing this same analysis delivers identical conclusions for Spain and the UK, I obviate repeating the procedure for the UK and present only the results for Spain.

First, I run labour augmented technology series for Spain against an intercept and a linear time trend. The results are:

Table 3: Labour augmented technology regression with the estimated coefficients of a constant and a time trend (i.e. $\omega_{0}$ and $\omega_{1}$ )

\begin{tabular}{|c|c|c|c|c|c|}
\hline \multicolumn{6}{|c|}{ Model 1: OLS, using observations $1985-2013(T=29)$} \\
\hline \multicolumn{6}{|c|}{ Dependent variable: SP } \\
\hline const & $\begin{array}{c}\text { Coefficient } \\
1.35602\end{array}$ & $\begin{array}{l}\text { Std. Error } \\
0.0160009\end{array}$ & $\begin{array}{c}\text { t-ratio } \\
84.7468\end{array}$ & $\begin{array}{c}\text { p-value } \\
<0.00001\end{array}$ & $* * *$ \\
\hline time & -0.0152641 & 0.000931607 & -16.3847 & $<0.00001$ & $* * *$ \\
\hline R-squared & 0.908616 & & & & \\
\hline
\end{tabular}

Table 4: AR(1) regression on the saved residual to get the autoregressive coefficient (i.e. $\rho$ )

\begin{tabular}{|lccccc|}
\hline \multicolumn{5}{|c|}{ Model 2: OLS, using observations $1986-2013(T=28)$} \\
\multicolumn{5}{c|}{ Dependent variable: uhat_SP } \\
uhat_SP_1 & Coefficient & Std. Error & t-ratio & p-value & \\
& $\mathbf{0 . 9 6 1 8 7 9}$ & 0.0926259 & 10.3845 & $<0.00001$ & $* * *$ \\
R-squared & & & & & \\
F(1, 27) & 0.799761 & & & & \\
Schwarz criterion & 107.8389 & $\mathbf{- 1 4 3 . 6 8 0 1}$ & P-value(F) & $6.28 \mathrm{e}-11$ & \\
\hline
\end{tabular}

Table 5: Saved error term from this latter AR(1) regression to get the standard deviation of the error term (i.e. $e_{t} \rightarrow \sigma$ )

Summary Statistics, using the observations $1985-2013$

for the variable ehat_SP (28 valid observations)

Std. Dev. 0.0178119

Looking at the outputs, I can determine that at a first glance I'm getting the desired results. I proceed on checking whether the detrending method of Eric Sims captures the cyclical component as 
well as the HP-filter does by plotting the saved residual series $\hat{u}_{t}$ against time on the one hand and the HP-filtered series of labour augmented technology on the other hand.

Figure 4: Eric Sims' detrending method

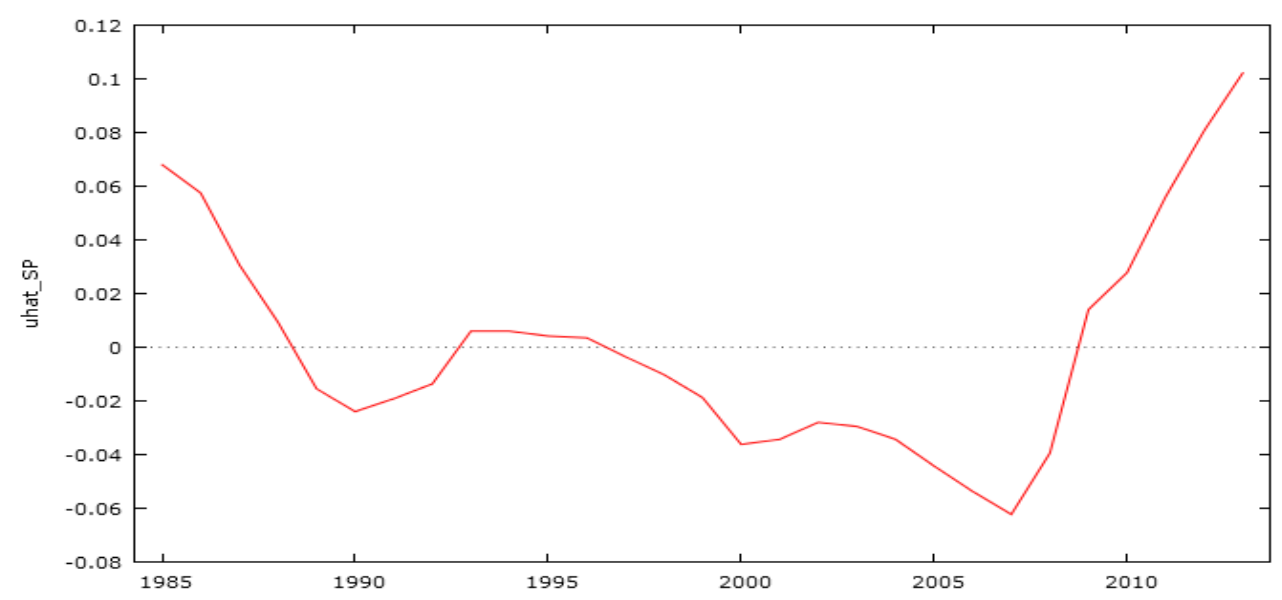

Figure 5: HP-filter detrending method

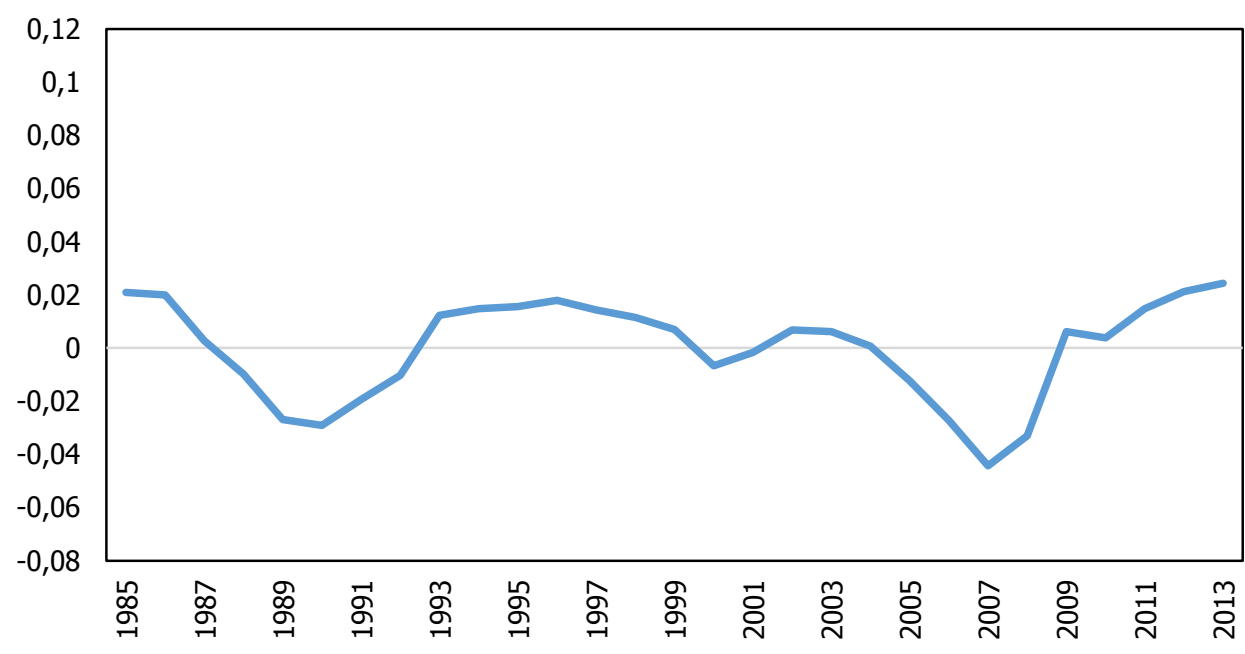

I can appreciate that Eric Sims method is capturing well the cyclical component of labour augmented technology speaking for the validity of this method. For an additional discussion on this refer to annex A.3.

Moreover, I assume that the cyclical component of labour augmented technology (i.e. $u_{t}$ ) is stationary in the AR(1) process. However, I analyse this fact through two channels: On the one hand by computing the roots of the autoregressive process in order to contrast its stability and on the other hand, by performing formal tests for stationarity. This is of remarkable importance in order to spot any possible unit roots that would lead to spurious relationships. Accordingly, I first solve for the root of the AR(1) process. Whenever the root of the AR polynomial lies outside the unit circle, it implies that the process is stationary and mean-reverting. To compute the root of the autoregressive process I set the polynomial to zero. Applying this theoretical procedure for the case of Spain delivers the following results: 


$$
\begin{gathered}
\hat{u}_{t}=0.961879 \hat{u}_{t-1}+e_{t} . \\
\text { Root }=\frac{1}{0.961879}=1.039632>1 \rightarrow \text { stable or stationary process. }
\end{gathered}
$$

Therefore, strictly speaking, there is no unit root implying that this process is stationary. Nonetheless, given the root is very close to one meaning the process is almost following a random walk, I undertake formal testing to ensure the stability of the process. The purpose is to get an overall picture based on the different conclusions I'm getting from these econometric tests. There is no unique test that predominates over the others, but rather they complement each other. The way the tests are presented is by first explaining their theoretical formalities of the test and then applying them to Spain. The critical values of the tests follow Enders (2010) tabulation. All the tests are undertaken using Gretl.

The first test I carry out is the Dickey-Fuller Test for stationarity.

DF Test:

$$
\begin{aligned}
& \left.\begin{array}{l}
\mathrm{H}_{0}=\text { Non stationary process } \\
\mathrm{H}_{1}=\text { Stationary process }
\end{array}\right\} D F_{0} \text { statistic } \sim \text { DF tabulation, } \\
& \text { if } D F_{0} \geq \text { critical value } \rightarrow \text { Reject } \mathrm{H}_{0}=\text { Stable process. } \\
& \text { if } D F_{0}<\text { critical value } \rightarrow \text { Fail Reject } \mathrm{H}_{0}=\text { Non stable process. }
\end{aligned}
$$

For all standard levels of significance (i.e. $1 \%, 5 \%$ and $10 \%$ ) I get to fail to reject the null hypothesis. Hence, I've enough empirical evidence to conclude that the cyclical component of technology as captured above is not stationary, contrary to what is suggested when computing the roots of the process. Nonetheless, I need to go deeper on this analysis because in the Dickey-Fuller regression for constructing the test it is assumed that the error term is uncorrelated to the lagged dependent variable among other assumptions ( $e_{t} \sim$ white noise), which is not always the case.

For this, I add another lag in the cyclical component of labour augmented technology in order to be able to construct the Augmented Dickey-Fuller regression. Thus, by introducing the first difference lagged dependent variable I ensure the error term is not correlated to the lagged dependent variable. Moreover, I analyse the possibility of including a constant or a deterministic trend component on the ADF regression. Adding an intercept or a time trend changes the specification of the regression but more importantly it changes the critical value with which I compare our ADF statistic. Following Enders (2010) procedure for this analysis, I end up concluding that there shouldn't be any additional component in the ADF regression for performing the ADF test.

ADF Test:

$$
\begin{aligned}
& \left.\begin{array}{l}
\mathrm{H}_{0}=\text { Non stationary process } \\
\mathrm{H}_{1}=\text { Stationary process }
\end{array}\right\} A D F_{0} \text { statistic } \sim A D F \text { tabulation, } \\
& \text { if } A D F_{0} \geq \text { critical value } \rightarrow \text { Reject } \mathrm{H}_{0}=\text { Stable process. } \\
& \text { if } A D F_{0}<\text { critical value } \rightarrow \text { Fail Reject } \mathrm{H}_{0}=\text { Non stable process. }
\end{aligned}
$$


When running the test I get sufficient empirical evidence to conclude that the process is nonstationary at a $1 \%$ and $5 \%$ significance level. Nevertheless, I need to emphasise that at a $10 \%$ significance level the process doesn't contain a unit root. This may explain why I get a stable process when pinning down the roots of the process but I end up concluding that the process is nonstationary when performing the DF and ADF test. This thin line between stationarity and unit roots in the cyclical component of technology remains manifested in this issue.

In order to try to clarify this, I proceed to test stationarity through the Kwiatkowski-PhillipsSchmidt-Shin test in order to complement the ADF test. One of the main issues of the ADF test is its low power when the root is close to 1 (as it is in my case). This high autoregressive coefficient can be due to the low sample of years considered in this thesis making the power of the test decrease. Thus, introducing the KPSS seems reasonable in order to check whether I get different conclusions. The main insight of the KPSS test is that the hypotheses are reversed in comparison to the ADF test such that the null hypothesis claims that the time series' order of integration is zero.

KPSS Test:

$$
\begin{aligned}
& \left.\begin{array}{l}
\mathrm{H}_{0}=\text { Stationary process } \\
\mathrm{H}_{1}=\text { Non stationary process }
\end{array}\right] K P S S_{0} \text { statistic } \sim \text { KPSS tabulation, } \\
& \text { if } K P S S_{0} \geq \text { critical value } \rightarrow \text { Reject } \mathrm{H}_{0}=\text { Non stable process. } \\
& \text { if } \mathrm{KPSS}_{0}<\text { critical value } \rightarrow \text { Fail Reject } \mathrm{H}_{0}=\text { Stable process. }
\end{aligned}
$$

I get the same conclusions as in the ADF test but at different significance levels. For $5 \%$ and $10 \%$ I observe that the process is not stationary, but at $1 \%$ significance, it is stationary. I also see through this test that the constant and time trend is not significant (the associated coefficients are zero and pvalues suggest that there is enough empirical evidence to fail to reject the null hypothesis of nonindividual significance). This means that the results coincide with the conclusions I got when implementing Enders' procedure explained above.

Summing up, the specification of the AR(1) process of cyclical technology should be captured without constant and without time trend. Moreover, the process is in a blurred line between stationarity and containing a unit root leading to spurious relations in the latter case. Depending on the level of significance I can conclude one thing or another. However, for argument's sake and to keep in line with Eric Sims methodology I proceed to analyse this model assuming that the series for cyclical component of technology are mean-reverting. This is legitimate given the essence of the model is to present technology shocks as the main drivers of business cycles and this implies that the associated first-order autocorrelation coefficient must be high. Despite the fact that one of the main caveats of the RBC model is precisely this high persistence of technology, it is valid to work with this assumption for analysing the model's performance and its business cycle mechanics.

\subsection{Results for Spain and the UK}

So far I've focused on describing the functioning of the RBC model and its extensions along theoretical dimensions. Also, I've explained how I've treated the model empirically in order to conduct the factual 
analysis. Accordingly, the aim of this thesis is by no means to analyse or discuss the theoretical models presented but to take them as given. With their corresponding insights, I then apply them to Spain and the UK. Hence, what I'm doing is to undertake an empirical exercise through resolving the benchmark model with the pertinent extensions, running them on Dynare and interpreting the outputs to extract conclusions. Having clarified this, I proceed with exposing my results for Spain and the UK.

\subsubsection{Empirical business cycles results}

Before comparing the theoretical model with the actual data, I've a look at the features of the HPfiltered cyclical components for each endogenous variable. For this, I observe the statistical moments and the plots of the model variables against time to undertake a comparison among countries. I present here the empirical moments and refer to the graphs in the annex A.4.

Table 6: Empirical moments for Spain and the UK

\begin{tabular}{c|cc|cc|cc|cc}
\hline \multirow{2}{*}{ Variable } & \multicolumn{2}{|c|}{$\begin{array}{c}\text { Standard } \\
\text { Deviation }\end{array}$} & \multicolumn{2}{|c|}{ Relative STD } & \multicolumn{2}{c|}{$\begin{array}{c}\text { Correlation to } \\
\text { Output }\end{array}$} & \multicolumn{2}{c}{$\begin{array}{c}1^{\text {st }} \text { order } \\
\text { Autocorrelation }\end{array}$} \\
\cline { 2 - 9 } & SP & UK & SP & UK & SP & UK & SP & UK \\
\hline $\ln y_{t}$ & 0.0237 & 0.0223 & 1.0000 & 1.0000 & 1.0000 & 1.0000 & 0.8046 & 0.6851 \\
\hline $\ln c_{t}$ & 0.0257 & 0.0225 & 1.0837 & 1.0108 & 0.9287 & 0.9297 & 0.8546 & 0.7895 \\
\hline $\ln i_{t}$ & 0.0775 & 0.0667 & 3.2702 & 2.9915 & 0.9672 & 0.7599 & 0.7664 & 0.5207 \\
\hline $\ln l_{t}$ & 0.0051 & 0.0071 & 0.2150 & 0.3191 & -0.1374 & 0.4843 & 0.6504 & 0.5118 \\
\hline $\ln k_{t}$ & 0.0078 & 0.0073 & 0.3276 & 0.3255 & -0.0620 & 0.2961 & 0.7110 & 0.7959 \\
\hline $\ln (y / l)_{t}$ & 0.0289 & 0.0190 & 1.2214 & 0.8522 & 0.9421 & 0.9486 & 0.8471 & 0.6770 \\
\hline $\ln w_{t}$ & 0.0921 & 0.0760 & 3.8851 & 3.4071 & 0.1014 & 0.6286 & 0.6242 & 0.6300 \\
\hline$r_{t}$ & 0.0167 & 0.0108 & 0.7051 & 0.4821 & 0.3490 & 0.2189 & -0.2260 & 0.2313 \\
\hline$z_{t}$ & 0.0186 & 0.0128 & 0.7865 & 0.5738 & -0.9521 & -0.8564 & 0.7710 & 0.6777 \\
\hline
\end{tabular}

The relevant statistics for capturing business cycles are standard deviation and relative standard deviation of the model variables to output for the purpose of the volatility of the variable. Contemporaneous correlation to output for analysing the cyclicality and the first order autocorrelation in order to measure the persistence of each variable. Let's remind quickly what economic theory says about the second-order statistical moments in business cycle variables compared to output. Mainly, consumption should be smoother than output and investment more volatile. Hours worked or labour should be as volatile as output whereas capital should be less volatile. Finally, labour productivity and technology should be far less volatile than output. Also, in the perfect competition framework of the neoclassical theory, input factors should be in line with their corresponding factor prices in terms of correlation and volatility. Regarding contemporaneous correlation to output, all variables should display a high pro-cyclical correlation to output besides productivity that should be less correlated. Last but not least, all variables should show a high level of autocorrelation to its own first lag meaning elevated persistence.

Without further hesitation, I delve into the empirical business cycles captured as the HP-filter cyclical component for the two countries. The economy of Spain is characterised by having output's volatility around 0.024 . I observe that consumption is almost as volatile as output whereas investment is significantly more volatile (about 3 times more). Hours worked measured in the intensive margin are about a fifth less volatile than output. The other factor of production, capital stock, is a bit more volatile than hours worked. Moving forward to productivity I can see that it is a bit more volatile than 
output and consumption, particularly $20 \%$ more volatile. Contrary, labour augmented technology is less volatile compared to output. Surprisingly, I observe that wages are the most volatile variable (even more than investment) whereas real interest rate has roughly the same level of volatility as labour augmented technology. The main characteristics of UK's economy are as follows: in terms of standard deviations output and consumption are roughly the same. As expected, investment is more volatile (about 3 times more as in Spain). Labour and capital stock are far less volatile than output with a relative STD of labour of $32 \%$ and Capital stock of $33 \%$ being the least volatile variables. Interestingly, the volatility of hours worked is higher in the UK than in Spain meaning there are higher fluctuations in the UK's employment level in case a shock strikes the economy. Labour productivity has $85 \%$ relative STD to output, whereas labour augmented technology and real interest rate are similar in terms of volatility. As it was in the case of Spain, I also observe high volatility in real wages. In general terms, the UK presents lower levels of volatility than Spain for all variables but hours worked.

Regarding the next relevant statistic, contemporaneous correlation, I observe that most variables of Spain are positively correlated to output as economic theory predicts. Contrary, there are some exceptions as for instance the factors of production: hours worked and capital stock are countercyclical to output, a fact that contradicts the theory. At least for capital stock, the correlation is almost 0 but for hours worked the negative correlation is of $13.7 \%$. This suggests that when Spain is in an economic boom, employment decreases. Obviously, this strange fact contradicts economic theory and it is an outlying finding only observable for Spain. The respective factor prices show positive correlation but far smaller than the rest of the variables. I also observe labour augmented technology being highly negative correlated to output suggesting technology regression. For the UK all variables are pro-cyclical and very much correlated, besides factor inputs and prices. In line with Spain, labour augmented technology is negatively correlated to output. I remark that for the UK I get less correlation to output for investment in comparison to Spain, meaning that investments co-move less with output for this former country. Apart from the fact that the UK follows economic theory in terms of the factor inputs being positively correlated to output as opposed to Spain, it is also true that the cyclicality of wages is remarkably higher for the UK than for Spain. Regarding the real interest rate, however, Spain presents higher cyclicality.

Lastly, the first order autocorrelation results reflect well what economic theory predicts for Spain and the UK. In particular, for Spain, the least persistent variable is hours worked and real wages and the most persistent one is consumption, merely because it is a stable variable and usually consumers try to smooth out their consumption choices over time. In exception to the rest of variables, real interest rate shows a negative autocorrelation for the years analysed. This is another non-coherent fact for Spain but this result may arise from the lack of data for this particular variable. In particular, the available data for Spain is between 1985 and 2002 whereas for the UK the full range of years (1985-2013) is available. So, even though this may not be the underlying reason for the observed negative correlation of real interest rate to output, it a possible explanation. Nonetheless, for the RBC model, where the interest rate is used as the real compensation of the marginal product of capital it is enough to have this reduced sample since it stills enables me calibrating the time discount preference of the Euler equation. In the UK variables reveal far less persistence than Spain. Consumption and capital stock are the most highly persistent. Nonetheless, output, labour productivity, wages and labour augmented technology are less persistent with values around 0.7 . The least persistent variables in the UK are investment, hours worked and real interest rate. In relative terms, the persistence levels among variables are the same between countries. This means for example that for both Spain and the 
UK, consumption is more persistent than output and other variables. The only exception in terms of Spain having a different relation between the persistence of output and another variable is capital stock and labour productivity. The former is less persistent and the former more in comparison to output in the case of Spain, whereas the opposite is true for the UK.

For the sake of getting a clearer picture of Spain's and the UK's business cycles for the main macroeconomic variables between 1985 and 2013, I also describe the characteristics of the graphical cyclical component of the HP-filtered available in annex A.4.

In general, without delving into the underlying (historical) reasons behind the observable economic booms and recessions, I clearly can recognise a wave stylish shape of the business cycles of all variables (comparable to a Fourier series or Sine function). In particular, for Spain's output, I identify a recession from 1985-1987 which turns into an economic boom until 1993. Then I see a prolonged decline in economic activity between 1993 and 1999 followed by a 10-year economic renaissance until the recent financial crisis breaks through. Hence in the period until 2013, a severe drop in output prevails. The UK follows similar patterns where I identify a decrease in economic activity from 19851987 which turns into an economic boom until 1991. Then I see a prolonged downturn between 1991 and 1999 followed by a 10-year economic recovery until the recent financial crisis strikes the country. Thus, in the period until 2013, a severe drop in output prevails with a sluggish economic recovery at the end.

Next, I analyse how the variables relate to each other for both countries and how they behave across countries. I observe output and consumption co-move almost one to one during the period analysed, while investment's plot also has the same shape but with sharper peaks and falls than the latter two variables described, hence corroborating the higher volatility of investment. For hours worked I see a rather small fluctuating series with just two outlying peaks. I recognise a positive peak in 2002 and an accentuated negative one in 2007. This seems reasonable given by the beginning of the 21st century lots of jobs have been created in the construction sector due to the housing bubble, whereas in 2007 most of the people employed back then were dismissed. When contrasting the pattern of hours worked, output, consumption and investment I don't see a clear co-movement though. Most striking are the countercyclical behaviour between 2005 and 2009. Whereas the three former variables show an economic boom, the latter variable presents a clear decline suggesting that when economic activity increased during that period, Spanish workers did work fewer hours than usually. However, when looking at labour productivity defined as output divided per hours worked, I see that the productivity was high during this period. Accordingly, it seems like Spain was producing more by working fewer hours between 2005 and 2009. When considering wages per hour I observe a similar pattern as in output in terms of economic fluctuations, while the volatility, in other words, the size of these peaks, are more similar to investment. Nonetheless, when looking closely I observe that wages are negatively co-moving with output in some periods (i.e. 1994-1999 and 1999-2003). The graph of capital stock tells me there is an analogous behaviour with output, consumption and so on, besides the beginning of the period analysed: from 1985-1997. During this period, when output increases, capital stock decreases and vice versa. For the rest of the years, the behaviour of capital is close to output. When it comes to real interest rate I discern a stable behaviour in terms of volatility oscillating the graph between 0,020 and $-0,010$, with the exception of the severe drop in 1986 and a noticeable increase in 1987. Lastly, labour augmented technology captured as the Solow residual from the Production function, is strictly countercyclical to output. In terms of shape, it is at the same scale as output but in the opposite direction. 
For the UK I observe similar patterns as in Spain, for this reason I only emphasise the main outlying results or severe differences with Spain. In particular, for hours worked I see fluctuations at a high frequency not observable in Spain. For this variable, I find accentuated peaks in 1988, 1992 and 2004. When contrasting the pattern of hours worked with output, consumption and investment, in general, I notice a clear co-movement among these variables, contrary to Spain where the comovement is not so clear. Apart from the UK's decline between 2003 and 2005 in hours that is not present in the other variables, the rest of fluctuations are quite similar across the variables. This fact replicates the economic intuition that hours worked is co-moving with economic activity better than it is the case for Spain. Still, the shape of hours worked is more similar to investment than to output or consumption, per se. When looking at labour productivity I want to emphasise a lower peak in the UK's productivity during the economic boom of the early 2000s. Thus, it seems as Spain was more productive in labour during the housing bubble. However, when zooming in 2003-2005 I observe that the UK is more productive than Spain, whereas in the same time period wages were low. Accordingly, it seems like the UK was producing more working fewer hours between 2003 and 2005 in contrast to Spain. When considering real wages I see a similar pattern as in output in terms of economic fluctuations, while the volatility, in other words, the size of these peaks, is more similar to investment. Nonetheless, when looking closely I observe that wages are negatively co-moving with output in some short periods (i.e. 1997-2002). The graph of capital stock is remarkable because it shows clear differences between countries. The most important time periods are between 1991-1999 and 20022008 because there the variable shows clear opposite patterns between Spain and the UK. When it comes to real interest rate I just want to underline that the UK presents fewer fluctuations in comparison to Spain, especially at the beginning of the period analysed. For labour augmented technology, the UK follows the same pattern as Spain.

As a final insight, I've a look at some endogenous variables jointly. In line with the RBC model analysed, the first joint graph is capturing the macroeconomic identity: output being equal to consumption and investment. As described above, I see a very similar co-movement along the period. Following economic theory, investment is much more volatile than output, whereas the volatility of consumption is much closer to output. Nevertheless, normally economic theory predicts that consumption is smoother than output, something not observable in here. This holds for Spain and for the UK. The other two joint graphs that are stressing out key facts about Spain's business cycles are the comparison between the input prices and the input factors. What I first notice when looking at wages and hours worked is the difference in the direction of fluctuations. Wages fluctuate much more than hours worked, too. Despite the fact that I see that hours worked co-move with wages in some periods as from 1993 to 1994, the main picture reveals that these variables display opposite comovement. This pattern becomes even clearer when looking at the capital stock and real interest rate. Here, volatility seems to be more aligned but the co-movement between 1985 and 1990 is negative. For the rest of periods, the correlation is tighter among the variables. Contrary, what I first notice when looking at wages and hours worked of the UK is that the patterns are very different to the ones of Spain. Here I see an almost perfect co-movement of wages and hours worked, replicating the neoclassical assumption that the price of labour is equal to its real compensation embodied in MPL. This pattern is also present in the capital and real interest rate. Here, fluctuations seem to be less aligned but the co-movement along the period is almost perfect.

Summing up, after having analysed all these features of Spain and the UK, I can conclude that the UK follows better than Spain the relations imposed by the neoclassical theory of business cycles, reassuring the initial statement of Spain being more structurally rigid than the UK. 


\subsubsection{Theoretical business cycles results}

For the sake of understanding best the application of the benchmark model and its extensions to Spain and the UK, I show the calibration results and steady-state values obtained for each country. Showing the specific values for calibration is important because I can check that what I'm getting is similar to the reference values shown in the theoretical block. Also, by presenting the steady-state values for the benchmark model I can check that the model is actually returning to its steady-state. For this latter issue, I check the steady-state values I get when plugging the calibrated parameters in the steady-state equations and compare these results with the steady-state values I obtain when running the RBC model on Dynare.

Table 7: Parameter calibration for Spain and the UK

\begin{tabular}{|c|c|c|}
\hline Parameter & Values for Spain & Values for the UK \\
\hline$\alpha$ & 0.3666 & 0.3823 \\
\hline$\beta$ & 0.9556 & 0.9733 \\
\hline$\delta$ & 0.0385 & 0.0439 \\
\hline$\psi$ & 3.0141 & 3.2864 \\
\hline$\rho$ & 0.9619 & 0.9659 \\
\hline$\sigma$ & 0.0179 & 0.0136 \\
\hline$A$ & 3.7738 & 4.0939 \\
\hline$\phi$ & 0.8546 & 0.7895 \\
\hline
\end{tabular}

Table 8: Steady-state values for Spain and the UK

\begin{tabular}{|c|c|c|}
\hline SS variable & Values for Spain & Values for the UK \\
\hline$l^{s S}$ & 0.2013 & 0.1973 \\
\hline$k^{s S}$ & 2.0245 & 2.9876 \\
\hline$i^{s S}$ & 0.0780 & 0.1314 \\
\hline$y^{S S}$ & 0.4692 & 0.5581 \\
\hline$c^{s S}$ & 0.3912 & 0.4267 \\
\hline
\end{tabular}

Subsequently, I can conclude that the parameter values are reasonably valid for the analysis given they are close to the reference values. Interestingly I notice that the values of the parameters are always greater for the UK than for Spain (with exception of the STD of the disturbance term and the habit formation parameter). Moreover, I'm getting the same steady-state values when running the model, so the theoretical moments that are about to be presented are consistent for Spain and the UK. Here, it is also the case that the steady-state values for the UK are greater than for Spain (except labour). This observation may be advancing me the possible pattern I probably will encounter when analysing the results of the theoretical moments for Spain and the UK.

\section{The benchmark model}

I proceed to expose the theoretical moments for each country as well as a summary table depicting the comparative statics of each variable of the model with its corresponding analogue from data. This is an illustrative way to analyse the predicting power of the benchmark model on the one hand, and 
on the other it also describes the direction of the impact of the technology shock on each variable, indicating how the shape of the IRF is.

Table 9: Theoretical moments for Spain and the UK: Benchmark model

\begin{tabular}{|cc|c|c|c|c|c|c|c|}
\hline \multirow{2}{*}{ Variable } & \multicolumn{2}{c}{$\begin{array}{c}\text { Standard } \\
\text { Deviation }\end{array}$} & \multicolumn{2}{c}{ Relative STD } & \multicolumn{2}{c|}{$\begin{array}{c}\text { Correlation to } \\
\text { Output }\end{array}$} & \multicolumn{2}{c|}{$\begin{array}{c}\mathbf{1}^{\text {st }} \text { order } \\
\text { Autocorrelation }\end{array}$} \\
\cline { 2 - 10 } & SP & UK & SP & UK & SP & UK & SP & UK \\
\hline $\ln \boldsymbol{y}_{\boldsymbol{t}}$ & 0.0146 & 0.0109 & 1.0000 & 1.0000 & 1.0000 & 1.0000 & 0.4838 & 0.4829 \\
\hline $\ln \boldsymbol{c}_{\boldsymbol{t}}$ & 0.0064 & 0.0045 & 0.4400 & 0.4100 & 0.9494 & 0.9571 & 0.5790 & 0.5621 \\
\hline $\ln \boldsymbol{i}_{\boldsymbol{t}}$ & 0.0583 & 0.0326 & 3.9900 & 2.9900 & 0.9848 & 0.9914 & 0.4614 & 0.4674 \\
\hline $\ln \boldsymbol{l}_{\boldsymbol{t}}$ & 0.0070 & 0.0054 & 0.4700 & 0.4900 & 0.9731 & 0.9807 & 0.4595 & 0.4649 \\
\hline $\ln \boldsymbol{k}_{\boldsymbol{t}}$ & 0.0041 & 0.0027 & 0.2800 & 0.2500 & 0.4992 & 0.4678 & 0.8476 & 0.8507 \\
\hline $\ln (\boldsymbol{y} / \boldsymbol{l})_{\boldsymbol{t}}$ & 0.0080 & 0.0057 & 0.5500 & 0.5200 & 0.9794 & 0.9830 & 0.5378 & 0.5265 \\
\hline $\ln \boldsymbol{w}_{\boldsymbol{t}}$ & 0.0080 & 0.0057 & 0.5500 & 0.5200 & 0.9794 & 0.9830 & 0.5378 & 0.5265 \\
\hline $\boldsymbol{r}_{\boldsymbol{t}}$ & 0.0011 & 0.0007 & 0.0753 & 0.0642 & 0.9592 & 0.9700 & 0.4603 & 0.4653 \\
\hline $\boldsymbol{z}_{\boldsymbol{t}}$ & 0.0164 & 0.0125 & 0.8900 & 1.1500 & 0.9989 & 0.9989 & 0.4753 & 0.4757 \\
\hline
\end{tabular}

Table 10: Summary of comparative statics between the benchmark model and the data for Spain and the UK

\begin{tabular}{|c|c|c|c|c|c|c|c|c|c|c|}
\hline \multirow[t]{2}{*}{ Variable } & \multicolumn{2}{|c|}{$\Delta$ Volatility } & \multicolumn{2}{|c|}{$\begin{array}{l}\Delta \text { Relative } \\
\text { Volatility }\end{array}$} & \multicolumn{2}{|c|}{$\Delta$ Cyclicality } & \multicolumn{2}{|c|}{$\Delta$ Persistence } & \multicolumn{2}{|c|}{$\begin{array}{c}\text { Impact of } \\
z_{t} \text { shock }\end{array}$} \\
\hline & SP & UK & SP & UK & SP & UK & SP & UK & SP & UK \\
\hline $\ln y_{t}$ & $\downarrow$ & $\downarrow$ & $=$ & $=$ & $=$ & $=$ & $\downarrow$ & $\downarrow$ & + & + \\
\hline $\ln c_{t}$ & $\downarrow$ & $\downarrow$ & $\downarrow$ & $\downarrow$ & $\uparrow$ & $\uparrow \uparrow$ & $\downarrow$ & $\downarrow$ & + & + \\
\hline $\ln i_{t}$ & $\downarrow$ & $\downarrow$ & $\uparrow$ & $\downarrow$ & $\uparrow$ & $\uparrow$ & $\downarrow$ & $\downarrow$ & + & + \\
\hline $\ln l_{t}$ & $\uparrow$ & $\downarrow$ & $\uparrow$ & $\uparrow$ & $\uparrow(+)$ & $\uparrow$ & $\downarrow$ & $\downarrow$ & + & + \\
\hline $\ln k_{t}$ & $\downarrow$ & $\downarrow$ & $\downarrow$ & $\downarrow$ & $\uparrow(+)$ & $\uparrow$ & $\uparrow$ & $\uparrow$ & + & + \\
\hline $\ln (y / l)_{t}$ & $\downarrow$ & $\downarrow$ & $\downarrow$ & $\downarrow$ & $\uparrow$ & $\uparrow$ & $\downarrow$ & $\downarrow$ & + & + \\
\hline $\ln w_{t}$ & $\downarrow$ & $\downarrow$ & $\downarrow$ & $\downarrow$ & $\uparrow$ & $\uparrow$ & $\downarrow$ & $\downarrow$ & + & + \\
\hline$r_{t}$ & $\downarrow$ & $\downarrow$ & $\downarrow$ & $\downarrow$ & $\uparrow$ & $\uparrow$ & $\uparrow(+)$ & $\uparrow$ & + & + \\
\hline$z_{t}$ & $\downarrow$ & $\downarrow$ & $\uparrow$ & $\uparrow$ & $\uparrow(+)$ & $\uparrow(+)$ & $\downarrow$ & $\downarrow$ & & \\
\hline
\end{tabular}

In general terms, I observe that the standard RBC model does a decent job on capturing the volatility of some variables, but fails drastically on others. I consider for example output, empirical data tells me Spain's volatility of output is 0.0237 but the model, in contrast, is telling me it is 0.0146 for the same time period. The same happens for the UK. Accordingly, there is a difference between empirical and theoretical moments of 0.0091 for Spain and 0.0114 for the UK. However, compared to other variables, this error margin may seem insignificant. In particular, in the empirical moments for both countries consumption and labour productivity have almost a 1 to 1 relation to output in terms of volatility (relative STD). Nonetheless, the RBC model shows that these variables are rather half as volatile as output. Most striking is the failure of predicting the volatility of the factor prices. Data tells me that factor prices of both countries are far more volatile than what the model is suggesting. This may be hand in hand with neoclassical assumptions of having factor prices equal to their respective 
factor compensations captured as the marginal products. I also want to underline the good performance of the model in terms of replicating the volatility of labour and investment, for both countries. With regards the cyclicality of the endogenous variables I notice generally high correlation to output in the RBC model, not quite reflecting the characteristics of Spain nor the UK. As in the previous case, this statistical moment has some lights and shadows in terms of reflecting correctly the countries' cyclicality. For the RBC model every variable, with exception of capital stock, is positively correlated to output at a degree of $>90 \%$. In contrast, I can just find this pattern in Spain's empirical moments of output, consumption, investment, labour productivity and labour augmented technology. For the UK this is only valid for consumption and labour productivity. What is more, for Spain the prices of factor inputs are not negatively correlated in the RBC model. Hence, it seems like the UK is more suitable for the benchmark model at least in this aspect. Additionally, data presents negative cyclicality of technology not reflected in the theoretical moments. Thus, the model assumes technology is procyclical whereas data tells me the opposite. This is the case for both countries. Things look better when comparing the persistence of the main economic indicators. Data shows an overall persistence of the variables around $70 \%-80 \%$ (excluding real interest rate) for Spain and around 50\%-70\% (excluding real interest rate) for the UK. In turn, the RBC model's average persistence oscillates between $40 \%$ and $50 \%$. Hence, the UK is more suitable. Also, this is true due to the fact that in the model every variable displays positive persistence in line with the UK. Still, the empirical moment of the real interest rate of Spain has negative persistence not captured by the model. In most of the cases, the pattern of these AR(1) coefficients is almost the same for both countries. For instance, in both cases: data statistics and model statistics, consumption is more persistent than output and investment for Spain and the UK.

As a last insight, I want to point out the summary table which is a good way to get an overall picture of the differences between theoretical and empirical moments. For instance, it summarises whether the volatility of theoretical moments for each variable has increased or decreased with respect to the empirical data. In the last column I also indicate the sign of the initial impact of the shock for each variable, say a positive technological shock has a positive initial impact on consumption for example. Also, whenever a sign is in brackets it means that the increase or decrease of that variable for that particular statistical moment has changed from being negative to positive (i.e. $(+)$ ) or has become from positive to negative (i.e. $(-))$. This is useful to identify the failures of the RBC model to capture the negative correlation of labour and capital or the negative persistence of real interest rate evident in Spain's empirical moment.

As a result, it seems that broadly speaking the RBC model underestimates the volatility of macroeconomic variables for Spain and the UK. This pattern is not recognisable for the relative standard deviation given it varies across variables. For the cyclicality, it seems as the RBC model overestimates this measure in line with one of the main drawbacks of this model exposed in the theoretical block. Finally, I identify a generalised underestimation of the model in terms of persistence for almost all variables. The impact of the technology shock is positive for all variables of Spain and the UK meaning the IRF reflect a positive initial jump (at different heights depending on the variable) followed by a downward sloping curve depicting the process when the model variables return to the steady-state equilibrium.

All in all, I conclude that the RBC model does a sufficiently good job on replicating the statistics of the UK, such that to consider it as an appropriate theoretical model for this economy, at least it is better represented than Spain. Nevertheless, there are evident pitfalls in the predicting power of the benchmark model, for instance when it comes to capturing the volatility from data for Spain and the 
UK. Also, there are some important contradictions between the model and the data in the sign of a number of statistical moments for Spain. Adding extensions with more realistic assumptions seems a necessary thing to do, so to assess further this model and to correct the above-stated drawbacks.

Accordingly, I proceed to present the results from the model extensions analysed in the theoretical block. The way of obtaining the theoretical moments is identical to the above-described case of the benchmark model. Furthermore, I present the same tables as in the standard RBC model for each model extension, and with an additional summary table that captures the differences between the theoretical moments of the model extension and the theoretical moments of the benchmark model. In this way, I can evaluate easier whether the model extension analysed actually improves the fit of the data or not. What is more, I add a column called "Improvement of fit?" on the table where empirical moments are contrasted with the theoretical moments of the extension in order to visualise whether it is worth keeping the model extension or it is more convenient to drop it from the analysis. I emphasise that the criterion I use to determine whether the model extension is doing a better job on matching the empirical moments compared to the benchmark case is by determining the error margin between theoretical moments (extension vs benchmark) in terms of standard deviations. This is just one dimension on which to determine the improvement of fit, but it is the most crucial one.

\section{Labour indivisibility}

In the case of indivisibility of labour, the calibration values for $A$ are greater for the UK than for Spain meaning workers in the UK prefer leisure relatively more than spanish workers under this framework. Therefore, I expect that the UK's hours worked vary less than Spain for a given positive technology shock because even though workers would earn more wages due to the increase in labour demand, they would be less willing to increase their labour supply since they value more leisure. Applying this new calibration together with the rest of calibrated parameters and running the model with the new set of steady-state equations delivers the following results:

Table 11: Theoretical Moments for Spain and the UK: Indivisibility of Labour

\begin{tabular}{|cc|c|c|c|c|c|c|c|}
\hline \multirow{2}{*}{ Variable } & \multicolumn{2}{c|}{$\begin{array}{c}\text { Standard } \\
\text { Deviation }\end{array}$} & \multicolumn{2}{c|}{ Relative STD } & \multicolumn{2}{c|}{$\begin{array}{c}\text { Correlation to } \\
\text { Output }\end{array}$} & \multicolumn{2}{c|}{$\begin{array}{c}1^{\text {st }} \text { order } \\
\text { Autocorrelation }\end{array}$} \\
\cline { 2 - 9 } & SP & UK & SP & UK & SP & UK & SP & UK \\
\hline $\ln \boldsymbol{y}_{\boldsymbol{t}}$ & 0.0167 & 0.0124 & 1.0000 & 1.0000 & 1.0000 & 1.0000 & 0.4796 & 0.4803 \\
\hline $\ln \boldsymbol{c}_{\boldsymbol{t}}$ & 0.0071 & 0.0049 & 0.4251 & 0.3952 & 0.9404 & 0.9494 & 0.5865 & 0.5693 \\
\hline $\ln \boldsymbol{i}_{\boldsymbol{t}}$ & 0.0682 & 0.0379 & 4.0838 & 3.0565 & 0.9843 & 0.9911 & 0.4567 & 0.4643 \\
\hline $\ln \boldsymbol{t}_{\boldsymbol{t}}$ & 0.0103 & 0.0079 & 0.6168 & 0.6371 & 0.9726 & 0.9804 & 0.4548 & 0.4618 \\
\hline $\ln \boldsymbol{k}_{\boldsymbol{t}}$ & 0.0048 & 0.0031 & 0.2874 & 0.2500 & 0.5032 & 0.4709 & 0.8450 & 0.8489 \\
\hline $\ln (\boldsymbol{y} / \boldsymbol{l})_{\boldsymbol{t}}$ & 0.0071 & 0.0049 & 0.4251 & 0.3952 & 0.9404 & 0.9494 & 0.5865 & 0.5693 \\
\hline $\ln \boldsymbol{w}_{\boldsymbol{t}}$ & 0.0071 & 0.0049 & 0.4251 & 0.3952 & 0.9404 & 0.9494 & 0.5865 & 0.5693 \\
\hline $\boldsymbol{r}_{\boldsymbol{t}}$ & 0.0012 & 0.0008 & 0.0719 & 0.0645 & 0.9573 & 0.9687 & 0.4557 & 0.4624 \\
\hline $\boldsymbol{z}_{\boldsymbol{t}}$ & 0.0164 & 0.0125 & 0.9820 & 1.0081 & 0.9997 & 0.9996 & 0.4753 & 0.4757 \\
\hline
\end{tabular}


Table 12: Summary of comparative statics between the model extension and the benchmark model for Spain and the UK

\begin{tabular}{|c|c|c|c|c|c|c|c|c|}
\hline \multirow{2}{*}{ Variable } & \multicolumn{2}{|c|}{$\Delta$ Volatility } & \multicolumn{2}{c|}{$\begin{array}{c}\text { Relative } \\
\text { Volatility }\end{array}$} & \multicolumn{2}{c|}{$\Delta$ Cyclicality } & \multicolumn{2}{c|}{$\Delta$ Persistence } \\
\cline { 2 - 9 } & SP & UK & SP & UK & SP & UK & SP & UK \\
\hline $\ln y_{t}$ & $\uparrow$ & $\uparrow$ & $=$ & $=$ & $=$ & $=$ & $\downarrow$ & $\downarrow$ \\
\hline $\ln c_{t}$ & $\uparrow$ & $\uparrow$ & $\downarrow$ & $\uparrow$ & $\downarrow$ & $\downarrow$ & $\uparrow$ & $\uparrow$ \\
\hline $\ln i_{t}$ & $\uparrow$ & $\uparrow$ & $\uparrow$ & $\uparrow$ & $\downarrow$ & $\downarrow$ & $\downarrow$ & $\downarrow$ \\
\hline $\ln l_{t}$ & $\uparrow$ & $\uparrow$ & $\uparrow$ & $\uparrow$ & $\downarrow$ & $\downarrow$ & $\downarrow$ & $\downarrow$ \\
\hline $\ln k_{t}$ & $\uparrow$ & $\uparrow$ & $\uparrow$ & $=$ & $\uparrow$ & $\uparrow$ & $\downarrow$ & $\downarrow$ \\
\hline $\ln (y / l)_{t}$ & $\downarrow$ & $\uparrow$ & $\downarrow$ & $\downarrow$ & $\downarrow$ & $\downarrow$ & $\uparrow$ & $\uparrow$ \\
\hline $\ln w_{t}$ & $\downarrow$ & $\uparrow$ & $\downarrow$ & $\downarrow$ & $\downarrow$ & $\downarrow$ & $\uparrow$ & $\uparrow$ \\
\hline$r_{t}$ & $\uparrow$ & $\uparrow$ & $\downarrow$ & $\uparrow$ & $\downarrow$ & $\downarrow$ & $\downarrow$ & $\downarrow$ \\
\hline$z_{t}$ & $=$ & $=$ & $\uparrow$ & $\downarrow$ & $\uparrow$ & $\uparrow$ & $=$ & $=$ \\
\hline
\end{tabular}

Table 13: Summary of comparative statics between the model extension and the data for Spain and the UK

\begin{tabular}{|c|c|c|c|c|c|c|c|c|c|c|}
\hline \multirow{2}{*}{ Variable } & \multicolumn{2}{|c|}{$\Delta$ Volatility } & \multicolumn{2}{c|}{$\begin{array}{c}\Delta \text { Relative } \\
\text { Volatility }\end{array}$} & \multicolumn{2}{|c|}{$\Delta$ Cyclicality } & \multicolumn{2}{c|}{$\Delta$ Persistence } & \multicolumn{2}{|c|}{$\begin{array}{c}\text { Improvement } \\
\text { in fit? }\end{array}$} \\
\cline { 2 - 12 } & SP & UK & SP & UK & SP & UK & SP & UK & SP & UK \\
\hline $\ln y_{t}$ & $\downarrow$ & $\downarrow$ & $=$ & $=$ & $=$ & $=$ & $\downarrow$ & $\downarrow$ & $\checkmark$ & $\checkmark$ \\
\hline $\ln c_{t}$ & $\downarrow$ & $\downarrow$ & $\downarrow$ & $\downarrow$ & $\uparrow$ & $\uparrow$ & $\downarrow$ & $\downarrow$ & $\checkmark$ & $\checkmark$ \\
\hline $\ln i_{t}$ & $\downarrow$ & $\downarrow$ & $\uparrow$ & $\uparrow$ & $\uparrow$ & $\uparrow$ & $\downarrow$ & $\downarrow$ & $\checkmark$ & $\checkmark$ \\
\hline $\ln l_{t}$ & $\uparrow$ & $\uparrow$ & $\uparrow$ & $\uparrow$ & $\uparrow(+)$ & $\uparrow$ & $\downarrow$ & $\downarrow$ & $\mathbf{x}$ & $\checkmark$ \\
\hline $\ln k_{t}$ & $\downarrow$ & $\downarrow$ & $\downarrow$ & $\downarrow$ & $\uparrow(+)$ & $\uparrow$ & $\uparrow$ & $\uparrow$ & $\checkmark$ & $\checkmark$ \\
\hline $\ln (y / l)_{t}$ & $\downarrow$ & $\downarrow$ & $\downarrow$ & $\downarrow$ & $\downarrow$ & $\uparrow$ & $\downarrow$ & $\downarrow$ & $\mathbf{x}$ & $\mathbf{x}$ \\
\hline $\ln w_{t}$ & $\downarrow$ & $\downarrow$ & $\downarrow$ & $\downarrow$ & $\uparrow$ & $\uparrow$ & $\downarrow$ & $\downarrow$ & $\mathbf{x}$ & $\mathbf{x}$ \\
\hline$r_{t}$ & $\downarrow$ & $\downarrow$ & $\downarrow$ & $\downarrow$ & $\uparrow$ & $\uparrow$ & $\uparrow(+)$ & $\downarrow$ & $\checkmark$ & $\checkmark$ \\
\hline$z_{t}$ & $\downarrow$ & $\downarrow$ & $\uparrow$ & $\uparrow$ & $\uparrow(+)$ & $\uparrow(+)$ & $\downarrow$ & $\downarrow$ & $=$ & $=$ \\
\hline
\end{tabular}

Regarding the theoretical moments, I see a greater amplification in volatility on almost all variables compared to the standard theoretical case. Hence, I notice that there are greater STDs in all variables for the UK, and for Spain, accentuated in output, consumption, investment, labour and capital. Accordingly, I can observe that making labour indivisible through the lottery framework makes the model fit better the data in terms of output, investment and consumption for instance, but not for labour given the empirical STD of labour is lower than in the model. This holds for both countries even though for the UK labour is being accurately captured by this extension (i.e. 0.0071 in the data and 0.0079 in the extension), hence improving the fit compared to the benchmark. What is more, I observe that the increase in the volatility of hours worked is more accentuated in Spain than in the UK compared to the benchmark model, thus corroborating the intuition behind the difference in calibrations among countries. Regarding correlation to output, I observe a small but sustained decline for almost all variables in this model extension for both countries. Consequently, this extension seems more in line with the empirical statistics. However, I need to point out that the decrease is in terms of $1 / 1000$ meaning the changes are almost insignificant. This means that the model still drastically overestimates some of the variables' cyclicality. The persistence remains relatively equal in terms of underestimating the empirical moments of each country. 
Because the indivisible labour scenario is isomorphic to the Frisch labour supply being infinite (i.e $\xi=0$ or $\chi=0$ ), the labour supply curve is perfectly horizontal here. This is why I get a bigger increase in the volatility of labour hours for the same exogenous shock. As a result, quantitatively, indivisible labour improves the fit of the model along several dimensions. First, it provides greater amplification (see STD changes). This means that I can match the output volatility from data with smaller technology shocks. Yet, in terms of correlation to output and $1^{\text {st }}$ order autocorrelation I see just light changes, which in turn are rather irrelevant. The main insight I'm getting here is that even when modelling households' labour supply choices in a more realistic way, I get the same predictive power (or even better in terms of capturing volatility) compared to the standard theoretical model. Thus, in order to efficiently get a general overview of the performance of this extension I directly refer to the "Improvement of fit" column. In this way I can determine the matching improvement of the model extension by counting the number of " $\checkmark$ " (which is basically telling me for which variables this extension is better compared to the benchmark under the particular criterion described above). Most importantly, I can conclude which country is better represented with this extension compared to the benchmark case by comparing the number of " $\checkmark$ " for each country.

As a result, I assert that including this extension is beneficial for matching better the volatility of variables, and what is more, it is more suitable for the UK than for Spain.

\section{Habit formation}

I get a higher habit formation parameter calibration for Spain than the UK, contrary to the pattern identified in the discussion from above. This means households of Spain get more accustomate to consumption habits than individuals in the UK. Hence, I expect that changes in the income of households, which can be given by technology shocks, don't make the consumption of Spain change as much as in the UK. The results I get under this calibration and the new steady-state solution are:

Table 14: Theoretical Moments for Spain and the UK: Habit Formation

\begin{tabular}{|cc|c|c|c|c|c|c|c|}
\hline \multirow{2}{*}{ Variable } & \multicolumn{2}{c}{$\begin{array}{c}\text { Standard } \\
\text { Deviation }\end{array}$} & \multicolumn{2}{c}{ Relative STD } & \multicolumn{2}{c|}{$\begin{array}{c}\text { Correlation to } \\
\text { Output }\end{array}$} & \multicolumn{2}{c|}{$\begin{array}{c}1^{\text {st }} \text { order } \\
\text { Autocorrelation }\end{array}$} \\
\cline { 2 - 9 } & SP & UK & SP & UK & SP & UK & SP & UK \\
\hline $\ln \boldsymbol{y}_{\boldsymbol{t}}$ & 0.0112 & 0.0094 & 1.0000 & 1.0000 & 1.0000 & 1.0000 & 0.4919 & 0.4987 \\
\hline $\ln \boldsymbol{c}_{\boldsymbol{t}}$ & 0.0030 & 0.0030 & 0.2679 & 0.3191 & 0.4997 & 0.5773 & 0.8543 & 0.8434 \\
\hline $\ln \boldsymbol{i}_{\boldsymbol{t}}$ & 0.0612 & 0.0492 & 5.4643 & 5.2340 & 0.9766 & 0.9691 & 0.4661 & 0.4571 \\
\hline $\ln \boldsymbol{l}_{\boldsymbol{t}}$ & 0.0016 & 0.0024 & 0.1429 & 0.2553 & 0.8484 & 0.9523 & 0.4568 & 0.4639 \\
\hline $\ln \boldsymbol{k}_{\boldsymbol{t}}$ & 0.0044 & 0.0035 & 0.3929 & 0.3723 & 0.5337 & 0.5636 & 0.8499 & 0.8455 \\
\hline $\ln \left(\boldsymbol{y} / \boldsymbol{l}_{\boldsymbol{t}}\right.$ & 0.0099 & 0.0071 & 0.8839 & 0.7553 & 0.9964 & 0.9948 & 0.5182 & 0.5256 \\
\hline $\ln \boldsymbol{w}_{\boldsymbol{t}}$ & 0.0099 & 0.0071 & 0.8839 & 0.7553 & 0.9964 & 0.9948 & 0.5182 & 0.5256 \\
\hline $\boldsymbol{r}_{\boldsymbol{t}}$ & 0.0008 & 0.0007 & 0.0714 & 0.0745 & 0.9215 & 0.9297 & 0.4635 & 0.4594 \\
\hline $\boldsymbol{z}_{\boldsymbol{t}}$ & 0.0164 & 0.0125 & 1.4643 & 1.3298 & 0.9946 & 0.9947 & 0.4753 & 0.4757 \\
\hline
\end{tabular}


Table 15: Summary of comparative statics between the model extension and the benchmark model for Spain and the UK

\begin{tabular}{|c|c|c|c|c|c|c|c|c|}
\hline \multirow{2}{*}{ Variable } & \multicolumn{2}{|c|}{$\Delta$ Volatility } & \multicolumn{2}{c|}{$\begin{array}{c}\Delta \text { Relative } \\
\text { Volatility }\end{array}$} & \multicolumn{2}{c|}{$\Delta$ Cyclicality } & \multicolumn{2}{c|}{$\Delta$ Persistence } \\
\cline { 2 - 9 } & SP & UK & SP & UK & SP & UK & SP & UK \\
\hline $\ln y_{t}$ & $\downarrow$ & $\downarrow$ & $=$ & $=$ & $=$ & $=$ & $\uparrow$ & $\uparrow$ \\
\hline $\ln c_{t}$ & $\downarrow$ & $\downarrow$ & $\downarrow$ & $\downarrow$ & $\downarrow$ & $\downarrow$ & $\uparrow$ & $\uparrow$ \\
\hline $\ln i_{t}$ & $\uparrow$ & $\uparrow$ & $\uparrow$ & $\uparrow$ & $\downarrow$ & $\downarrow$ & $\uparrow$ & $\downarrow$ \\
\hline $\ln l_{t}$ & $\downarrow$ & $\downarrow$ & $\downarrow$ & $\downarrow$ & $\downarrow$ & $\downarrow$ & $\uparrow$ & $\downarrow$ \\
\hline $\ln k_{t}$ & $\uparrow$ & $\uparrow$ & $\uparrow$ & $\uparrow$ & $\uparrow$ & $\uparrow$ & $\uparrow$ & $\downarrow$ \\
\hline $\ln (y / l)_{t}$ & $\uparrow$ & $\uparrow$ & $\uparrow$ & $\uparrow$ & $\uparrow$ & $\uparrow$ & $\downarrow$ & $\downarrow$ \\
\hline $\ln w_{t}$ & $\uparrow$ & $\uparrow$ & $\uparrow$ & $\uparrow$ & $\uparrow$ & $\uparrow$ & $\downarrow$ & $\downarrow$ \\
\hline$r_{t}$ & $\downarrow$ & $=$ & $\downarrow$ & $\uparrow$ & $\downarrow$ & $\downarrow$ & $\uparrow$ & $\downarrow$ \\
\hline$z_{t}$ & $=$ & $=$ & $\uparrow$ & $\uparrow$ & $\downarrow$ & $\downarrow$ & $=$ & $=$ \\
\hline
\end{tabular}

Table 16: Summary of comparative statics between the model extension and the data for Spain and the UK

\begin{tabular}{|c|c|c|c|c|c|c|c|c|c|c|}
\hline \multirow[t]{2}{*}{ Variable } & \multicolumn{2}{|c|}{$\Delta$ Volatility } & \multicolumn{2}{|c|}{$\begin{array}{l}\Delta \text { Relative } \\
\text { Volatility }\end{array}$} & \multicolumn{2}{|c|}{$\Delta$ Cyclicality } & \multicolumn{2}{|c|}{$\Delta$ Persistence } & \multicolumn{2}{|c|}{$\begin{array}{c}\text { Improvement } \\
\text { in fit? }\end{array}$} \\
\hline & SP & UK & SP & UK & SP & UK & SP & UK & SP & UK \\
\hline $\ln y_{t}$ & $\downarrow$ & $\downarrow$ & $=$ & $=$ & $=$ & $=$ & $\downarrow$ & $\downarrow$ & $x$ & $x$ \\
\hline $\ln c_{t}$ & $\downarrow$ & $\downarrow$ & $\downarrow$ & $\downarrow$ & $\downarrow$ & $\downarrow$ & $\downarrow$ & $\uparrow$ & $x$ & $x$ \\
\hline $\ln i_{t}$ & $\downarrow$ & $\downarrow$ & $\uparrow$ & $\uparrow$ & $\uparrow$ & $\uparrow$ & $\downarrow$ & $\downarrow$ & $\checkmark$ & $\checkmark$ \\
\hline $\ln l_{t}$ & $\downarrow$ & $\downarrow$ & $\downarrow$ & $\uparrow$ & $\uparrow(+)$ & $\uparrow$ & $\downarrow$ & $\downarrow$ & $x$ & $x$ \\
\hline $\ln k_{t}$ & $\downarrow$ & $\downarrow$ & $\uparrow$ & $\uparrow$ & $\uparrow(+)$ & $\uparrow$ & $\uparrow$ & $\uparrow$ & $\checkmark$ & $\checkmark$ \\
\hline $\ln (y / l)_{t}$ & $\downarrow$ & $\downarrow$ & $\downarrow$ & $\downarrow$ & $\uparrow$ & $\uparrow$ & $\downarrow$ & $\downarrow$ & $\checkmark$ & $\checkmark$ \\
\hline $\ln w_{t}$ & $\downarrow$ & $\downarrow$ & $\downarrow$ & $\downarrow$ & $\uparrow$ & $\uparrow$ & $\downarrow$ & $\downarrow$ & $\checkmark$ & $\checkmark$ \\
\hline$r_{t}$ & $\downarrow$ & $\downarrow$ & $\downarrow$ & $\downarrow$ & $\uparrow$ & $\uparrow$ & $\uparrow(+)$ & $\uparrow$ & $x$ & $=$ \\
\hline$z_{t}$ & $\downarrow$ & $\downarrow$ & $\uparrow$ & $\uparrow$ & $\uparrow(+)$ & $\uparrow(+)$ & $\downarrow$ & $\downarrow$ & $=$ & $=$ \\
\hline
\end{tabular}

I observe that introducing habit formation affects the volatility of the endogenous variables in different manners. For instance for Spain, the STD of output, consumption, hours worked and real interest rate falls but it increases for investment, capital, wages and labour productivity. For the UK the same holds but interestingly the interest rate remains the same. In particular, for Spain, I see consumption's volatility drop by more than $50 \%$ and hours worked declines from roughly half of the relative STD to output to $14 \%$ relative STD when introducing habit formation. So, for these latter variables, the model is failing to capture the empirical moments more than the standard case. In contrast, this model extension does a better job when replicating the volatility of investment. For the UK, I see consumption's volatility drop by more than $1 / 3$ and hours worked declines from roughly half of the relative STD to output to $25 \%$ relative STD when introducing habit formation. Hence, for these latter variables, the model is failing to capture the empirical moments more than the benchmark model. In contrast, introducing habit formation implies replicating the volatility of investment better. Moving further, I observe an accentuated drop of consumption on the contemporaneous correlation to output, diverging clearly from the same empirical moment for both countries. Related to this, I also notice an almost perfect fit of the first-order autocorrelation with regards to consumption for Spain 
and the UK. This is something I expect given I'm using the first order autocorrelation coefficient of the $\mathrm{AR}(1)$ regression for the calibration of the habit formation parameter. I conclude that a shock has greater persistence on consumption such that any effect of the technology shock on consumption has long lasting effects. The intuition for this is that high consumption today lowers utility tomorrow the bigger is $\phi$, other things being equal. Thus, people behave "cautiously" in essence by not adjusting consumption by much. With regards the rest of the variables, the correlation to output and autocorrelation indicators are very similar to the standard case (i.e. this is not going to improve the fit of the model along those dimensions).

Once again, the results I'm getting are the expected ones along with what theory says. The volatility of consumption decreases compared to the standard case, labour decreases and wages go up for all countries. In terms of improvement of fit, I see that this extension makes a better job on other variables not considered until now. For example, it fits better investment, capital, labour productivity and wages, where the latter two indivisibility of labour did a worse job, in other words, habit formation may be a good complement to the already studied extensions. However, along with what Eric Sims says, the inclusion of habit formation helps the model match the data not precisely in terms of unconditional moments, but rather in terms of conditional impulse response functions. Most estimated impulse responses to identified shocks (say, monetary policy shocks) show "humped shaped" responses to consumption. This is achieved with habit formation and it is difficult to generate without it.

Lastly, once again the UK is a better candidate for this model extension under the criteria considered.

\section{Preferences shock}

Following the calibration for the intratemporal and intertemporal shock described in the theoretical block, and with the correspondent calibration of the rest of the variables I get:

Table 17: Theoretical Moments for Spain and the UK: Preference Shock

\begin{tabular}{|c|c|c|c|c|c|c|c|c|}
\hline \multirow{2}{*}{ Variable } & \multicolumn{2}{c}{$\begin{array}{c}\text { Standard } \\
\text { Deviation }\end{array}$} & \multicolumn{2}{c}{ Relative STD } & \multicolumn{2}{c|}{$\begin{array}{c}\text { Correlation to } \\
\text { Output }\end{array}$} & \multicolumn{2}{c|}{$\begin{array}{c}\text { 1st order } \\
\text { Autocorrelation }\end{array}$} \\
\cline { 2 - 9 } & SP & UK & SP & UK & SP & UK & SP & UK \\
\hline $\ln \boldsymbol{y}_{\boldsymbol{t}}$ & 0.0166 & 0.0136 & 1.0000 & 1.0000 & 1.0000 & 1.0000 & 0.4820 & 0.4799 \\
\hline $\ln \boldsymbol{c}_{\boldsymbol{t}}$ & 0.0078 & 0.0066 & 0.4699 & 0.4853 & 0.7394 & 0.5269 & 0.5600 & 0.5278 \\
\hline $\ln \boldsymbol{i}_{\boldsymbol{t}}$ & 0.0758 & 0.0499 & 4.5663 & 3.6691 & 0.9376 & 0.9312 & 0.4568 & 0.4605 \\
\hline $\ln \boldsymbol{l}_{\boldsymbol{t}}$ & 0.0144 & 0.0143 & 0.8675 & 1.0515 & 0.8252 & 0.8420 & 0.4555 & 0.4582 \\
\hline $\ln \boldsymbol{k}_{\boldsymbol{t}}$ & 0.0053 & 0.0040 & 0.3193 & 0.2941 & 0.4849 & 0.4537 & 0.8449 & 0.8467 \\
\hline $\ln (\boldsymbol{y} / \boldsymbol{l})_{\boldsymbol{t}}$ & 0.0094 & 0.0079 & 0.5663 & 0.5809 & 0.5022 & 0.1909 & 0.5161 & 0.4959 \\
\hline $\ln \boldsymbol{w}_{\boldsymbol{t}}$ & 0.0094 & 0.0079 & 0.5663 & 0.5809 & 0.5022 & 0.1909 & 0.5161 & 0.4959 \\
\hline $\boldsymbol{r}_{\boldsymbol{t}}$ & 0.0012 & 0.0009 & 0.0723 & 0.0662 & 0.9441 & 0.9516 & 0.4628 & 0.4667 \\
\hline $\boldsymbol{z}_{\boldsymbol{t}}$ & 0.0164 & 0.0125 & 0.9880 & 0.9191 & 0.8800 & 0.8029 & 0.4753 & 0.4757 \\
\hline
\end{tabular}


Table 18: Summary of comparative statics between the model extension and the benchmark model for Spain and the UK

\begin{tabular}{|c|c|c|c|c|c|c|c|c|c|c|c|c|}
\hline \multirow[t]{2}{*}{ Variable } & \multicolumn{2}{|c|}{$\Delta$ Volatility } & \multicolumn{2}{|c|}{$\begin{array}{l}\Delta \text { Relative } \\
\text { Volatility }\end{array}$} & \multicolumn{2}{|c|}{$\Delta$ Cyclicality } & \multicolumn{2}{|c|}{$\Delta$ Persistence } & \multicolumn{2}{|c|}{$\begin{array}{c}\text { Impact of } \\
\theta_{t} \text { shock }\end{array}$} & \multicolumn{2}{|c|}{$\begin{array}{c}\text { Impact of } \\
\vartheta_{t} \text { shock }\end{array}$} \\
\hline & SP & UK & SP & UK & SP & UK & SP & UK & SP & UK & SP & UK \\
\hline $\ln y_{t}$ & $\bar{\uparrow}$ & $\uparrow$ & $=$ & $=$ & $=$ & $=$ & $\downarrow$ & $\downarrow$ & - & - & - & - \\
\hline $\ln c_{t}$ & $\uparrow$ & $\uparrow$ & $\uparrow \uparrow$ & $\uparrow$ & $\downarrow$ & $\downarrow$ & $\downarrow$ & $\downarrow$ & + & + & - & - \\
\hline $\ln i_{t}$ & $\uparrow$ & $\uparrow$ & $\uparrow$ & $\uparrow$ & $\downarrow$ & $\downarrow$ & $\downarrow$ & $\downarrow$ & - & - & - & - \\
\hline $\ln l_{t}$ & $\uparrow$ & $\uparrow$ & $\uparrow$ & $\downarrow$ & $\downarrow$ & $\downarrow$ & $\downarrow$ & $\uparrow$ & - & - & - & - \\
\hline $\ln k_{t}$ & $\uparrow$ & $\uparrow$ & $\uparrow$ & $\downarrow$ & $\downarrow$ & $\downarrow$ & $\downarrow$ & $\downarrow$ & - & - & - & - \\
\hline $\ln (y / l)_{t}$ & $\uparrow$ & $\uparrow$ & $\uparrow$ & $\uparrow$ & $\downarrow$ & $\downarrow$ & $\downarrow$ & $\downarrow$ & + & + & + & + \\
\hline $\ln w_{t}$ & $\uparrow$ & $\uparrow$ & $\uparrow$ & $\uparrow$ & $\downarrow$ & $\downarrow$ & $\downarrow$ & $\downarrow$ & + & + & + & + \\
\hline$r_{t}$ & $\uparrow$ & $\uparrow$ & $\downarrow$ & $\uparrow$ & $\downarrow$ & $\downarrow$ & $\uparrow$ & $\uparrow$ & - & - & - & - \\
\hline$z_{t}$ & $=$ & $\uparrow$ & $\uparrow$ & $\downarrow$ & $\downarrow$ & $\downarrow$ & $=$ & $=$ & & & & \\
\hline
\end{tabular}

Table 19: Summary of comparative statics between the model extension and the data for Spain and the UK

\begin{tabular}{|c|c|c|c|c|c|c|c|c|c|c|}
\hline \multirow{2}{*}{ Variable } & \multicolumn{2}{|c|}{$\Delta$ Volatility } & \multicolumn{2}{c|}{$\begin{array}{c}\Delta \text { Relative } \\
\text { Volatility }\end{array}$} & \multicolumn{2}{c|}{$\Delta$ Cyclicality } & \multicolumn{2}{c|}{$\Delta$ Persistence } & \multicolumn{2}{|c|}{$\begin{array}{c}\text { Improvement } \\
\text { in fit? }\end{array}$} \\
\cline { 2 - 13 } & SP & UK & SP & UK & SP & UK & SP & UK & SP & UK \\
\hline $\ln y_{t}$ & $\downarrow$ & $\downarrow$ & $=$ & $=$ & $=$ & $=$ & $\downarrow$ & $\downarrow$ & $\checkmark$ & $\checkmark$ \\
\hline $\ln c_{t}$ & $\downarrow$ & $\downarrow$ & $\downarrow$ & $\downarrow$ & $\downarrow$ & $\downarrow$ & $\downarrow$ & $\downarrow$ & $\checkmark$ & $\checkmark$ \\
\hline $\ln i_{t}$ & $\downarrow$ & $\downarrow$ & $\uparrow$ & $\uparrow$ & $\downarrow$ & $\uparrow$ & $\downarrow$ & $\downarrow$ & $\checkmark$ & $\checkmark$ \\
\hline $\ln l_{t}$ & $\uparrow$ & $\uparrow$ & $\uparrow$ & $\uparrow$ & $\uparrow(+)$ & $\uparrow$ & $\downarrow$ & $\downarrow$ & $\mathbf{x}$ & $\mathbf{x}$ \\
\hline $\ln k_{t}$ & $\downarrow$ & $\downarrow$ & $\downarrow$ & $\downarrow$ & $\uparrow(+)$ & $\uparrow$ & $\uparrow$ & $\uparrow$ & $\checkmark$ & $\checkmark$ \\
\hline $\ln (y / l)_{t}$ & $\downarrow$ & $\downarrow$ & $\downarrow$ & $\downarrow$ & $\downarrow$ & $\downarrow$ & $\downarrow$ & $\downarrow$ & $\checkmark$ & $\checkmark$ \\
\hline $\ln w_{t}$ & $\downarrow$ & $\downarrow$ & $\downarrow$ & $\downarrow$ & $\uparrow$ & $\downarrow$ & $\downarrow$ & $\downarrow$ & $\checkmark$ & $\checkmark$ \\
\hline$r_{t}$ & $\downarrow$ & $\downarrow$ & $\downarrow$ & $\downarrow$ & $\uparrow$ & $\uparrow$ & $\uparrow(+)$ & $\uparrow$ & $\checkmark$ & $\checkmark$ \\
\hline$z_{t}$ & $\downarrow$ & $\downarrow$ & $\uparrow$ & $\uparrow$ & $\uparrow(+)$ & $\uparrow(+)$ & $\downarrow$ & $\downarrow$ & $=$ & $=$ \\
\hline
\end{tabular}

When interpreting the outputs related to the extensions that include new shocks I'll first analyse the statistical moments as usual and then move towards analysing the impact of the new shock on the endogenous variables.

Therefore, I begin to analyse the values of STDs of the preference shock and compare it with the standard case and with the empirical statistics. At a first glance, I remark that the volatility of all variables increase compared to the benchmark model for both countries, meaning this model extension is getting closer to the empirical moments. This is very useful given one of the main drawbacks from the standard case is precisely its low generation of volatility for most of the variables. Nonetheless, some volatilities seem to increase more than others. For example, I see a modest increase for the variables describing the macroeconomic identity in our model: output, consumption and investment, but there is an increase of $105 \%$ for Spain and $164 \%$ for the UK in hours worked in terms of volatility. This is a severe failure given the standard version of the RBC model already does a decent job of capturing this volatility. Interestingly, I can appreciate much heavier changes in the 
correlation to output compared to the benchmark. Given the standard case only considers labour augmented technology as the shock driver, when adding new shocks together with the technology one I expect a different behaviour on variables with this new combination of shocks. I underline a big drop in the cyclicality on consumption, labour productivity and wages for both countries, even though it is more accentuated in the UK (i.e. the correlation of labour productivity to output decreases down to $50 \%$ in Spain but down to $20 \%$ in the UK). When it comes to first order autocorrelations I don't observe any evident change, as it is the case for the extensions analysed until now.

Moving forward to the impact of these new shocks I focus on the initial period of the IRFs for the sake of assessing the effects on each variable of the model. The following interpretation holds for both countries. Output, investment, hours, capital, and real interest rate, all decline immediately, while consumption, labour productivity and the real wage increase. What is going on here is the following. The increase in $\theta_{t}$ is effectively like a decrease in the discount factor: the household values current utility relative more than future utility (i.e. they are less impatient). This means it wants to consume more and work less in the current period, hence it increases consumption and declines hours worked (in a mechanical sense from the FOC for labour the increase in consumption shifts the labour supply curve in). The inward shift of labour supply along on a stable labour demand curve leads to an increase in wages. Falling hours with no immediate change in technology or capital stock means that output must fall. Output falling with consumption increasing means that investment has to fall. What is more, the real interest rate falls immediately. There are two ways to see this. First, since consumption increases, the real interest rate must fall for the Euler equation to hold. Second, the fall in hours worked lowers the marginal product of capital and with capital fixed this means that the rental rate on capital must decline.

Next, consider the intratemporal preference shock. This leads to a reduction in consumption, hours worked, capital, real interest rate, output and investment, with an increase in labour productivity and wages. So, the key difference is the negative impact on consumption. The increase in $\vartheta_{t}$ means people dislike labour relative more, in other words, they want to work less. As before, this shifts the labour supply curve in; along with a stable labour demand curve, this means that wages must rise. Lower employment means lower output. Consumption also falls: this occurs naturally because households' income declines. Investment falls, too.

Unlike the intertemporal preference shock, the intratemporal preference shock can produce comovement between consumption and output and employment. Under the RBC model, the characteristic equation of labour supply captures the difficulty for consumption and employment to move together unless technology changes. In a mechanical sense here, an increase in $\vartheta_{t}$ functionally plays a similar role. Actually, what is needed to get comovement between consumption and hours worked is for either the labour demand or supply curves to shift for a reason other than pure wealth effect of consumption shifting the labour supply curve. The shock embodied in $\vartheta_{t}$ does this job, as it would a change in the tax rate on labour income.

When referring to the model improvement it is tempting to assert that this type of shock is suitable for both countries and helpful in terms of matching empirical moments but it is necessary to be cautious. It is displaying this level of improvement given the main difference between the standard RBC model and the real economy is that the values for volatilities in the RBC model are far too low compared to the economy, per se. Ergo, I'm increasing the volatility of those variables by adding another source of the shock, particularly, a preference shock. But there is no fundamental change in the mechanics of the model, hence there is no underlying feature backing up this improvement. What 
it is telling me, however, is that it may be advisable to add a preference shock along with the technology shock in order to describe better the economies of Spain and the UK. This means that the structure of these economies is more sensible to changes to the household's preferences than to variations in the level of technology.

Lastly, for the comparison across countries, there is no clear candidate for one being more suitable for this shock because the effects on the volatility for each variable are very similar.

\section{Extended model}

Given the parameters are already known by now and without further hesitation, the theoretical moments for Spain and the UK are:

Table 20: Theoretical Moments for Spain and the UK: Extended Model

\begin{tabular}{|cc|c|c|c|c|c|c|c|}
\hline \multirow{2}{*}{ Variable } & \multicolumn{2}{c}{$\begin{array}{c}\text { Standard } \\
\text { Deviation }\end{array}$} & \multicolumn{2}{c}{ Relative STD } & \multicolumn{2}{c|}{$\begin{array}{c}\text { Correlation to } \\
\text { Output }\end{array}$} & \multicolumn{2}{c|}{$\begin{array}{c}\text { 1st order } \\
\text { Autocorrelation }\end{array}$} \\
\cline { 2 - 9 } & SP & UK & SP & UK & SP & UK & SP & UK \\
\hline $\ln \boldsymbol{y}_{\boldsymbol{t}}$ & 0.0152 & 0.0152 & 1.0000 & 1.0000 & 1.0000 & 1.0000 & 0.4708 & 0.4745 \\
\hline $\ln \boldsymbol{c}_{\boldsymbol{t}}$ & 0.0034 & 0.0034 & 0.2237 & 0.2237 & 0.3859 & 0.3763 & 0.8562 & 0.8458 \\
\hline $\ln \boldsymbol{i}_{\boldsymbol{t}}$ & 0.0862 & 0.0615 & 5.5711 & 4.0461 & 0.9830 & 0.9861 & 0.4591 & 0.4622 \\
\hline $\ln \boldsymbol{l}_{\boldsymbol{t}}$ & 0.0159 & 0.0189 & 1.0461 & 1.2434 & 0.7252 & 0.8623 & 0.4382 & 0.4492 \\
\hline $\ln \boldsymbol{k}_{\boldsymbol{t}}$ & 0.0061 & 0.0050 & 0.4013 & 0.3289 & 0.4909 & 0.4719 & 0.8459 & 0.8471 \\
\hline $\ln \left(\boldsymbol{y} / \boldsymbol{l}_{\boldsymbol{t}}\right.$ & 0.0115 & 0.0096 & 0.7566 & 0.6316 & 0.3193 & -0.1096 & 0.5096 & 0.4887 \\
\hline $\ln \boldsymbol{w}_{\boldsymbol{t}}$ & 0.0115 & 0.0096 & 0.7566 & 0.6316 & 0.3193 & -0.1096 & 0.5096 & 0.4887 \\
\hline $\boldsymbol{r}_{\boldsymbol{t}}$ & 0.0011 & 0.0009 & 0.0724 & 0.0592 & 0.9088 & 0.9395 & 0.4645 & 0.4640 \\
\hline $\boldsymbol{z}_{\boldsymbol{t}}$ & 0.0164 & 0.0125 & 1.0789 & 0.8224 & 0.7698 & 0.6859 & 0.4753 & 0.4757 \\
\hline
\end{tabular}

Table 21: Summary comparative statics between the model extension and the benchmark model for Spain and the UK

\begin{tabular}{|c|c|c|c|c|c|c|c|c|c|c|c|c|}
\hline \multirow[t]{2}{*}{ Variable } & \multicolumn{2}{|c|}{$\Delta$ Volatility } & \multicolumn{2}{|c|}{$\begin{array}{l}\Delta \text { Relative } \\
\text { Volatility }\end{array}$} & \multicolumn{2}{|c|}{$\Delta$ Cyclicality } & \multicolumn{2}{|c|}{$\Delta$ Persistence } & \multicolumn{2}{|c|}{$\begin{array}{c}\text { Impact of } \\
\theta_{t} \text { shock }\end{array}$} & \multicolumn{2}{|c|}{$\begin{array}{c}\text { Impact of } \\
\vartheta_{t} \text { shock }\end{array}$} \\
\hline & SP & UK & SP & UK & SP & UK & SP & UK & SP & UK & SP & UK \\
\hline $\ln y_{t}$ & $\uparrow$ & $\uparrow$ & $=$ & $=$ & $=$ & $=$ & $\downarrow$ & $\downarrow$ & - & - & - & - \\
\hline $\ln c_{t}$ & $\downarrow$ & $\downarrow$ & $\downarrow$ & $\downarrow$ & $\downarrow$ & $\downarrow$ & $\uparrow$ & $\uparrow$ & + & + & - & - \\
\hline $\ln i_{t}$ & $\uparrow$ & $\uparrow$ & $\uparrow$ & $\uparrow$ & $\downarrow$ & $\downarrow$ & $\downarrow$ & $\downarrow$ & - & - & - & - \\
\hline $\ln l_{t}$ & $\uparrow$ & $\uparrow$ & $\uparrow$ & $\uparrow$ & $\downarrow$ & $\downarrow$ & $\downarrow$ & $\downarrow$ & - & - & - & - \\
\hline $\ln k_{t}$ & $\uparrow$ & $\uparrow$ & $\uparrow$ & $\uparrow$ & $\uparrow$ & $\uparrow$ & $\downarrow$ & $\downarrow$ & - & - & - & - \\
\hline $\ln (y / l)_{t}$ & $\uparrow$ & $\uparrow$ & $\uparrow$ & $\uparrow$ & $\downarrow$ & $\downarrow(-)$ & $\downarrow$ & $\downarrow$ & + & + & + & + \\
\hline $\ln w_{t}$ & $\uparrow$ & $\uparrow$ & $\uparrow$ & $\uparrow$ & $\downarrow$ & $\downarrow(-)$ & $\downarrow$ & $\downarrow$ & + & + & + & + \\
\hline$r_{t}$ & $=$ & $\uparrow$ & $\downarrow$ & $\downarrow$ & $\downarrow$ & $\downarrow$ & $\uparrow$ & $\downarrow$ & - & - & - & - \\
\hline$z_{t}$ & $=$ & $=$ & $\uparrow$ & $\downarrow$ & $\downarrow$ & $\downarrow$ & $=$ & $=$ & & & & \\
\hline
\end{tabular}


Table 22: Summary comparative statics between the model extension and the data for Spain and the UK

\begin{tabular}{|c|c|c|c|c|c|c|c|c|c|c|}
\hline \multirow{2}{*}{ Variable } & \multicolumn{2}{|c|}{$\Delta$ Volatility } & \multicolumn{2}{|c|}{$\begin{array}{c}\Delta \text { Relative } \\
\text { Volatility }\end{array}$} & \multicolumn{2}{|c|}{$\Delta$ Cyclicality } & \multicolumn{2}{|c|}{$\Delta$ Persistence } & \multicolumn{2}{|c|}{$\begin{array}{c}\text { Improvement } \\
\text { in fit? }\end{array}$} \\
\cline { 2 - 13 } & SP & UK & SP & UK & SP & UK & SP & UK & SP & UK \\
\hline $\ln y_{t}$ & $\downarrow$ & $\downarrow$ & $=$ & $=$ & $=$ & $=$ & $\downarrow$ & $\downarrow$ & $\checkmark$ & $\checkmark$ \\
\hline $\ln c_{t}$ & $\downarrow$ & $\downarrow$ & $\downarrow$ & $\downarrow$ & $\downarrow$ & $\downarrow$ & $\uparrow$ & $\uparrow$ & $\mathbf{x}$ & $\mathbf{x}$ \\
\hline $\ln i_{t}$ & $\uparrow$ & $\downarrow$ & $\uparrow$ & $\uparrow$ & $\uparrow$ & $\uparrow$ & $\downarrow$ & $\downarrow$ & $\checkmark$ & $\checkmark$ \\
\hline $\ln l_{t}$ & $\uparrow$ & $\uparrow$ & $\uparrow$ & $\uparrow$ & $\uparrow(+)$ & $\uparrow$ & $\downarrow$ & $\downarrow$ & $\mathbf{x}$ & $\mathbf{x}$ \\
\hline $\ln k_{t}$ & $\downarrow$ & $\downarrow$ & $\uparrow$ & $\uparrow$ & $\uparrow(+)$ & $\uparrow$ & $\uparrow$ & $\uparrow$ & $\checkmark$ & $\checkmark$ \\
\hline $\ln (y / l)_{t}$ & $\downarrow$ & $\downarrow$ & $\downarrow$ & $\downarrow$ & $\downarrow$ & $\downarrow(-)$ & $\downarrow$ & $\downarrow$ & $\checkmark$ & $\checkmark$ \\
\hline $\ln w_{t}$ & $\downarrow$ & $\downarrow$ & $\downarrow$ & $\downarrow$ & $\uparrow$ & $\downarrow(-)$ & $\downarrow$ & $\downarrow$ & $\checkmark$ & $\checkmark$ \\
\hline$r_{t}$ & $\downarrow$ & $\downarrow$ & $\downarrow$ & $\downarrow$ & $\uparrow$ & $\uparrow$ & $\uparrow(+)$ & $\uparrow$ & $=$ & $\checkmark$ \\
\hline$z_{t}$ & $\downarrow$ & $\downarrow$ & $\uparrow$ & $\uparrow$ & $\uparrow(+)$ & $\uparrow(+)$ & $\downarrow$ & $\downarrow$ & $=$ & $=$ \\
\hline
\end{tabular}

The extended version of the RBC model clearly improves the fit of the empirical statistical moments compared to the benchmark, as expected. The degree of improvement is discussable, yet. Based on the summary table I see a better fit in terms of capturing volatility along several variables. In particular, compared to indivisible labour solely, the volatility of wages and labour productivity increase, getting closer to the empirical moments. However, this comes at the expense of having worse fit in consumption. For the case of habit formation, the fit on output and real interest rate improve in this new version. Also, the consumption fit is less bad in this combined version than in habit formation on its own. Nonetheless, for hours worked, this combined version is performing worse than if I'd consider indivisible labour solely or habit formation solely as well. Lastly, for the preference shock, it improves the fit of wages and labour productivity but makes consumption fit less well (merely due to habit formation). In relation to the preference shock, I can point out that some variables react more intensively to the shock in this version than when considering the extension alone. For instance, here I've appreciated in the IRFs of the intertemporal shock that output is having a smaller initial negative jump compared to the version with just preference shocks. Also, the IRF of output has become more concave. I also observe that the initial effect on consumption is around zero and then it drops a few periods later, whereas in the version with only preference shock I can see first an immediate increase and then a drop. For investment and hours worked I don't see any significant change in the shape, however, when looking closely I can appreciate a bigger drop in hours worked at the beginning of the period in this extended RBC model. In the intratemporal shock, I notice that the fall in consumption is much more moderate in this version at the beginning of the period than it is the case when the preference shock is considered solely. The same applies for capital, whilst the curvature of the IRF is also less pronounced in this model.

The whole point of combining these extensions has been to add more realistic features to the baseline RBC model and also including a new driver for business cycles that fits the data well (i.e. apparently in this case it has been the preference shock compared to the other shocks considered in annex B). Thus, even if the combination of these extensions don't deliver the best fit possible, I can conclude that this extended version is matching the empirical STDs for Spain and the UK better than the benchmark model. To put differently, including popular extensions of the RBC literature to the 
benchmark is also positive for replicating better the behaviour of Spain's and the UK's business cycles between 1985 and 2013.

As a final insight I state that on the one hand it seems like the UK is a better candidate than Spain in order to be represented by the standard version of the RBC model whereas on the other hand, both countries have improved equally their fit of empirical moments when adding extensions individually and jointly (with the exception of labour indivisibility that is more adequate for the UK than for Spain). 


\section{CONCLUSIONS}

The utilisation of the RBC model for the sake of replicating Spain's and the UK's business cycles turns out to be a good predictor for a restricted number of variables in terms of volatility. Broadly speaking, I could also include the measure of cyclicality to this latter statement but persistence is far too low for most variables compared to data. As a result, I conclude that the benchmark model performs considerably well in terms of fitting empirical moments, but it does so just for some variables. Moreover, when comparing between countries the results indicate that the UK is better represented by the baseline model than Spain. Nevertheless, when adding extensions there are evident improvements for both countries such that neither Spain nor the UK dominates in terms of being more suitable for the extended model.

In particular, the RBC model succeeds in capturing the volatility of output, investment, hours worked, the input factors and labour augmented technology. It drastically fails, however, on describing correctly the volatility of consumption, labour productivity and the input prices: real wages and real interest rate. Even though this model cannot replicate accurately the cyclicality of the variables, it does a decent job on netting the direction with which the variables co-move with output. Actually, it just fails to depict the negative correlation of the input factors with output present in Spain's empirical moments. Finally, the persistence of the macroeconomic variables is imitated in a very precise manner in relative terms. This means that the model is able to capture the degree of persistence among variables, but in absolute terms, the persistence is lower in the RBC model than in reality. Remarkably, the inclusion of different model extensions and the combination of themselves, improves the model fit of all variables but consumption and hours worked (this is the case for the extended model).

Consequently, I conclude that despite the neoclassical assumptions of the baseline RBC model are too simplistic in order to properly capture the second order moments of real business cycles for Spain and the UK, this model is powerful enough as to consider it as a reference model for replicating business cycles for these countries. In line with the hypothesis stated in the introduction and based on the results I get, I confirm that the UK is the country that is better reflected in the standard RBC model indicating so that this economy is less structurally rigid and closer to the Neoclassics. 


\section{BIBLIOGRAPHY}

Adjemian, S., H. Bastani, F. Karamé, M. Juillard, J. Maih, F. Mihoubi, G. Perendia, J. Pfeifer, M. Ratto and S. Villemot (2014). "Dynare Reference Manual". Unpublished Manual. Available at http://www.dynare.org/documentation-and-support. [Last accessed 09/2016].

Berlemann, M. and J.E. Wesselhöft (2014). "Estimating Aggregate Capital Stocks Using the Perpetual Inventory Method". Review of Economics, Vol. 65, No.1, pp. 1-34.

Blanchard, O.J. (2008). "The State of Macro". NBER Working Paper, No. 14259.

Carlin, W. and D. Soskice (2015). "Macroeconomics: Institutions, Instability, and the Financial System".

Carlin, W. and D. Soskice (2006). "Macroeconomics: Imperfections, Institutions, and Policies".

Christiano, L.J., M. Eichenbaum and C.L. Evans (2005). "Nominal Rigidities and the Dynamic Effects of a Shock to Monetary Policy". Journal of Political Economy, Vol. 113, No. 1, pp. 1-45.

Cooley, T.F. (1997). "Calibrated Models". Oxford Review of Economic Policy, Vol. 13, No. 3, pp. 5569.

Del Negro, M. and F. Schorfheide (2006). "How Good Is What You've Got? DGSE-VAR as a Toolkit for Evaluating DSGE Models". Federal Reserve Bank of Atlanta Economic Review, Vol. 91, No. 2, pp. 21 37.

Enders, W. (2014). "Applied Econometric Time Series", 4" edition.

Fernández-Villaverde, J. (2016). "Real Business Cycles". Unpublished lecture notes, University of Pennsy/vania. Available at http://economics.sas.upenn.edu/ jesusfv/index.html. [Last accessed 10/2016].

Fernández-Villaverde, J. (2009). "The Econometrics of DSGE models". NBER Working Paper, No. 14677.

Fernández-Villaverde, J. and J.F. Rubio-Ramírez (2004). "Comparing dynamic equilibrium models to data: a Bayesian approach". Journal of Econometrics, Vol. 123, No. 1, pp. 153-187.

Giacomini, R. (2013). "The relationship between DSGE and VAR models". Advances in econometrics, Vol. 32, pp. 1-25.

Griffoli, T.M. (2007-2008). "Dynare User Guide". Unpublished User Guide. Available at http://www.dynare.org/documentation-and-support. [Last accessed 09/2016].

Haberger, A.C. (1978). "Perspectives on Capital and Technology in Less Developed countries". Contemporary economic analysis, pp. 15-40.

Hansen, G.D. (1985). "Indivisible Labor and the Business Cycle". Journal of Monetary Economics, Vol. 16, No. 3, pp. 309-327.

Hodrick, R.J. and E.C. Prescott (1997). "Post-war U.S. Business Cycles: An Empirical Investigation". Journal of Money, Credit, and Banking, Vol.29, No. 1, pp. 1-16. 
Jerbashian, V. (2016). "Macroeconomics III". Unpublished lecture notes, University of Barcelona. Available at https://vjerbashian.wordpress.com/. [Last accessed 10/2016].

Kydland, F.E. and E.C. Prescott (1991). "The Econometrics of the General Equilibrium Approach to Business Cycles". The Scandinavian Journal of Economics, Vol. 93, No. 2, pp. 161-178.

Kydland, F.E. and E.C. Prescott (1982). "Time to Build and Aggregate Fluctuations". Econometrica, Vol. 50, No. 6, pp. 1345-1370.

Lucas, R.E. (1987). "Models of Business Cycles".

Lucas, R.E. (1980). "Methods and Problems in Business Cycle Theory". Journal of Money, Credit, and Banking, Vol. 12, No.4 (Part 2), pp. 696-713.

Lucas, R.E. (1976). "Econometric Policy Evaluation: A Critique". Carnegie-Rochester Conference Series on Public Policy, Vol. 1, pp. 19-46.

Mankiw, G. (2006). "Macroeconomics", 6 $6^{\text {th }}$ edition.

Manuelli, R.E. (1986). "Modern Business Cycle Analysis: A Guide to the Prescott-Summer Debate". Federal Reserve Bank of Minneapolis Quarterly Review, Vol. 10, No.4, pp. 3-7.

Mc Candles, G. (2008). "The ABCs of RBCs".

Prescott, E.C. (2006). "The Transformation of Macroeconomic Policy and Research". Journal of Political Economy, Vol. 114, No. 2, pp. 203-235.

Ramsey, F.P. (1928). "A mathematical theory of saving". The Economic Journal, Vol. 38, No. 152, pp. 543-559.

Rebelo, S. (2005). "Real Business Cycle Models: Past, Present, and Future". NBER Working Paper, No. 11401.

Rogerson. R. (1988). "Indivisible Labor, Lotteries and Equilibrium". Journal of Monetary Economics, Vol. 21, No. 1, pp. 3-16.

Sims, E. (2016). "The Real Business Cycle Model". Unpublished lecture notes, University of Notre Dame. Available at http://www3.nd.edu/ esims1/. [Last accessed 10/2016].

Sims, E. (2016). "Stylized Business Cycle Facts and the Quantitative Performance of the RBC model". Unpublished lecture notes, University of Notre Dame. Available at http://www3.nd.edu/ esims1/. [Last accessed 10/2016].

Sims, E. (2016). "Extensions of Basic RBC Framework". Unpublished lecture notes, University of Notre Dame. Available at http://www3.nd.edu/ esims1/. [Last accessed 11/2016].

Sims, E. (2016). "Notes on Log-Linearization". Unpublished lecture notes, University of Notre Dame. Available at http://www3.nd.edu/ esims1/. [Last accessed 11/2016].

Smets, F. and R. Wouters (2003). "An Estimated Dynamic Stochastic General Equilibrium Model of the Euro Area". Journal of the European Economic Association, Vol. 1, No. 5, pp. 1123-1175.

Summers, L.H. (1986). "Some Skeptical Observations on Real Business Cycle Theory". Federal Reserve Bank of Minneapolis Quarterly Review Vol. 10, No. 4, pp. 23-26. 


\section{ANNEX}

\section{Annex A: Complementary material}

\section{Annex A.1}

I solve for the steady-state in a different way, which entails having this new set of equations:

$$
\begin{gathered}
l^{s s}=\frac{\left(\frac{1-\alpha}{\psi}\right)\left(\frac{k}{l}\right)^{\alpha}}{\left(\frac{\psi+1-\alpha}{\psi}\right)\left(\frac{k}{l}\right)^{\alpha}-\delta\left(\frac{k}{l}\right)}, \quad \text { ith } \frac{k}{l}=\left(\frac{\alpha}{\frac{1}{\beta}-(1-\delta)}\right)^{\frac{1}{1-\alpha}}, \\
k^{s s}=\left(\frac{\alpha}{\frac{1}{\beta}-(1-\delta)}\right)^{\frac{1}{1-\alpha}} l^{s s}, \\
y^{s s}=k^{s s^{\alpha}} l^{s s^{1-\alpha}}, \\
i^{s s}=\delta k^{s s}, \\
c^{s s}=y^{s s}-i^{s s} .
\end{gathered}
$$

I now show that the two solutions presented are the same by proofing that the expression for $l^{s s}$ in the first solution equals the expression for $l^{s s}$ in second, from now on $l_{1}^{s s}$ and $l_{2}^{s s}$.

Recall:

$$
\begin{gathered}
l_{1}^{s s}=\frac{(1-\alpha)\left(\frac{1}{\beta}-(1-\delta)\right)}{\psi\left(\frac{1}{\beta}-(1-\delta)-\alpha \delta\right)+(1-\alpha)\left(\frac{1}{\beta}-(1-\delta)\right)^{\prime}} \\
l_{2}^{s s}=\frac{\left(\frac{1-\alpha}{\psi}\right)\left(\left(\frac{\alpha}{\frac{1}{\beta}-(1-\delta)}\right)^{\frac{1}{1-\alpha}}\right)^{\alpha}}{\left(\frac{\psi+1-\alpha}{\psi}\right)\left(\left(\frac{\alpha}{\frac{1}{\beta}-(1-\delta)}\right)^{\frac{1}{1-\alpha}}\right)^{\alpha}-\delta\left(\left(\frac{\alpha}{\frac{1}{\beta}-(1-\delta)}\right)^{\frac{1}{1-\alpha}}\right)} .
\end{gathered}
$$

For the sake of simplicity, I define $A=\left(\frac{\alpha}{\frac{1}{\beta}-(1-\delta)}\right)^{\frac{1}{1-\alpha}}$ and $B=\frac{1}{\beta}-(1-\delta)$ such that $A=\left(\frac{\alpha}{B}\right)^{\frac{1}{1-\alpha}}$. 
I substitute these constants in the expressions from above:

$$
\begin{gathered}
l_{1}^{s s}=\frac{(1-\alpha) B}{\psi(B-\alpha \delta)+(1-\alpha) B}, \\
l_{2}^{s s}=\frac{\left(\frac{1-\alpha}{\psi}\right)(A)^{\alpha}}{\left(\frac{\psi+1-\alpha}{\psi}\right)(A)^{\alpha}-\delta(A)} .
\end{gathered}
$$

Hence, I want to show that: $l_{2}^{s s}=l_{1}^{s s}$.

The first step I undertake is to manipulate the expression of $l_{2}^{s s}$ :

I take $A^{\alpha}$ out of the division:

$$
\begin{gathered}
l_{2}^{s s}=\frac{A^{\alpha}}{A^{\alpha}} \frac{\left(\frac{1-\alpha}{\psi}\right)}{\left(\frac{\psi+1-\alpha}{\psi}\right)-\delta A^{\frac{1}{1-\alpha}}}, \\
\text { given } A^{\alpha} A^{\frac{1}{1-\alpha}}=A^{\alpha} A^{-(\alpha-1)}=A^{\alpha-\alpha+1}=A . \\
l_{2}^{s s}=\frac{\left(\frac{1-\alpha}{\psi}\right)}{\left(\frac{\psi+1-\alpha}{\psi}\right)-\delta A^{1-\alpha}}, \\
\text { given } A^{\frac{1}{1-\alpha}}=A^{-(\alpha-1)}=A^{-\alpha+1}=A^{1-\alpha} .
\end{gathered}
$$

I plug in the expression for $A$ and get the following result:

$$
l_{2}^{s s}=\frac{\left(\frac{1-\alpha}{\psi}\right)}{\left(\frac{\psi+1-\alpha}{\psi}\right)-\frac{\alpha \delta}{B}}
$$

I take $\frac{1}{\psi}$ out of the division:

$$
\begin{aligned}
& l_{2}^{s s}=\frac{\frac{1}{\psi}}{\frac{1}{\psi}} \frac{1-\alpha}{\left(\psi+1-\alpha-\frac{\psi \alpha \delta}{B}\right)}, \\
& \text { given } \frac{1}{\psi} \frac{\psi \alpha \delta}{B}=\frac{\psi}{\psi} \frac{\alpha \delta}{B}=\frac{\alpha \delta}{B} .
\end{aligned}
$$

Consequently:

$$
l_{2}^{s s}=\frac{1-\alpha}{\psi+1-\alpha-\frac{\psi \alpha \delta}{B}} .
$$


The second and final step I make is to manipulate the expression of $l_{1}^{s s}$ :

I take $B$ out of the division:

$$
\begin{aligned}
& l_{1}^{s s}=\frac{B}{B} \frac{(1-\alpha)}{\left(\psi-\frac{\psi \alpha \delta}{B}+(1-\alpha)\right)}, \\
& \text { given } B \frac{\psi \alpha \delta}{B}=\frac{B}{B} \psi \alpha \delta=\psi \alpha \delta .
\end{aligned}
$$

Hence:

$$
l_{1}^{s S}=\frac{(1-\alpha)}{\psi+1-\alpha-\frac{\psi \alpha \delta}{B}} .
$$

Accordingly, comparing both results it follows that: $l_{2}^{s s}=l_{1}^{s s}$. 


\section{Annex A.2}

Here, I present how the derived benchmark model looks like in the Dynare .mod file. I remark that this script is as valid for Spain and the UK. The only thing that changes among countries is the calibration block. What is more, between the benchmark model and the model extensions, the only aspect that is different is the preamble where variables and parameters are defined and the model block, given the characteristic equations vary. Lastly, in the case of additional shocks, these must be included in the last part. As a result, for the sake of illustration, I just present the script of the benchmark model for Spain.

\section{Script 1: Dynare code for the benchmark model calibrated for Spain}

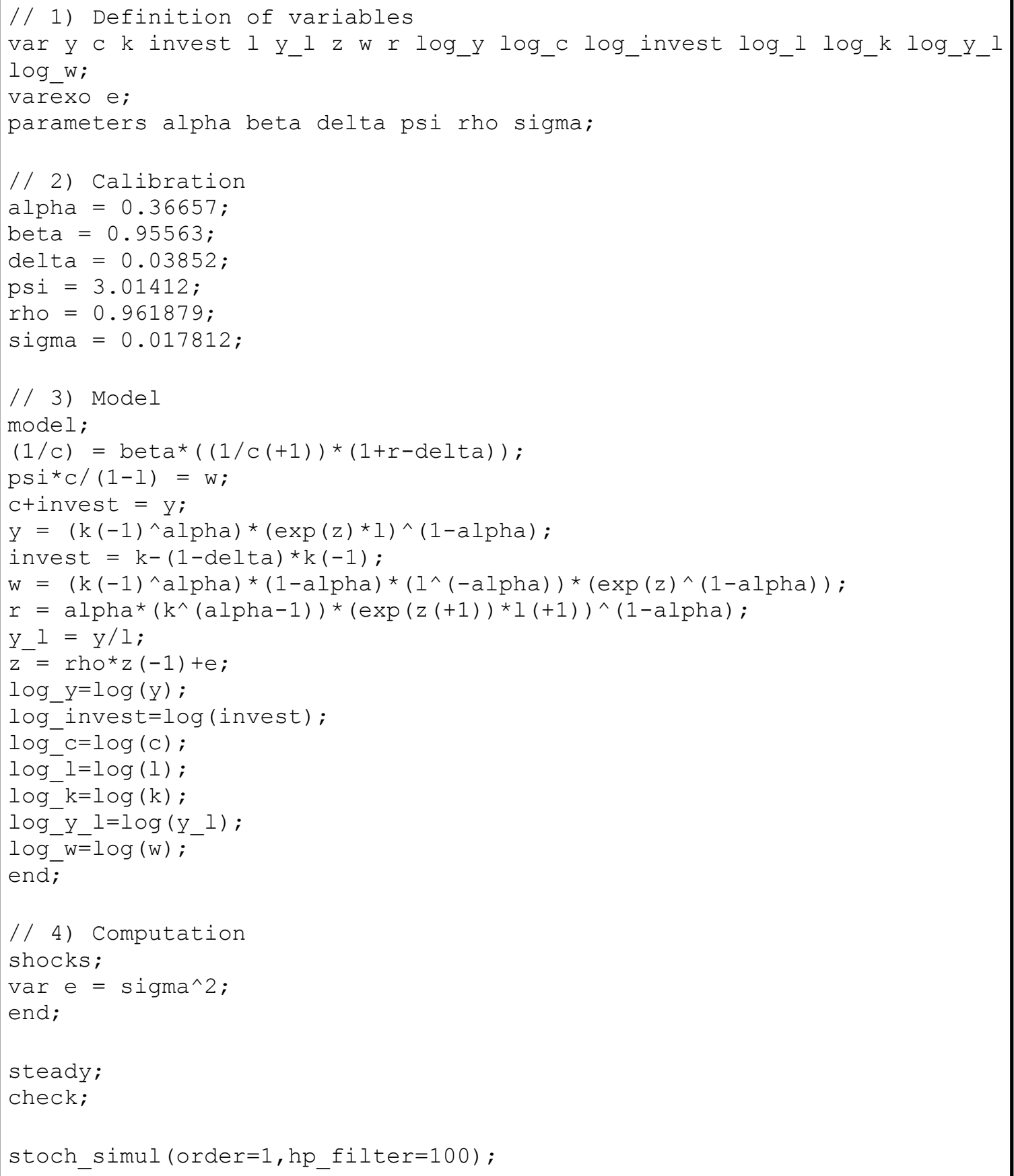


Regarding the Matlab function that contains the steady-state equations for solving the model, I underline that it doesn't change across countries but it does for each model extension. This is like this because every set of characteristic equations has assigned a particular solution. As above the following Matlab function corresponds to the benchmark model.

\section{Script 2: Matlab function code for the benchmark model}

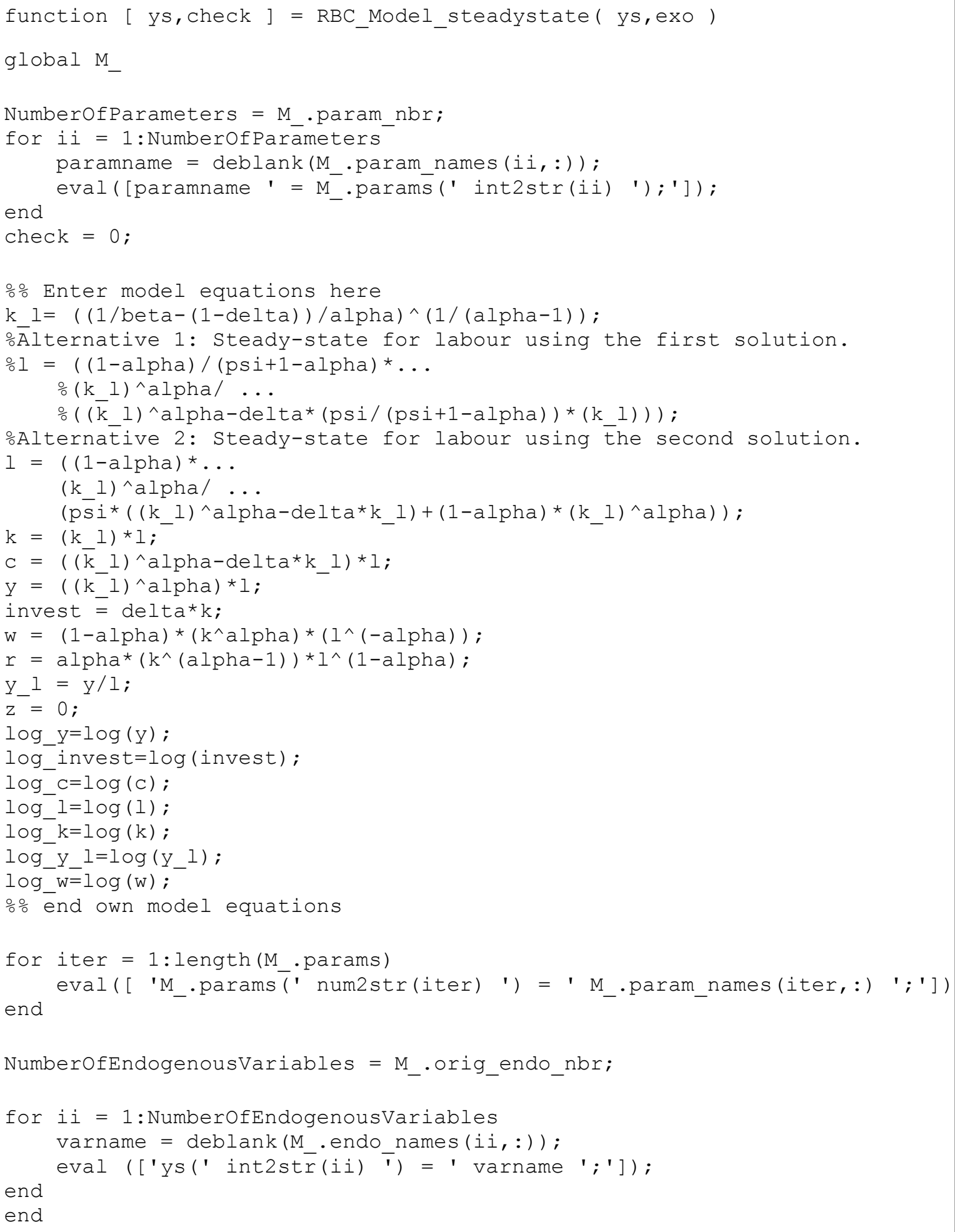




\section{Annex A.3}

In this section, I explore Eric Sims' methodology for modelling the technology shock at an even deeper level by checking whether it is appropriate to have assumed a linear time trend in the regression of labour augmented technology or if including just a constant does the detrending job as well.

Hence, I repeat the steps for the case of only including an intercept in the detrending regression and compare the results.

Table 23: Labour augmented technology regression with the estimated coefficient of a constant (i.e. $\omega_{0}$ )

\begin{tabular}{|lccccc|}
\hline \multicolumn{5}{c|}{ Model 3: OLS, using observations } & 1985-2013 $(\mathrm{T}=29)$ \\
& \multicolumn{5}{c|}{ Dependent variable: SP } \\
const & Coefficient & Std. Error & t-ratio & p-value & \\
R-squared & $\mathbf{1 . 1 2 7 0 6}$ & 0.0253192 & 44.5142 & $<0.00001$ & $* * *$ \\
& 0.000000 & & & & \\
\hline
\end{tabular}

Table 24: AR(1) regression on the saved residual to get the autoregressive coefficient (i.e. $\rho$ )

\begin{tabular}{|c|c|c|c|c|c|}
\hline \multicolumn{6}{|c|}{$\begin{array}{c}\text { Model 4: OLS, using observations 1986-2013 }(T=28) \\
\text { Dependent variable: uhat_SP }\end{array}$} \\
\hline uhat_SP_1 & $\begin{array}{l}\text { Coefficient } \\
0.92023\end{array}$ & $\begin{array}{l}\text { Std. Error } \\
0.028186\end{array}$ & $\begin{array}{c}\text { t-ratio } \\
32.6484\end{array}$ & $\begin{array}{l}\text { p-value } \\
<0.00001\end{array}$ & $* * *$ \\
\hline R-squared & 0.975296 & & & & \\
\hline$F(1,27)$ & 1065.919 & & P-value(F) & $3.09 \mathrm{e}-23$ & \\
\hline Schwarz criterion & -137.0429 & & Akaike criterion & -138.3751 & \\
\hline
\end{tabular}

Table 25: Saved error term from this latter AR(1) regression to get the standard deviation of the error term (i.e. $e_{t} \rightarrow \sigma$ )

Summary Statistics, using the observations $1985-2013$ for the variable ehat_SP (28 valid observations)

Std. Dev. 0.0144335 
Figure 6: Eric Sims' detrending method

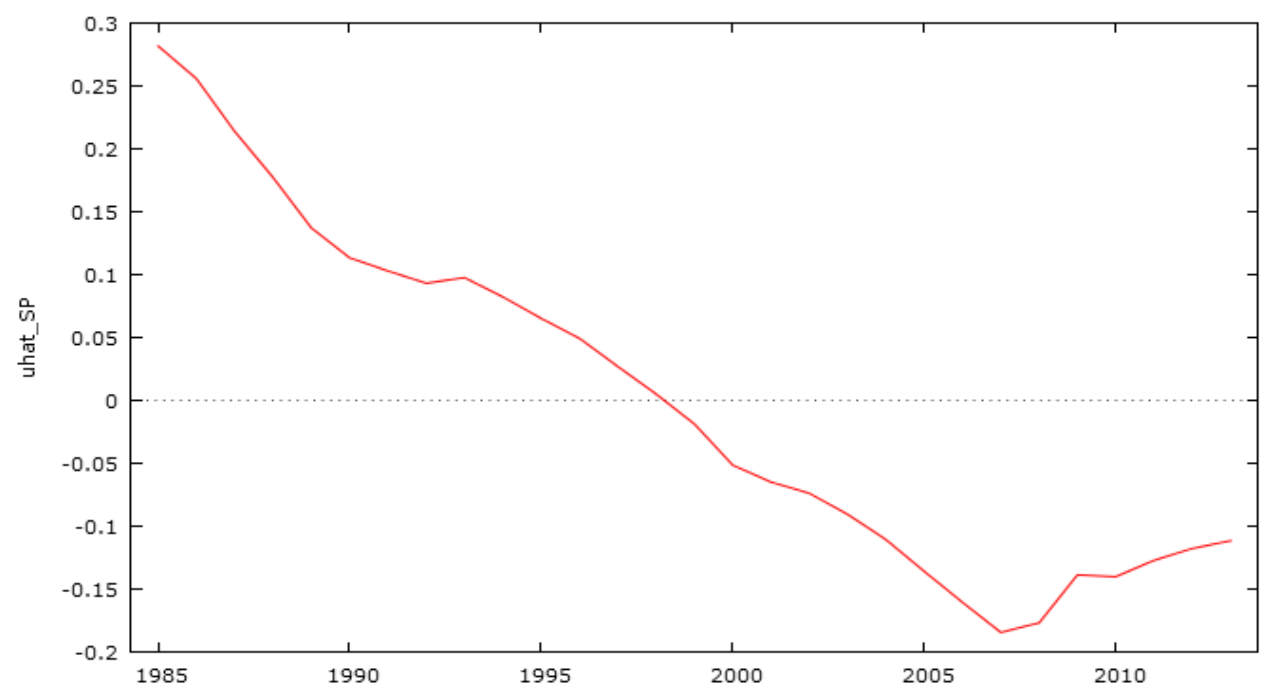

Figure 7: HP-filter detrending method

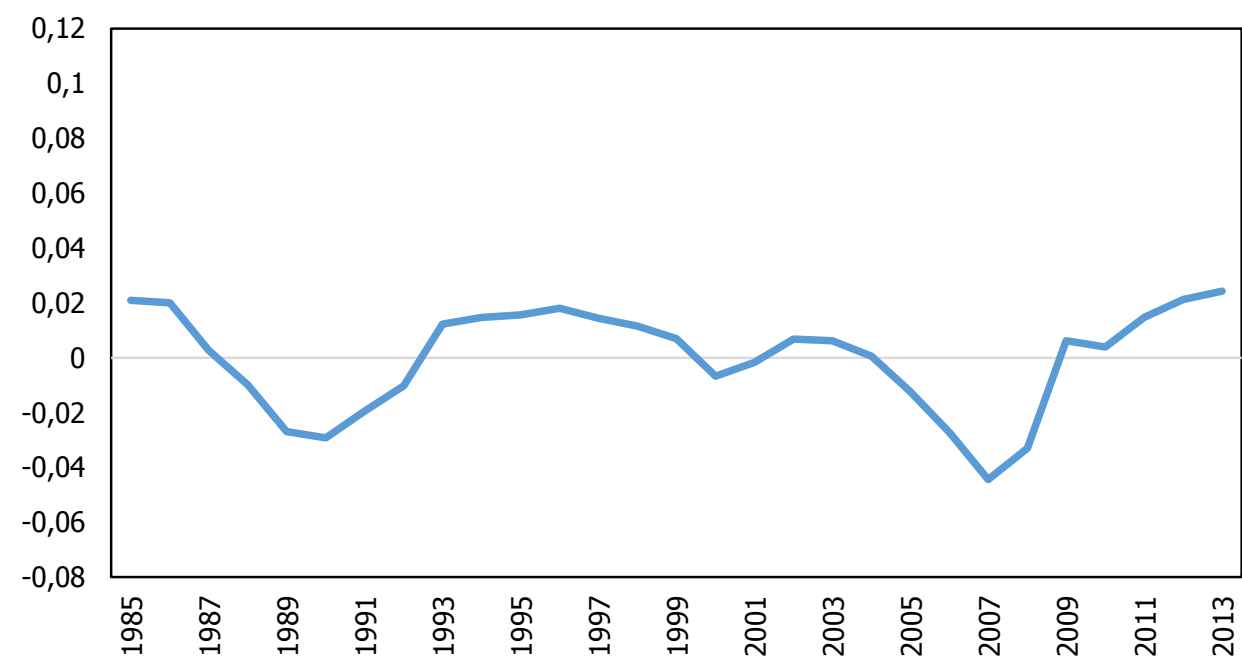

As a result, the comparison I make is terms of whether it is more suitable to include a deterministic time trend and a constant in the regression as in the first case or whether it is more accurate to leave out the time trend and only consider the intercept. Based on the results I obtain I conclude that having included the time trend as in the first case is correct. The main two reasons for that are the following: first, just having a look at the graphs for each case I'm able to see that adding a time trend in the detrending regression makes the disturbance term "uhat" capture much better the cyclical component than when I leave it out. For this, I compare the plottings from calibrated labour augmented technology for both cases (with and without time trend) versus the plotting of labour augmented technology from actual data. The differences are evident. Also, for the case of only having an intercept (without time trend), I clearly see in the plotting of the disturbance against time that there exists a well-defined time trend. The second and most important argument that backs up including a time trend is based on the results I obtain from model selection criteria. For this, I look at the Gretl output of model 2 and 4 (Table 4 and 24) and determine the lowest value (or highest in absolute terms) of the Schwarz and the Akaike information criteria. order to be able to determine 
which model delivers a better performance. Clearly, the model 2 has lower values for both criteria. For instance, when comparing the output for the Akaike information criterion I get the following result: $|-145.0123|>|-138.3751|$, where the first value corresponds to model 2 (regression with time trend) and the latter to model 4.

Accordingly, summing up:

$$
\begin{gathered}
\hat{z}_{t}=\omega_{0}+\omega_{1} t_{t}+u_{t} \rightarrow \hat{u}_{t}=\rho \hat{u}_{t-1}+e_{t}, \\
\text { is preferred over } \\
\hat{z}_{t}=\omega_{0}+u_{t} \rightarrow \hat{u}_{t}=\rho \hat{u}_{t-1}+e_{t} .
\end{gathered}
$$




\section{Annex A.4}

Figure 8: Empirical business cycles for Spain and the UK
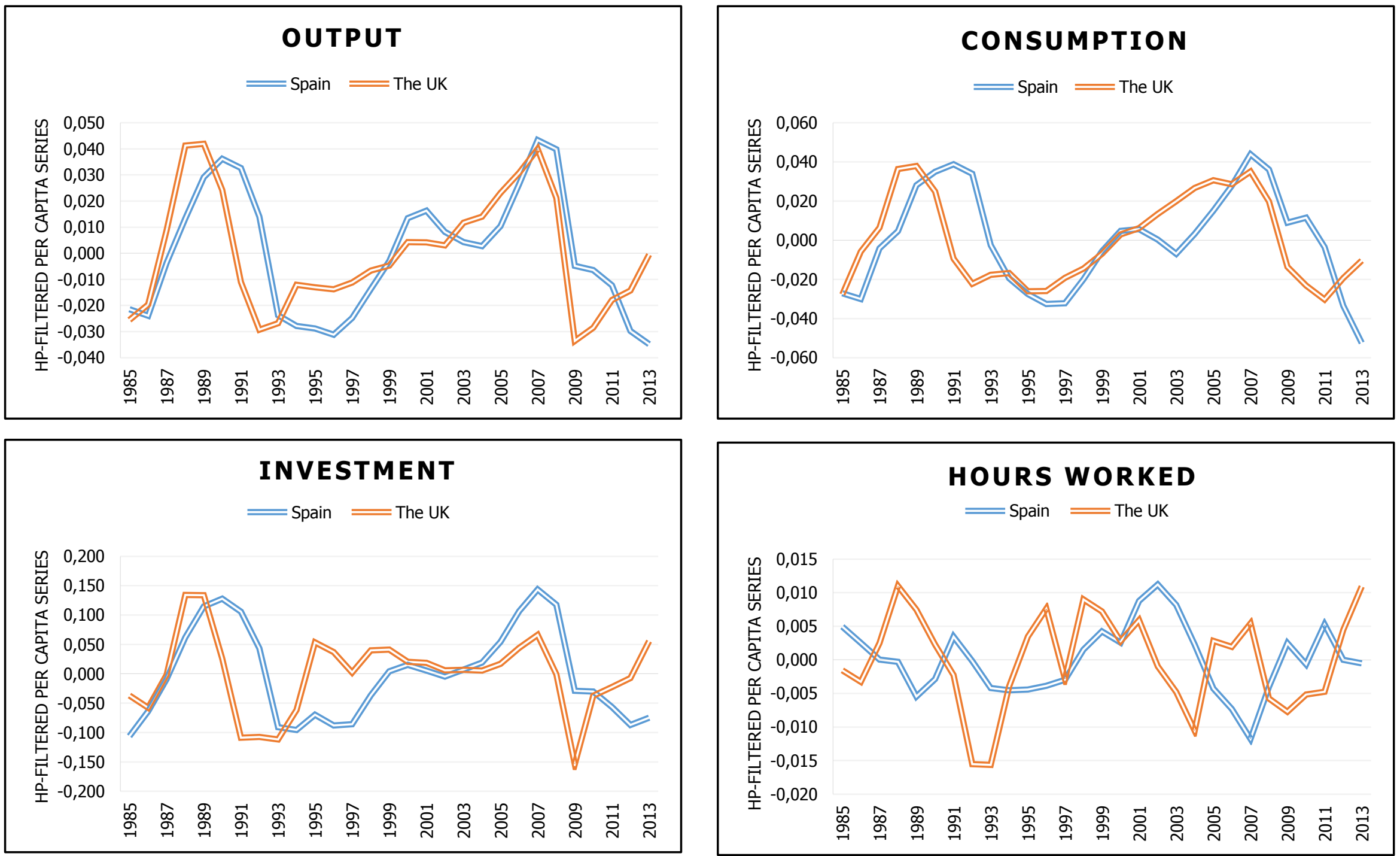

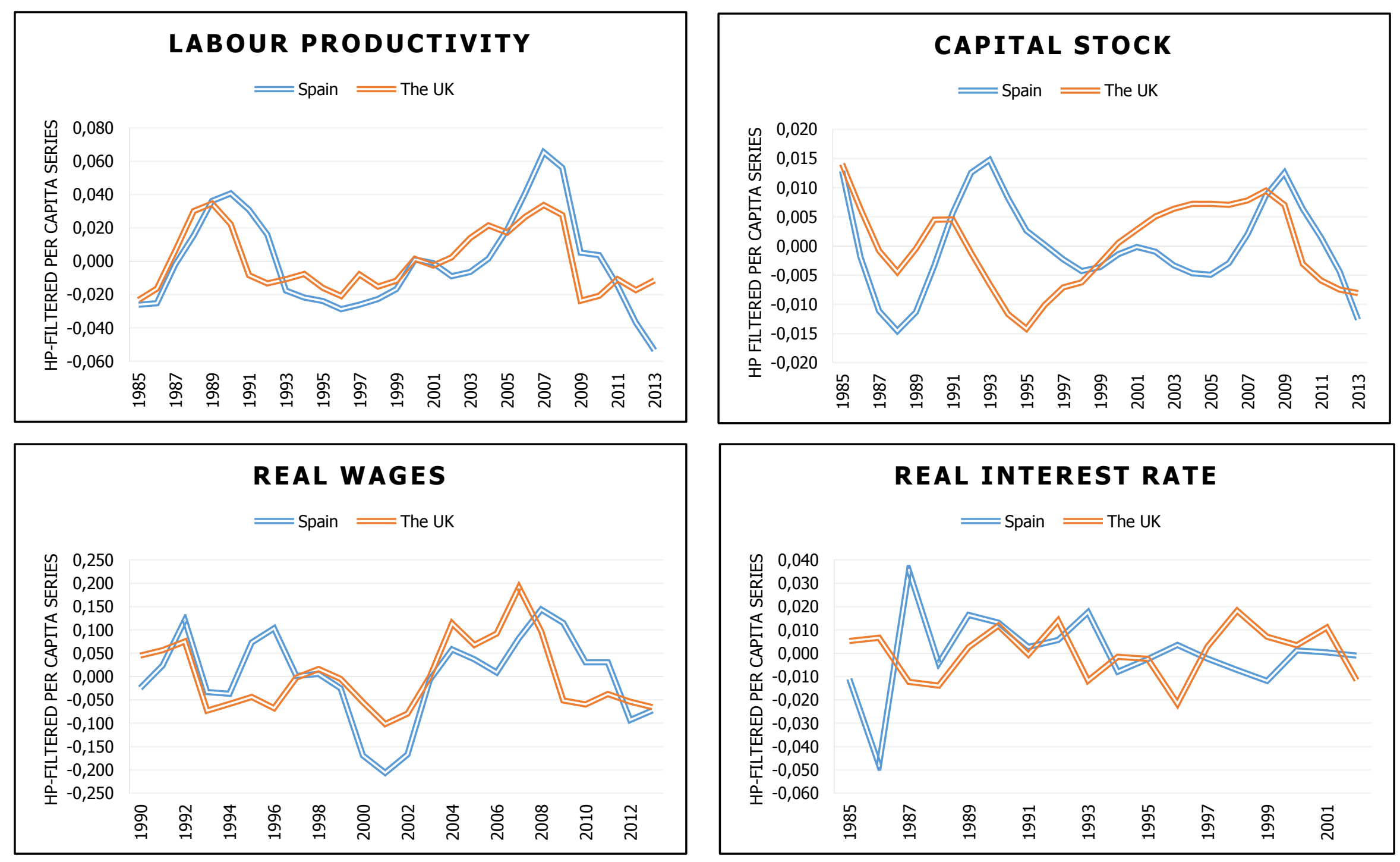

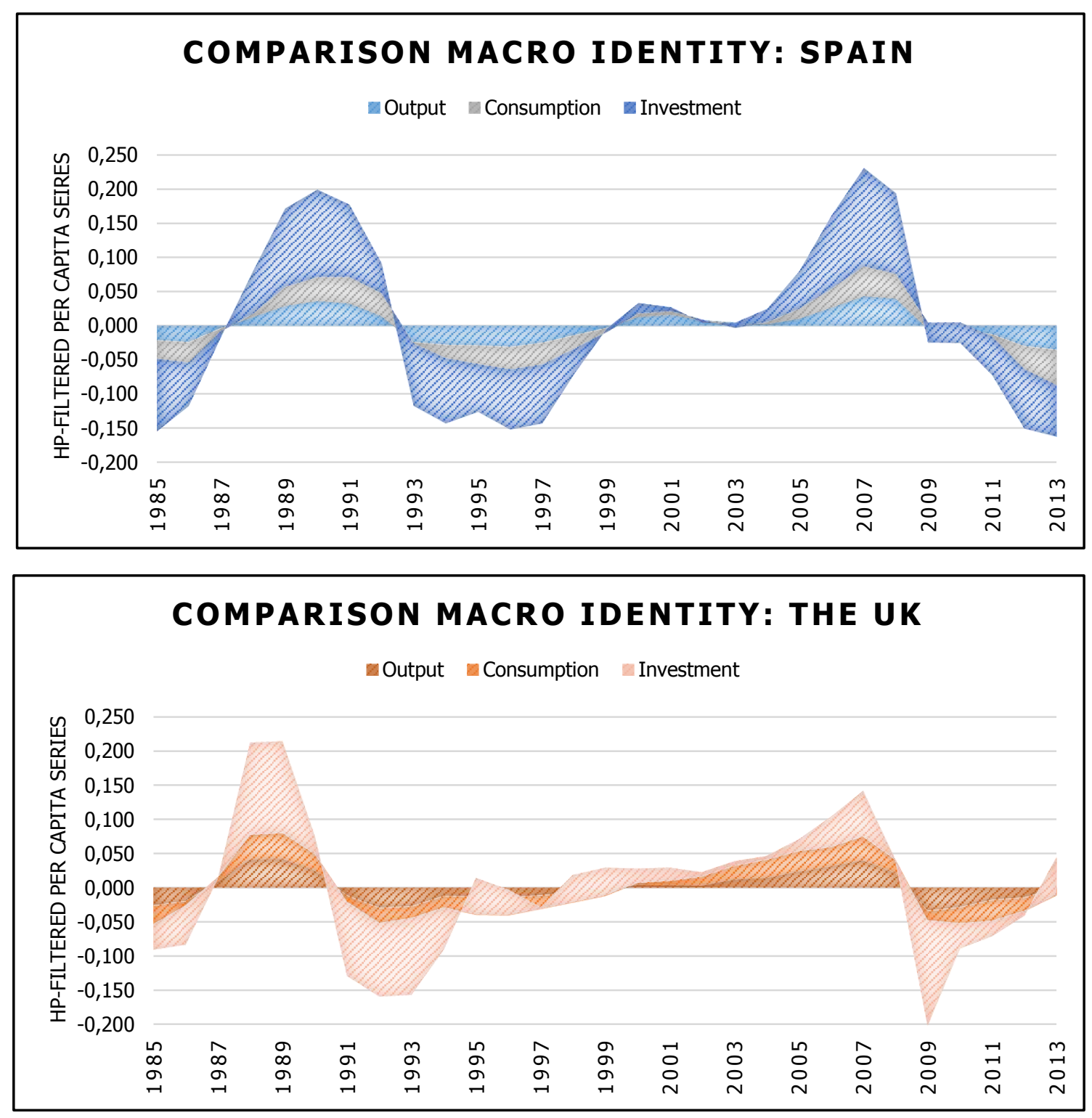

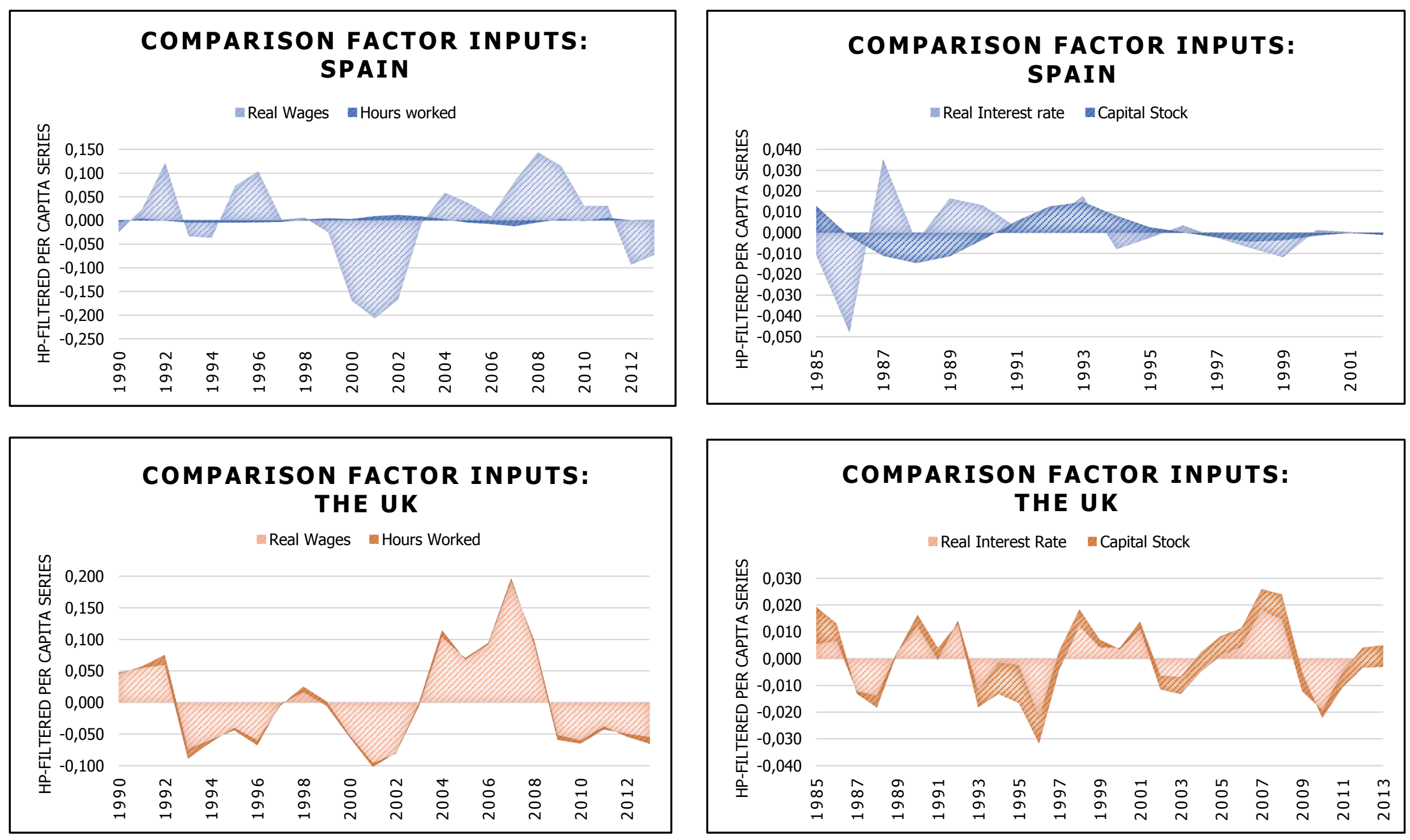


\section{Annex B: Additional model extensions}

\section{Controlling for the Frisch elasticity}

In order to identify what the Frisch elasticity is I take the equation (2) from the benchmark model and log-linearise it about the steady-state:

$$
\gamma \tilde{l}_{t}=-\tilde{c}_{t}+\widetilde{w}_{t}, \quad \text { with } \gamma=\frac{l^{*}}{1-l^{*}}
$$

Where variables with "tilda" denote the percentage variation of contemporaneous variables with their corresponding steady-state values. The Frisch labour supply elasticity is defined as the derivative of natural log hours of work to natural log wages, holding marginal utility of consumption fixed. Since $\tilde{l}_{t}=\ln l_{t}-\ln l^{*}=\frac{l_{t}-l^{*}}{l^{*}}$, then the Frisch elasticity is:

$$
\frac{1}{\gamma}=\frac{1-l^{*}}{l^{*}} \Leftrightarrow \frac{d \tilde{l}_{t}}{d \widetilde{w}_{t}} \mid \tilde{\lambda}_{t}=\frac{1}{\gamma} .
$$

The target level for hours worked are the ones of the US in the analysis of Eric Sims being the steady-state value: $l^{*}=1 / 3$, hence meaning that people in the US devote roughly $33 \%$ of their time to work. In line with the reference calibration values the one of the Frisch elasticity corresponds to: $\frac{1}{\gamma}=2$. This elasticity is crucial for the model because it governs how elastic the labour supply is: the flatter the labour supply curve is the more fluctuations in labour demand driven by the technology shock exist, which in turn affects hours worked and output.

In order to analyse the implications of the Frisch elasticity I consider the functional specification for preferences not over leisure but rather over hours worked:

$$
\ln c_{t}-\psi \frac{l_{t}^{1+\chi}}{1+\chi}
$$

When I resolve the first-order conditions from the household's optimisation problem, in particular, equation (2), I get the following labour supply equation:

$$
\psi l_{t}^{\chi}=\frac{1}{c_{t}} w_{t} .
$$

Again, I log-linearise about the steady-state and obtain the following result:

$$
\chi \tilde{l}_{t}=-\tilde{c}_{t}+\widetilde{w}_{t} .
$$

Therefore, the Frisch elasticity in this case is $\frac{1}{\chi}$. It is controlled by one sole parameter $\chi$ instead of depending on $l^{*}$ as in the previous case.

When I solve for the steady-state only equation (4) varies, meaning that equations (5), (6) and (7) remain as in the benchmark model:

$$
l^{s s}=\left[\frac{\frac{1-\alpha}{\psi}\left(\frac{k}{l}\right)^{\alpha}}{\left(\frac{k}{l}\right)^{\alpha}-\delta\left(\frac{k}{l}\right)}\right]^{\frac{1}{1+\chi}}, \quad \text { with } \frac{k}{l}=\left(\frac{\alpha}{\frac{1}{\beta}-(1-\delta)}\right)^{\frac{1}{1-\alpha}} .
$$


The key difference is that on the one hand I still calibrate $\psi$ to generate a target level of $l^{*}$ but on the other, I don't alter the labour supply elasticity. Manipulating labour supply delivers the following calibration:

$$
\psi=\frac{1}{l^{1+\chi}} \frac{(1-\alpha)\left(\frac{k}{l}\right)^{\alpha}}{\left(\frac{k}{l}\right)^{\alpha}-\delta \frac{k}{l}} .
$$

For the sake of controlling the Frisch elasticity under this new utility function specification I let $\chi$ to be a free parameter and analyse three different scenarios:

$$
\chi=1, \chi=0.5 \text { and } \chi=0 .
$$

I use the calibration derived and depending on the value I give for the Frisch elasticity I get larger volatility of labour input to output. Setting the Frisch elasticity to different values: $\chi=1$ implying inelastic labour supply, $\chi=0$ perfect elasticity and $\chi=0.5$, affects the calibration $\psi$ and hours worked in different ways. Moreover, I want to emphasise that the Frisch elasticity for Spain and the UK is different from the one in the reference, given $\frac{1}{\gamma}=\frac{1-l^{*}}{l^{*}} \approx 4$ for both countries, hence labour supply is elastic such that any exogenous shock creates high volatility in the main economic variables. Also, this is the same as $\gamma=0.25$ so I'd expect that when controlling for labour supply elasticity as in this current analysis, the results more closely to the standard case should be when $0 \leq \chi \leq 0.5$. Recall that whenever the value of $\chi$ decreases, then the Frisch elasticity increases implying more elastic labour supply. I just present the results of inelastic labour supply (i.e. $\chi=1$ ) and then comment the conclusions obtained from lowering the value of $\chi$.

Table 26: Theoretical Moments for Spain and the UK: Frisch elasticity

\begin{tabular}{|cc|c|c|c|c|c|c|c|}
\hline \multirow{2}{*}{ Variable } & \multicolumn{2}{c}{$\begin{array}{c}\text { Standard } \\
\text { Deviation }\end{array}$} & \multicolumn{2}{c}{ Relative STD } & \multicolumn{2}{c|}{$\begin{array}{c}\text { Correlation to } \\
\text { Output }\end{array}$} & $\begin{array}{c}\text { 1 } \text { 1 }^{\text {st }} \text { order } \\
\text { Autocorrelation }\end{array}$ \\
\cline { 2 - 9 } & SP & UK & SP & UK & SP & UK & SP & UK \\
\hline $\ln \boldsymbol{y}_{\boldsymbol{t}}$ & 0.0125 & 0.0093 & 1.0000 & 1.0000 & 1.0000 & 1.0000 & 0.4873 & 0.4853 \\
\hline $\ln \boldsymbol{c}_{\boldsymbol{t}}$ & 0.0058 & 0.0041 & 0.4640 & 0.4409 & 0.9581 & 0.9648 & 0.5706 & 0.5540 \\
\hline $\ln \boldsymbol{i}_{\boldsymbol{t}}$ & 0.0486 & 0.0271 & 3.8880 & 2.9140 & 0.9854 & 0.9918 & 0.4656 & 0.4702 \\
\hline $\ln \boldsymbol{l}_{\boldsymbol{t}}$ & 0.0036 & 0.0028 & 0.2880 & 0.3011 & 0.9737 & 0.9811 & 0.4637 & 0.4677 \\
\hline $\ln \boldsymbol{k}_{\boldsymbol{t}}$ & 0.0035 & 0.0022 & 0.2800 & 0.2366 & 0.4946 & 0.4641 & 0.8500 & 0.8524 \\
\hline $\ln \left(\boldsymbol{y} / \boldsymbol{l}_{\boldsymbol{t}}\right.$ & 0.0091 & 0.0066 & 0.7280 & 0.7097 & 0.9959 & 0.9968 & 0.5078 & 0.5011 \\
\hline $\ln \boldsymbol{w}_{\boldsymbol{t}}$ & 0.0091 & 0.0066 & 0.7280 & 0.7097 & 0.9959 & 0.9968 & 0.5078 & 0.5011 \\
\hline $\boldsymbol{r}_{\boldsymbol{t}}$ & 0.0010 & 0.0006 & 0.0800 & 0.0645 & 0.9614 & 0.9714 & 0.4643 & 0.4681 \\
\hline $\boldsymbol{z}_{\boldsymbol{t}}$ & 0.0164 & 0.0125 & 1.3120 & 1.3441 & 0.9974 & 0.9977 & 0.4753 & 0.4757 \\
\hline
\end{tabular}


Table 27: Summary of comparative statics between the model extension and the benchmark model for Spain and the UK

\begin{tabular}{|c|c|c|c|c|c|c|c|c|}
\hline \multirow{2}{*}{ Variable } & \multicolumn{2}{|c|}{$\Delta$ Volatility } & \multicolumn{2}{c|}{$\begin{array}{c}\Delta \text { Relative } \\
\text { Volatility }\end{array}$} & \multicolumn{2}{c|}{$\Delta$ Cyclicality } & \multicolumn{2}{c|}{$\Delta$ Persistence } \\
\cline { 2 - 9 } & SP & UK & SP & UK & SP & UK & SP & UK \\
\hline $\ln y_{t}$ & $\downarrow$ & $\downarrow$ & $=$ & $=$ & $=$ & $=$ & $\uparrow$ & $\uparrow$ \\
\hline $\ln c_{t}$ & $\downarrow$ & $\downarrow$ & $\uparrow$ & $\uparrow$ & $\uparrow$ & $\uparrow$ & $\downarrow$ & $\downarrow$ \\
\hline $\ln i_{t}$ & $\downarrow$ & $\downarrow$ & $\downarrow$ & $\downarrow$ & $\uparrow$ & $\uparrow$ & $\uparrow$ & $\uparrow$ \\
\hline $\ln l_{t}$ & $\downarrow$ & $\downarrow$ & $\downarrow$ & $\downarrow$ & $\uparrow$ & $\uparrow$ & $\uparrow$ & $\uparrow$ \\
\hline $\ln k_{t}$ & $\downarrow$ & $\downarrow$ & $=$ & $\downarrow$ & $\downarrow$ & $\downarrow$ & $\uparrow$ & $\uparrow$ \\
\hline $\ln (y / l)_{t}$ & $\uparrow$ & $\uparrow$ & $\uparrow$ & $\uparrow$ & $\uparrow$ & $\uparrow$ & $\downarrow$ & $\downarrow$ \\
\hline $\ln w_{t}$ & $\uparrow$ & $\uparrow$ & $\uparrow$ & $\uparrow$ & $\uparrow$ & $\uparrow$ & $\downarrow$ & $\downarrow$ \\
\hline$r_{t}$ & $\downarrow$ & $\downarrow$ & $\uparrow$ & $\uparrow$ & $\uparrow$ & $\uparrow$ & $\uparrow$ & $\uparrow$ \\
\hline$z_{t}$ & $=$ & $=$ & $\uparrow$ & $\uparrow$ & $\downarrow$ & $\downarrow$ & $=$ & $=$ \\
\hline
\end{tabular}

Table 28: Summary of comparative statics between the model extension and the data for Spain and the UK

\begin{tabular}{|c|c|c|c|c|c|c|c|c|c|c|}
\hline \multirow{2}{*}{ Variable } & \multicolumn{2}{|c|}{$\Delta$ Volatility } & \multicolumn{2}{|c|}{\begin{tabular}{c}
\multicolumn{2}{c|}{ Relative } \\
Volatility
\end{tabular}} & \multicolumn{2}{|c|}{$\Delta$ Cyclicality } & \multicolumn{2}{|c|}{$\Delta$ Persistence } & \multicolumn{2}{|c|}{$\begin{array}{c}\text { mprovement } \\
\text { in fit? }\end{array}$} \\
\cline { 2 - 11 } & SP & UK & SP & UK & SP & UK & SP & UK & SP & UK \\
\hline $\ln y_{t}$ & $\downarrow$ & $\downarrow$ & $=$ & $=$ & $=$ & $=$ & $\downarrow$ & $\downarrow$ & $\mathbf{x}$ & $\mathbf{x}$ \\
\hline $\ln c_{t}$ & $\downarrow$ & $\downarrow$ & $\downarrow$ & $\downarrow$ & $\uparrow$ & $\uparrow$ & $\downarrow$ & $\downarrow$ & $\mathbf{x}$ & $\mathbf{x}$ \\
\hline $\ln i_{t}$ & $\downarrow$ & $\downarrow$ & $\uparrow$ & $\downarrow$ & $\uparrow$ & $\uparrow$ & $\downarrow$ & $\downarrow$ & $\mathbf{x}$ & $\mathbf{x}$ \\
\hline $\ln l_{t}$ & $\downarrow$ & $\downarrow$ & $\uparrow$ & $\downarrow$ & $\uparrow(+)$ & $\uparrow$ & $\downarrow$ & $\downarrow$ & $\checkmark$ & $\mathbf{x}$ \\
\hline $\ln k_{t}$ & $\downarrow$ & $\downarrow$ & $\downarrow$ & $\downarrow$ & $\uparrow(+)$ & $\uparrow$ & $\uparrow$ & $\uparrow$ & $\mathbf{x}$ & $\mathbf{x}$ \\
\hline $\ln (y / l)_{t}$ & $\downarrow$ & $\downarrow$ & $\downarrow$ & $\downarrow$ & $\uparrow$ & $\uparrow$ & $\downarrow$ & $\downarrow$ & $\checkmark$ & $\checkmark$ \\
\hline $\ln w_{t}$ & $\downarrow$ & $\downarrow$ & $\downarrow$ & $\downarrow$ & $\uparrow$ & $\uparrow$ & $\downarrow$ & $\downarrow$ & $\checkmark$ & $\checkmark$ \\
\hline$r_{t}$ & $\downarrow$ & $\downarrow$ & $\downarrow$ & $\downarrow$ & $\uparrow$ & $\uparrow$ & $\uparrow(+)$ & $\uparrow$ & $\mathbf{x}$ & $\mathbf{x}$ \\
\hline$z_{t}$ & $\downarrow$ & $\downarrow$ & $\uparrow$ & $\uparrow$ & $\uparrow(+)$ & $\uparrow(+)$ & $\downarrow$ & $\downarrow$ & $=$ & $=$ \\
\hline
\end{tabular}

When $\chi=1 \mathrm{I}$ observe for both countries that the standard deviation of hours worked decreases significantly compared to the benchmark model meaning that more inelastic labour supply causes less volatility, as theory predicts. Thus, when comparing this current case with the standard case, I observe that setting the Frisch elasticity at a low value implies a decrease in the volatility as well as a smaller "jump" for the endogenous variables in the IRF, given an exogenous technology shock. Moving to the rest of the variables, I only remark that the standard deviation of all variables decrease significantly but labour productivity, wages and technology for Spain and the UK. For instance, output's volatility decreases from 0.0146 to 0.0125 for Spain and from 0.0109 to 0.0093 for the UK. Hence, I can conclude that having inelastic labour supply affects heavily the STD values for almost all variables. Regarding correlation to output I notice a general light increase with exception of capital. The pattern is not so clear for the first order autocorrelation though. For some variables as output, consumption, labour and capital, the value increases, for the rest of the variables it decreases. The conclusions are the same for Spain and the UK. 
If I double the labour supply elasticity by setting $\chi=0.5$ I observe the same pattern as in the previous case in terms of how the variables are affected but in the opposite direction. In this way I'm getting closer to the standard case. In particular, STDs decrease less and the first order autocorrelations increase less compared to benchmark model. For instance, for Spain (the UK) the volatility of hours worked decreased from $0.0070(0.0054)$ in the standard case (with high elasticity in labour supply) to $0.0036(0.0028)$ when setting $\chi=1$ (inelastic labour supply) and then increased to 0.0053 (0.0041) when augmenting the elasticity, getting very close to the empirical moment (this latter statement is not true for the UK).

Most interestingly, when setting $\chi=0$, in other words, having high elastic labour supply (surpassing the elasticity of the standard case), I've high levels of volatility compared to the benchmark. This implies that the calibration of having $\chi$ as an independent parameter (i.e. not having the Frisch elasticity dependent on labour as in the standard case) and setting it to zero, is equivalent to have roughly the same elasticity results as in the standard case: $\frac{1}{\gamma} \approx \frac{1}{\chi}$. In turn, this approximation holds for $0 \leq \chi \leq 0.5$. Additionally, setting $\chi=0$ and the subsequent rise in the volatility of all endogenous variables makes the model statistics fit better the empirical statistics for some of the variables (i.e. outputs, consumption, investment etc.), performing better in terms of statistical fit than the benchmark RBC model.

All in all, controlling for the Frisch elasticity allows me to evaluate different degrees of labour supply elasticity and see whether this makes hours worked more volatile or not. I conclude that setting lower values for $\chi$ implies higher labour supply elasticity. In particular, setting $0 \leq \chi \leq$ 0.5 replicates the standard case, making low technological shocks have great effects on the economy. It is very important to remark though, that for Spain it is $\chi=0.5$ when labour volatility is closest to the empirical data: 0.0053 (model with $\chi=0.5$ ) and 0.0051 (data). However, for the UK it is $\chi=0$ when the labour volatility is closest to its corresponding empirical moment: 0.0079 (model with $\chi=0$ ) and 0.0071 (data). This implies that higher elasticity in the RBC model represents better the UK, contrary to Spain where the RBC model needs a higher calibration for $\chi$ in order to match hours worked better. This fact speaks in favour of the statement I make about the UK being more structurally flexible than Spain. The "Improvement of fit" column for the outputs shown above $(\chi=1)$ corroborates this given Spain seems to be more suitable than the UK for this level of labour supply elasticity (relatively inelastic). At a modelling level, it is the case that the benchmark RBC model is assuming higher volatility in labour supply contrary to what the empirical data is telling us, hence overestimating the volatility of hours worked for Spain. Contrary, the opposite is true for the UK: the standard model assumes lower volatility in labour supply in disagreement with the empirical moment of labour, consequently underestimating its volatility. This doesn't hold for the rest of the variables, yet.

As a result, the important insight I'm getting from this analysis is that for the neoclassical modelling of Spain's economy I should be taking a Frisch elasticity of 2 rather than 4 as calibration suggests, in order to replicate best the volatility of hours worked. For the UK I should select a higher calibration than 4 . 


\section{Investment shock}

Another type of disturbance I contemplate is a shock to the marginal efficiency of investment (MEI). This investment shock makes the economy more productive at transforming investment into new physical capital (in a way somewhat analogous to how the technology shock, makes firms more productive at transforming capital and labour into output). I denote $v_{t}$ as the investment shock. It enters the capital accumulation equation in the following way:

$$
k_{t+1}=v_{t} i_{t}+(1-\delta) k_{t} .
$$

Consequently, a rise in $v_{t}$ means I get more $k_{t+1}$ for a given amount of investment, i.e. increasing the efficiency of investment. Effectively, this shock is a reduced form proxy for modelling the health of the financial system: the financial system essentially turns investment into capital, so the higher (or lower) $v_{t}$ is, the better (or worse) the financial system is.

I apply this extension to my standard optimisation problem such that I get the following analogues to equations (1) and (3):

$$
\begin{gathered}
\frac{1}{c_{t}}=\beta E_{t}\left[\frac{1}{c_{t+1}} \frac{v_{t}}{v_{t+1}}\left[v_{t+1} \alpha k_{t+1}^{\alpha-1}\left(e^{z_{t+1}} l_{t+1}\right)^{1-\alpha}+(1-\delta)\right]\right], \\
k_{t+1}=v_{t}\left(k_{t}^{\alpha}\left(e^{z_{t}} l_{t}\right)^{1-\alpha}-c_{t}\right)+(1-\delta) k_{t} .
\end{gathered}
$$

As in every shock that is included in the RBC model, the steady-state equations remain unchanged.

Also, in line with the preference shock, I assume that $v_{t}$ follows an $\mathrm{AR}(1)$ process:

$$
\ln v_{t}=\rho_{v} \ln v_{t-1}+\varepsilon_{v, t}, \text { assuming } \varepsilon_{v, t} \sim \text { White noise. }
$$

With the standard parametrisation of $\rho_{v}=0.9$ and $\sigma_{v}=0.01$ for the same reason as for the preference shock.

When resolving the model on Dynare with this new source of shock I get the following results:

Table 29: Theoretical Moments for Spain and the UK: Investment Shock

\begin{tabular}{|c|c|c|c|c|c|c|c|c|}
\hline \multirow{2}{*}{ Variable } & \multicolumn{2}{c|}{$\begin{array}{c}\text { Standard } \\
\text { Deviation }\end{array}$} & \multicolumn{2}{c|}{ Relative STD } & \multicolumn{2}{c|}{$\begin{array}{c}\text { Correlation to } \\
\text { Output }\end{array}$} & \multicolumn{2}{c|}{$\begin{array}{c}1^{\text {st }} \text { order } \\
\text { Autocorrelation }\end{array}$} \\
\cline { 2 - 10 } & SP & UK & SP & UK & SP & UK & SP & UK \\
\hline $\ln \boldsymbol{y}_{\boldsymbol{t}}$ & 0.0328 & 0.0414 & 1.0000 & 1.0000 & 1.0000 & 1.0000 & 0.4444 & 0.2704 \\
\hline $\ln \boldsymbol{c}_{\boldsymbol{t}}$ & 0.0343 & 0.0468 & 1.0457 & 1.1304 & -0.6718 & -0.8695 & 0.4220 & 0.2430 \\
\hline $\ln \boldsymbol{i}_{\boldsymbol{t}}$ & 0.3379 & 0.3176 & 10.3018 & 7.6715 & 0.9264 & 0.9716 & 0.3942 & 0.2304 \\
\hline $\ln \boldsymbol{l}_{\boldsymbol{t}}$ & 0.0490 & 0.0685 & 1.4939 & 1.6546 & 0.9105 & 0.9626 & 0.3928 & 0.2284 \\
\hline $\ln \boldsymbol{k}_{\boldsymbol{t}}$ & 0.0245 & 0.0225 & 0.7470 & 0.5435 & 0.5535 & 0.5574 & 0.8111 & 0.7255 \\
\hline $\ln \left(\boldsymbol{y} / \boldsymbol{l}_{\boldsymbol{t}}\right.$ & 0.0234 & 0.0307 & 0.7134 & 0.7415 & -0.5022 & -0.7971 & 0.4631 & 0.2706 \\
\hline $\ln \boldsymbol{w}_{\boldsymbol{t}}$ & 0.0234 & 0.0307 & 0.7134 & 0.7415 & -0.5022 & -0.7971 & 0.4631 & 0.2706 \\
\hline $\boldsymbol{r}_{\boldsymbol{t}}$ & 0.0022 & 0.0016 & 0.0671 & 0.0386 & 0.5873 & 0.5515 & 0.5718 & 0.5200 \\
\hline $\boldsymbol{z}_{\boldsymbol{t}}$ & 0.0164 & 0.0125 & 0.5000 & 0.3019 & 0.4453 & 0.2631 & 0.4753 & 0.4757 \\
\hline
\end{tabular}


Table 30: Summary of comparative statics between model extension and the benchmark model for Spain and the UK

\begin{tabular}{|c|c|c|c|c|c|c|c|c|c|c|}
\hline \multirow[t]{2}{*}{ Variable } & \multicolumn{2}{|c|}{$\Delta$ Volatility } & \multicolumn{2}{|c|}{$\begin{array}{l}\Delta \text { Relative } \\
\text { Volatility }\end{array}$} & \multicolumn{2}{|c|}{$\Delta$ Cyclicality } & \multicolumn{2}{|c|}{$\Delta$ Persistence } & \multicolumn{2}{|c|}{$\begin{array}{c}\text { Impact } \\
\text { of } \\
v_{t} \text { shock }\end{array}$} \\
\hline & SP & UK & SP & UK & SP & UK & SP & UK & $\mathrm{SP}$ & UK \\
\hline $\ln y_{t}$ & $\uparrow$ & $\uparrow$ & $=$ & $=$ & $=$ & $=$ & $\downarrow$ & $\downarrow$ & + & + \\
\hline $\ln c_{t}$ & $\uparrow$ & $\uparrow$ & $\uparrow$ & $\uparrow$ & $\downarrow(-)$ & $\downarrow(-)$ & $\downarrow$ & $\downarrow$ & - & - \\
\hline $\ln i_{t}$ & $\uparrow$ & $\uparrow$ & $\uparrow$ & $\uparrow$ & $\downarrow$ & $\downarrow$ & $\downarrow$ & $\downarrow$ & + & + \\
\hline $\ln l_{t}$ & $\uparrow$ & $\uparrow$ & $\uparrow$ & $\uparrow$ & $\downarrow$ & $\downarrow$ & $\downarrow$ & $\downarrow$ & + & + \\
\hline $\ln k_{t}$ & $\uparrow$ & $\uparrow$ & $\uparrow$ & $\uparrow$ & $\uparrow$ & $\uparrow$ & $\downarrow$ & $\downarrow$ & + & + \\
\hline $\ln (y / l)_{t}$ & $\uparrow$ & $\uparrow$ & $\uparrow$ & $\uparrow$ & $\downarrow(-)$ & $\downarrow(-)$ & $\downarrow$ & $\downarrow$ & - & - \\
\hline $\ln w_{t}$ & $\uparrow$ & $\uparrow$ & $\uparrow$ & $\uparrow$ & $\downarrow(-)$ & $\downarrow(-)$ & $\downarrow$ & $\downarrow$ & - & - \\
\hline$r_{t}$ & $\uparrow$ & $\uparrow$ & $\downarrow$ & $\downarrow$ & $\downarrow$ & $\downarrow$ & $\uparrow$ & $\uparrow$ & + & + \\
\hline$z_{t}$ & $=$ & $=$ & $\downarrow$ & $\downarrow$ & $\downarrow$ & $\downarrow$ & $\uparrow$ & $=$ & & \\
\hline
\end{tabular}

Table 31: Summary of comparative statics between model extension and the data for Spain and the UK

\begin{tabular}{|c|c|c|c|c|c|c|c|c|c|c|}
\hline \multirow{2}{*}{ Variable } & \multicolumn{2}{|c|}{$\Delta$ Volatility } & \multicolumn{2}{c|}{\begin{tabular}{c}
\multicolumn{2}{c|}{ Relative } \\
Volatility
\end{tabular}} & \multicolumn{2}{|c|}{$\Delta$ Cyclicality } & \multicolumn{2}{|c|}{$\Delta$ Persistence } & \multicolumn{2}{|c|}{$\begin{array}{c}\text { Improvement } \\
\text { in fit? }\end{array}$} \\
\cline { 2 - 14 } & SP & UK & SP & UK & SP & UK & SP & UK & SP & UK \\
\hline $\ln y_{t}$ & $\uparrow$ & $\uparrow$ & $=$ & $=$ & $=$ & $=$ & $\downarrow$ & $\downarrow$ & $=$ & $\mathbf{x}$ \\
\hline $\ln c_{t}$ & $\uparrow$ & $\uparrow$ & $\downarrow$ & $\uparrow$ & $\downarrow(-)$ & $\downarrow(-)$ & $\downarrow$ & $\downarrow$ & $\checkmark$ & $\mathbf{x}$ \\
\hline $\ln i_{t}$ & $\uparrow$ & $\uparrow$ & $\uparrow$ & $\uparrow$ & $\downarrow$ & $\uparrow$ & $\downarrow$ & $\downarrow$ & $\mathbf{x}$ & $\mathbf{x}$ \\
\hline $\ln l_{t}$ & $\uparrow$ & $\uparrow$ & $\uparrow$ & $\uparrow$ & $\uparrow(+)$ & $\uparrow$ & $\downarrow$ & $\downarrow$ & $\mathbf{x}$ & $\mathbf{x}$ \\
\hline $\ln k_{t}$ & $\uparrow$ & $\uparrow$ & $\uparrow$ & $\uparrow$ & $\uparrow(+)$ & $\uparrow$ & $\uparrow$ & $\downarrow$ & $\mathbf{x}$ & $\mathbf{x}$ \\
\hline $\ln (y / l)_{t}$ & $\downarrow$ & $\uparrow$ & $\downarrow$ & $\downarrow$ & $\downarrow(-)$ & $\downarrow(-)$ & $\downarrow$ & $\downarrow$ & $\checkmark$ & $\checkmark$ \\
\hline $\ln w_{t}$ & $\downarrow$ & $\downarrow$ & $\downarrow$ & $\downarrow$ & $\downarrow(-)$ & $\downarrow(-)$ & $\downarrow$ & $\downarrow$ & $\checkmark$ & $\checkmark$ \\
\hline$r_{t}$ & $\downarrow$ & $\downarrow$ & $\downarrow$ & $\downarrow$ & $\uparrow$ & $\uparrow$ & $\uparrow(+)$ & $\uparrow$ & $\checkmark$ & $\checkmark$ \\
\hline$z_{t}$ & $\downarrow$ & $\downarrow$ & $\downarrow$ & $\downarrow$ & $\uparrow(+)$ & $\uparrow(+)$ & $\downarrow$ & $\downarrow$ & $=$ & $=$ \\
\hline
\end{tabular}

I notice that the investment shock leads to a big increase in the volatility of all endogenous variables but real interest rate (where the increase is substantially smaller). It seems like the investment shock is inflating the STD of the variables drastically, which in turn makes the RBC model replicate the real economy better for some variables. For example, with the investment shock output and consumption have about the same volatility as in the data, whereas in the standard case, output is far more volatile than consumption. So this extension improves the performance of predicting empirical moments for those variables where the standard model was failing. In contrast, given this extension has increased the STD of almost all variables in a generalised way, the variables where the standard model is doing a good job is now failing with the inclusion of this extension. In particular, the standard model does a good job of replicating the volatility of investment but when I introduce the investment shock I see an increase of investment's volatility of $436 \%$ for Spain and 9 times for the UK indicating that investment is far more volatile than it truly is. The same happens to labour, where the relative STD goes from 0.47 in the standard case to 1.49 in the extension for Spain and from 0.49 to 1.65 for the UK. When it comes to contemporaneous correlation to output I can see a very different pattern 
compared to the standard model for both countries. In particular, consumption, labour productivity and wages are negatively correlated to output now. Also, the degree of correlation has declined for all variables but for those ones that present high volatility (investment and labour as explained above). There is nothing to underline for the $1^{\text {st }}$ order autocorrelation.

Looking at how the investment shock is affecting the model variables I determine the following: the direction of the initial jump given by such shock differs among variables. The shock of MEI affects positively output, investment, hours worked and capital stock, whereas it affects negatively consumption, labour productivity, wages and real interest rate. The intuition for what is going on is as follows: When $v_{t}$ increases, given turning investment into capital becomes more efficient it makes sense to save more through capital. Hence, consumption jumps down. These results in an outward shift of the labour supply curve which leads to an increase in hours worked and a reduction in wages. The increase in hours worked results in an increase in output, which combined with the reduction of consumption means investment is higher. The real interest rate rises because the marginal product of capital is initially higher. As time goes by, capital accumulates further, and the $v_{t}$ shock fades away. Consumption begins to increase, which shifts labour supply back in, driving down labour and wages up. There is no room for co-movement between consumption and hours worked, and output and investment here for reasons that I mention in the preference shock extension: with my standard labour supply relationship, absent a change in technology, consumption and hours cannot move together. Thus, while the investment shock produces interesting dynamics here, the model as currently presented cannot be a major source of business cycle fluctuations as it fails heavily on replicating Spain's and the UK's empirical moments.

As it was the case of preference shock, the investment shock also replicates what the theory says in terms of the impact of the new shock on the model variables. However, the model improvement is not as good as in the preference shock. This is because this extension is performing better than the standard case with just a technology shock given now the volatility of most variables have increased substantially, but this increase is artificial and not really capturing the empirical moments. For instance, the volatility of investment increases so much with the investment shock that it has worsened drastically the fit of real data. Nonetheless, this extension allows for a very recognisable improvement in the relative STD of consumption to output, something the preference shock is not able to capture. As a result, there is no categoric conclusion on the performance of this model extension, given it improves some aspects of the standard case but it worsens others.

I need to underline that this extension is special because it augments the second-order statistical moments of the UK more than the ones of Spain, contrary to the rest of extensions. This implies that changes on the financial system captured by the higher marginal efficiency of investment have greater effects on the UK than in Spain, something I expect given the characteristics of the UK's economy. Nonetheless, sticking to the criteria used in the "Improvement of fit" indicator it is not worth including this extension for Spain and the UK. 


\section{Imperfect competition}

In this last extension, I deviate from the assumption of perfect competition. For this, I break the production function up into two sectors. The first is the "final goods" sector and is competitive, so I think about there being representative final goods firms. These latter ones don't use any factors of production, but rather "bundle" intermediate goods into a final good. The intermediate goods sector uses capital and labour to produce. There is a continuum of intermediate goods firms who together compress into the unit interval. This is just a convenient normalisation: the point is that there are a significant number of intermediate goods firms, but they produce differentiated goods.

It follows that the final good is a fixed elasticity of substitution aggregate of intermediate goods. The production function is:

$$
y_{t}=\left(\int_{0}^{1} y_{j, t}^{\frac{v-1}{v}} d j\right)^{\frac{v}{v-1}} .
$$

This is the sum of each intermediate input raised to a power, with the whole sum raised to a power that is the inverse of the power on each intermediate input. I assume that $v$ is positive and it governs the degree of substitutability among intermediate inputs. As it goes to infinity, this just becomes the sum of intermediate goods (i.e. goods are perfect substitutes). As it goes to zero, the production function becomes Leontief (i.e. goods are perfect complementarians). For $v=1$, there is a "unity elasticity of substitution" and the production function becomes Cobb-Douglas. I assume from now on that $v>1$.

The final goods firm wants to maximise (nominal) profits, given a final good price $p_{t}$ and taking intermediate good prices $p_{j, t}$ as given. The optimisation problem looks like this:

$$
\max _{y_{j, t}} \Pi_{t}{ }^{F}=p_{t}\left(\int_{0}^{1} y_{j, t}^{\frac{v-1}{v}} d j\right)^{\frac{v}{v-1}}-\int_{0}^{1} p_{j, t} y_{j, t} d j .
$$

The solution to this problem is given by the first-order condition which I rearrange to get:

$$
y_{j, t}=\left(\frac{p_{j, t}}{p_{t}}\right)^{-v} y_{t} .
$$

In words, the relative demand for differentiated intermediate goods $j$ depends on its relative price, with $v$ being the price elasticity of demand. I can now solve for the aggregate price index. The nominal value of the final good is just the sum of prices times quantities of intermediate goods.

Using the above demand specification I get:

$$
p_{t} y_{t}=\int_{0}^{1} p_{j, t} y_{j, t} d j
$$

which I simplify to:

$$
p_{t}=\left(\int_{0}^{1} p_{j, t}^{1-v} d j\right)^{\frac{1}{1-v}}
$$


The intermediate goods firms produce output using capital and labour, according to the standard production function considered so far:

$$
y_{j, t}=k_{j, t}^{\alpha}\left(e^{z_{t}} l_{j, t}\right)^{1-\alpha} .
$$

Where $z_{t}$ denotes labour augmented technology as in the standard case and is common across intermediate goods firms. It follows that aggregate capital and aggregate employment are just the sum of these factors across intermediate goods firms:

$$
k_{t}=\int_{0}^{1} k_{j, t} d j \text { and } l_{t}=\int_{0}^{1} l_{j, t} d j .
$$

I assume that the intermediate goods firm rents capital from households. These firms all face the same factor prices (rental rate and wage rate). The firms do, however, have the ability to set their own price, given that they face downward sloping demand curves (as long as $v$ is not infinity). Hence, they want to solve the following constrained problem:

$$
\begin{gathered}
\max _{p_{j, t}, y_{j, t}, l_{j, t}, k_{j, t}} \Pi_{t}^{I}=p_{j, t} y_{j, t}-w_{t} l_{j, t}-r_{t} k_{j, t} \\
\text { s.t. } \\
y_{j, t}=k_{j, t}^{\alpha}\left(e^{z_{t}} l_{j, t}\right)^{1-\alpha} \text { and } y_{j, t}=\left(\frac{p_{j, t}}{p_{t}}\right)^{-v} y_{t} .
\end{gathered}
$$

I solve for the Lagrangian with two multipliers $\lambda_{1, t}^{j}$ and $\lambda_{2, t}^{j}$, and I rearrange the terms to get the following expression:

$$
\lambda_{2, t}^{j}=\frac{p_{j, t}}{v} .
$$

I take this equation and plug it into the FOC of output in order to get:

$$
p_{j, t}=\frac{v}{v-1} \lambda_{1, t}^{j} \Leftrightarrow \lambda_{1, t}^{j}=p_{j, t} \frac{v-1}{v} .
$$

Given $\frac{v}{v-1} \geq 1$, the variable $\lambda_{1, t}^{j}$ can be interpreted as the marginal cost. It is the shadow value on the first constraint: if firms produce a little less, by how much do profits go up (equivalently how much do costs go down). So, this expression says that the optimal pricing rule for firms is to set price equal to a "markup" of the price over marginal cost, where I define the markup as being $\varphi=\frac{v}{v-1}$. The less substitutable the intermediate goods are (i.e. smaller $v$ ) the bigger the markup will be.

I plug this last expression into the marginal products for capital and labour resulting from the firm's optimisation problem. This allows to write these expressions in terms of the real product wage and real product rental rate (the "product" qualifier means that I divide the nominal factor price by the price of the product, not the price level of all goods, this is the real factor price relevant for firm decision-making):

$$
\begin{gathered}
\frac{r_{t}}{p_{j, t}}=\frac{v-1}{v} \alpha k_{j, t}^{\alpha-1}\left(e^{z_{t}} l_{j, t}\right)^{1-\alpha}, \\
\frac{w_{t}}{p_{j, t}}=\frac{v-1}{v}(1-\alpha) k_{j, t}^{\alpha}\left(e^{z_{t}} l_{j, t}\right)^{1-\alpha} l_{j, t}^{-1} .
\end{gathered}
$$


Because $\frac{v-1}{v} \leq 1$, factors will be paid less than their marginal products giving rise to economic profits for the intermediate goods firms.

Now I use the FOC for labour and capital to eliminate $\lambda_{1, t}^{j}$ and get:

$$
\frac{k_{j, t}}{l_{j, t}}=\frac{\alpha}{1-\alpha} \frac{w_{t}}{r_{t}}
$$

This last condition is crucial. It says that all firms will hire capital and labour in the same ratio, since the wage, the rental rate, and $\alpha$ are common to all firms. I use this fact to go back to the expression for $\lambda_{1, t}^{j}$, which again has the interpretation as marginal cost:

$$
\lambda_{1, t}^{j}=\frac{r_{t}}{\alpha e^{z_{t}(1-\alpha)}\left(\frac{k_{j, t}}{l_{j, t}}\right)^{\alpha-1}} .
$$

Since all firms will hire capital and labour in the same ratio, this means that they all have the same marginal cost. But going back to the pricing rule, if they all have the same marginal cost, then they all will charge the same price. Hence, using the formula of aggregate price level I conclude:

$$
p_{j, t}=p_{t} \forall j
$$

In other words, all firms charge the same price, which is equal to the final goods price. From the demand specification, if all firms charge the same price, they must produce the same amount of output:

$$
y_{j, t}=y_{t} \forall j .
$$

At first, this may seem contradictive since final goods firms with perfect competition and intermediate goods with monopolistic power produce identically the same, but this is the advantage of defining firms as existing over the unit interval: the output of any firm is equal to the aggregate output which is equal to the average output. Thus, the individual production function becomes now:

$$
y_{j, t}=e^{z_{t}(1-\alpha)}\left(\frac{k_{j, t}}{l_{j, t}}\right)^{\alpha} l_{j, t} .
$$

Since all firms hire capital and labour in the same ratio and also produce the same amount of output, I can see that they must all hire the same amount of labour, and therefore the same amount of capital:

$$
k_{j, t}=k_{t} \text { and } l_{j, t}=l_{t} \forall j .
$$

This means that I can think of there being an aggregate production function for final goods that is identical to the production function of any intermediate good firm:

$$
y_{t}=k_{t}^{\alpha}\left(e^{z_{t}} l_{t}\right)^{1-\alpha} .
$$

Because all firms charge the same price, the relative price of all goods turns out to be 1 in equilibrium. The level of prices is indeterminate without specifying some process for money (this would mean deviating from the neoclassical money neutrality assumption and move towards new Keynesian versions). Hence, I can normalise all prices to one, this implies there is 
no difference between real and nominal factor prices. The new marginal products are defined as:

$$
\begin{gathered}
r_{t}=\frac{v-1}{v} \alpha k_{t}^{\alpha-1}\left(e^{z_{t}} l_{t}\right)^{1-\alpha}, \\
w_{t}=\frac{v-1}{v}(1-\alpha) k_{t}^{\alpha}\left(e^{z_{t}} l_{t}\right)^{1-\alpha} l_{t}^{-1} .
\end{gathered}
$$

Accordingly, when I resolve the model the only set of dynamic equilibrium equations that vary are equations (1) and (2):

$$
\begin{gathered}
\frac{1}{c_{t}}=\beta E_{t}\left[\frac{1}{c_{t+1}}\left[\varphi^{-1} \alpha k_{t+1}^{\alpha-1}\left(e^{Z_{t+1}} l_{t+1}\right)^{1-\alpha}+(1-\delta)\right]\right], \\
\varphi \psi \frac{c_{t}}{1-l_{t}}=(1-\alpha) k_{t}^{\alpha}\left(e^{z_{t}} l_{t}\right)^{1-\alpha} l_{t}^{-1} .
\end{gathered}
$$

Therefore, the sole difference with respect the RBC model without any extension is the inclusion of the inverse of the price markup in the factor demand equations (i.e. $\varphi^{-1}=\frac{v-1}{v}$ ).

If I assume that $v$ is constant, then the only thing that will be different about this model is the steady-state, in particular, $v<\infty$ will distort the steady-state values. In a linearisation of the model, the IRFs will be identical. Essentially the imperfect competition is a steady-state distortion. Nonethless, to a first order approximation it doesn't impact the dynamics of the model. I can introduce fluctuations in $v$, still. I can think of these as being markup shocks. Suppose that the log of $\varphi$ follows a stationary $\operatorname{AR}(1)$ :

$$
\ln \varphi_{t}=\left(1-\rho_{\varphi}\right) \varphi^{*}+\rho_{\varphi} \ln \varphi_{t-1}+\varepsilon_{\varphi, t}, \quad \text { assuming } \varepsilon_{\varphi, t} \sim \text { White noise. }
$$

I'm just going to create parameterisation of the process for $\varphi$ as Eric Sims does: I assume that $\varphi^{*}=1.2$ (equivalently $v^{*}=5$, that $\rho_{\varphi}=0.9$ and that the standard deviation of the random variable is 0.01 ). Using standard parameterisation for the rest of the parameters results into the following theoretical moments for Spain and the UK:

Table 32: Theoretical Moments for Spain and the UK: Imperfect Competition

\begin{tabular}{|cc|c|c|c|c|c|c|c|}
\hline \multirow{2}{*}{ Variable } & \multicolumn{2}{c}{$\begin{array}{c}\text { Standard } \\
\text { Deviation }\end{array}$} & \multicolumn{2}{c|}{ Relative STD } & \multicolumn{2}{c|}{$\begin{array}{c}\text { Correlation to } \\
\text { Output }\end{array}$} & \multicolumn{2}{c|}{$\begin{array}{c}1^{\text {st }} \text { order } \\
\text { Autocorrelation }\end{array}$} \\
\cline { 2 - 9 } & SP & UK & SP & UK & SP & UK & SP & UK \\
\hline $\ln \boldsymbol{y}_{\boldsymbol{t}}$ & 0.0687 & 0.0535 & 1.0000 & 1.0000 & 1.0000 & 1.0000 & 0.3268 & 0.3259 \\
\hline $\ln \boldsymbol{c}_{\boldsymbol{t}}$ & 0.0142 & 0.0095 & 0.2067 & 0.1776 & 0.0978 & -0.0095 & 0.7565 & 0.7313 \\
\hline $\ln \boldsymbol{i}_{\boldsymbol{t}}$ & 0.4122 & 0.2299 & 6.0000 & 4.2972 & 0.9850 & 0.9908 & 0.3013 & 0.3074 \\
\hline $\ln \boldsymbol{l}_{\boldsymbol{t}}$ & 0.1088 & 0.0870 & 1.5837 & 1.6262 & 0.9810 & 0.9842 & 0.3012 & 0.3058 \\
\hline $\ln \boldsymbol{k}_{\boldsymbol{t}}$ & 0.0235 & 0.0151 & 0.3421 & 0.2822 & 0.5324 & 0.5050 & 0.7630 & 0.7670 \\
\hline $\ln \left(\boldsymbol{y} / \boldsymbol{l}_{\boldsymbol{t}}\right.$ & 0.0436 & 0.0356 & 0.6346 & 0.6654 & -0.8751 & -0.9014 & 0.3101 & 0.3112 \\
\hline $\ln \boldsymbol{w}_{\boldsymbol{t}}$ & 0.0436 & 0.0356 & 0.6346 & 0.6654 & -0.8751 & -0.9014 & 0.3101 & 0.3112 \\
\hline $\boldsymbol{r}_{\boldsymbol{t}}$ & 0.0032 & 0.0022 & 0.0466 & 0.0411 & 0.8536 & 0.9037 & 0.3668 & 0.3491 \\
\hline $\boldsymbol{z}_{\boldsymbol{t}}$ & 0.0164 & 0.0125 & 0.2387 & 0.2336 & 0.2131 & 0.2038 & 0.4753 & 0.4757 \\
\hline
\end{tabular}


Table 33: Summary of comparative statics between the model extension and the benchmark model for Spain and the UK

\begin{tabular}{|c|c|c|c|c|c|c|c|c|c|c|}
\hline \multirow[t]{2}{*}{ Variable } & \multicolumn{2}{|c|}{$\Delta$ Volatility } & \multicolumn{2}{|c|}{$\begin{array}{l}\Delta \text { Relative } \\
\text { Volatility }\end{array}$} & \multicolumn{2}{|c|}{$\Delta$ Cyclicality } & \multicolumn{2}{|c|}{$\Delta$ Persistence } & \multicolumn{2}{|c|}{$\begin{array}{c}\text { Impact of } \\
\varphi_{t} \text { shock }\end{array}$} \\
\hline & SP & UK & SP & UK & SP & UK & SP & UK & SP & UK \\
\hline $\ln y_{t}$ & $\uparrow$ & $\uparrow$ & $=$ & $=$ & $=$ & $=$ & $\downarrow$ & $\downarrow$ & - & - \\
\hline $\ln c_{t}$ & $\uparrow$ & $\uparrow$ & $\downarrow$ & $\downarrow$ & $\downarrow$ & $\downarrow(-)$ & $\uparrow$ & $\uparrow$ & - & - \\
\hline $\ln i_{t}$ & $\uparrow$ & $\uparrow$ & $\uparrow$ & $\uparrow$ & $\uparrow$ & $\downarrow$ & $\downarrow$ & $\downarrow$ & - & - \\
\hline $\ln l_{t}$ & $\uparrow$ & $\uparrow$ & $\uparrow$ & $\uparrow$ & $\uparrow$ & $\uparrow$ & $\downarrow$ & $\downarrow$ & - & - \\
\hline $\ln k_{t}$ & $\uparrow$ & $\uparrow$ & $\uparrow$ & $\uparrow$ & $\uparrow$ & $\uparrow$ & $\downarrow$ & $\downarrow$ & - & - \\
\hline $\ln (y / l)_{t}$ & $\uparrow$ & $\uparrow$ & $\uparrow$ & $\uparrow$ & $\downarrow(-)$ & $\downarrow(-)$ & $\downarrow$ & $\downarrow$ & + & + \\
\hline $\ln w_{t}$ & $\uparrow$ & $\uparrow$ & $\uparrow$ & $\uparrow$ & $\downarrow(-)$ & $\downarrow(-)$ & $\downarrow$ & $\downarrow$ & + & + \\
\hline$r_{t}$ & $\uparrow$ & $\uparrow$ & $\uparrow$ & $\downarrow$ & $\downarrow$ & $\downarrow$ & $\downarrow$ & $\downarrow$ & - & - \\
\hline$z_{t}$ & $=$ & $=$ & $\downarrow$ & $\downarrow$ & $\downarrow$ & $\downarrow$ & $=$ & $=$ & & \\
\hline
\end{tabular}

Table 34: Summary of comparative statics between the model extension and the data for Spain and the UK

\begin{tabular}{|c|c|c|c|c|c|c|c|c|c|c|}
\hline \multirow{2}{*}{ Variable } & \multicolumn{2}{|c|}{$\Delta$ Volatility } & \multicolumn{2}{|c|}{$\begin{array}{c}\Delta \text { Relative } \\
\text { Volatility }\end{array}$} & \multicolumn{2}{|c|}{$\Delta$ Cyclicality } & \multicolumn{2}{|c|}{$\Delta$ Persistence } & \multicolumn{2}{|c|}{$\begin{array}{c}\text { Improvement } \\
\text { in fit? }\end{array}$} \\
\cline { 2 - 13 } & SP & UK & SP & UK & SP & UK & SP & UK & SP & UK \\
\hline $\ln y_{t}$ & $\uparrow$ & $\uparrow$ & $=$ & $=$ & $=$ & $=$ & $\downarrow$ & $\downarrow$ & $\mathbf{x}$ & $\mathbf{x}$ \\
\hline $\ln c_{t}$ & $\downarrow$ & $\downarrow$ & $\downarrow$ & $\downarrow$ & $\downarrow$ & $\downarrow(-)$ & $\downarrow$ & $\downarrow$ & $\checkmark$ & $\checkmark$ \\
\hline $\ln i_{t}$ & $\uparrow$ & $\uparrow$ & $\uparrow$ & $\uparrow$ & $\uparrow$ & $\uparrow$ & $\downarrow$ & $\downarrow$ & $\mathbf{x}$ & $\mathbf{x}$ \\
\hline $\ln l_{t}$ & $\uparrow$ & $\uparrow$ & $\uparrow$ & $\uparrow$ & $\uparrow(+)$ & $\uparrow$ & $\downarrow$ & $\downarrow$ & $\mathbf{x}$ & $\mathbf{x}$ \\
\hline $\ln k_{t}$ & $\uparrow$ & $\uparrow$ & $\uparrow$ & $\downarrow$ & $\uparrow(+)$ & $\uparrow$ & $\uparrow$ & $\downarrow$ & $\mathbf{x}$ & $\mathbf{x}$ \\
\hline $\ln (y / l)_{t}$ & $\uparrow$ & $\uparrow$ & $\downarrow$ & $\downarrow$ & $\downarrow(-)$ & $\downarrow(-)$ & $\downarrow$ & $\downarrow$ & $\checkmark$ & $\checkmark$ \\
\hline $\ln w_{t}$ & $\downarrow$ & $\downarrow$ & $\downarrow$ & $\downarrow$ & $\downarrow(-)$ & $\downarrow(-)$ & $\downarrow$ & $\downarrow$ & $\checkmark$ & $\checkmark$ \\
\hline$r_{t}$ & $\downarrow$ & $\downarrow$ & $\downarrow$ & $\downarrow$ & $\uparrow$ & $\uparrow$ & $\uparrow(+)$ & $\uparrow$ & $\checkmark$ & $\checkmark$ \\
\hline$z_{t}$ & $\downarrow$ & $\downarrow$ & $\downarrow$ & $\downarrow$ & $\uparrow(+)$ & $\uparrow(+)$ & $\downarrow$ & $\downarrow$ & $=$ & $=$ \\
\hline
\end{tabular}

In line with the results, I obtain from the investment shock, including the markup shock through the marginal products of the factor inputs implies having a huge increase in the volatility of the variables. Consequently, for some variables, this increase is beneficial in terms of replicating more accurately the empirical moments (i.e. consumption and labour productivity). Contrary, for other variables this increase results into an overestimation of the volatility, as it is for output, investment, hours worked or capital. This speaks against adding this extension, given the standard model is already doing a good job. However, I emphasise that the increase in the predictive power for consumption and labour productivity is just improving the fit in absolute terms, not in relative ones as it remains clear when having a look at the relative standard deviations. For the contemporaneous correlation to output, there are a couple of features worth mentioning. Even if the cyclicality of investment, hours worked, capital and real interest rate don't change drastically compared to the standard case, it changes heavily for consumption, labour productivity, wages and labour augmented technology. For this latter for instance, the correlation reduces by 0.6769 for Spain and by 0.7951 for the UK. Moreover, consumption's correlation to output for Spain decreases much more, specifically, 10 times compared to the standard case. Most striking is the case of the UK, where consumption's 
correlation to output decreases 100 times compared to the standard case and becomes negative. Also for both countries, wages and labour productivity change their sign with regards the correlation to output and are now negatively correlated. Remarkably, the autocorrelation coefficients to the first lag decrease for all variables but for consumption compared to the benchmark model. As it was the case of the standard version, the RBC model with or without extension doesn't capture the autocorrelation coefficients especially well.

There are a couple of things worth mentioning when I look on the sign of the shock's impact on Spain's and the UK's variables. First, the markup shock causes consumption, hours, output, investment, capital and real interest rate decline together. But second, average labour productivity and wages go up, which means that hours are falling by more than output. Also adding a markup shock makes the cyclicality of Spain's factor inputs become positive in the model extension (given in the data it is negative) and the persistence of real interest rate also turns into being positive compared to data.

Hence, given the data features of Spain, the changes resulting from this model extension are not speaking for the inclusion of rigidities in the model. When I look at the summary table I conclude that the UK isn't an exception for that. As a result, adding rigidities to the model through a markup shock is not the best option to replicate the real business cycles of the countries analysed. 